ORNL/TM-2000/123

\title{
An Equilibrium-Based Model of Gas Reaction and Detonation
}

\author{
L. D. Trowbridge
}


Chemical Technology Division

\title{
An Equilibrium-Based Model of Gas Reactions and Detonations
}

\author{
L. D. Trowbridge
}

Date Published: April 2000

Prepared by the OAK RIDGE NATIONAL LABORATORY

Oak Ridge, Tennessee 37831-6285 managed by

UT-Battelle, LLC for the U.S. DEPARTMENT OF ENERGY under contract DE-AC05-00OR22725 


\section{CONTENTS}

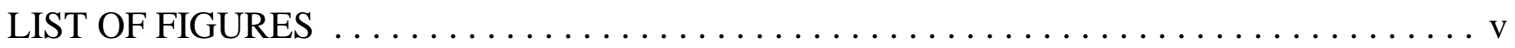

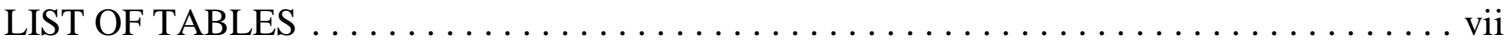

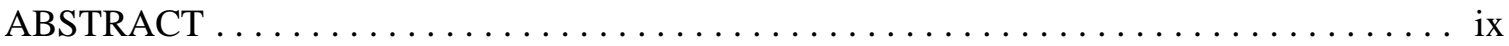

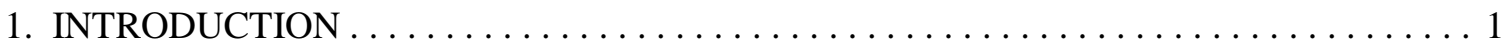

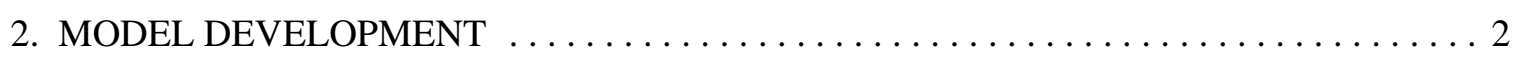

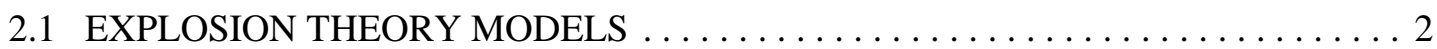

2.1 .11992 Explosion Theory Models . . . . . . . . . . . . . . . . . . . . . . 2

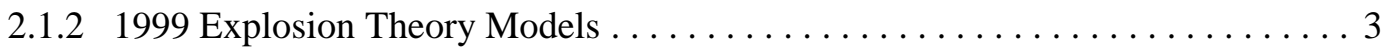

2.1.3 Equilibrium-Based Detonation Model $\ldots \ldots \ldots \ldots \ldots \ldots \ldots \ldots$

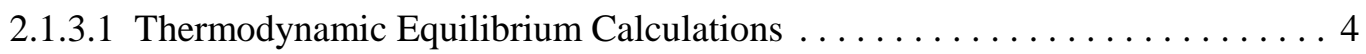

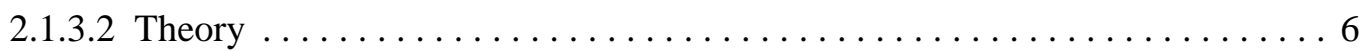

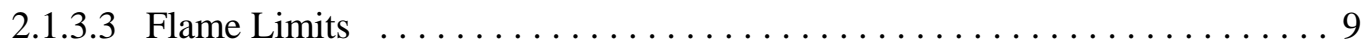

2.1.3.4 Model Implementation $\ldots \ldots \ldots \ldots \ldots \ldots \ldots \ldots \ldots \ldots \ldots \ldots \ldots \ldots \ldots$

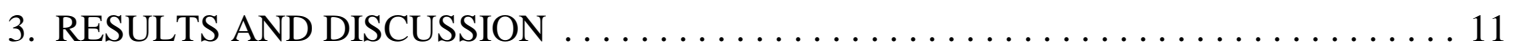

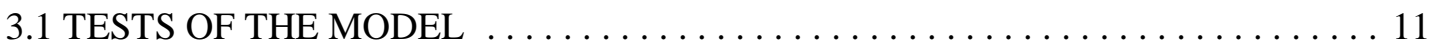

3.2 COMPARISON WITH FIXED REACTION DETONATION MODELS $\ldots \ldots \ldots . .$.

3.3 SELECTION OF PRODUCT SPECIES $\ldots \ldots \ldots \ldots \ldots \ldots \ldots \ldots \ldots \ldots \ldots \ldots \ldots \ldots \ldots \ldots$

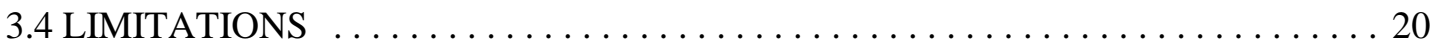

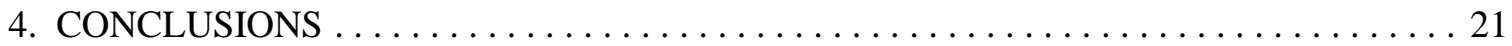

\section{APPENDIX A. FUEL-OXIDIZER EXPLOSION MODEL OPERATING INSTRUCTIONS}

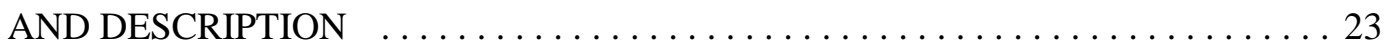

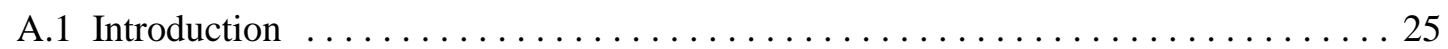

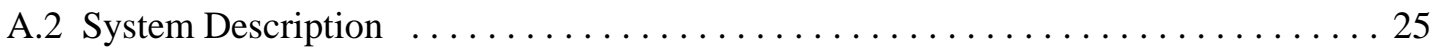

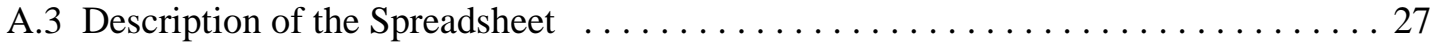

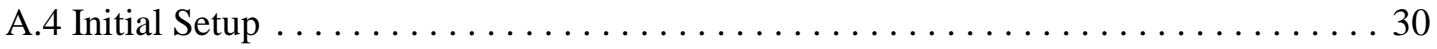

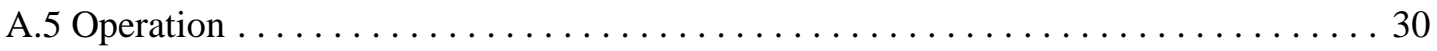

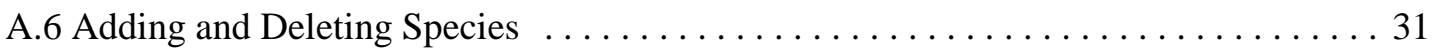

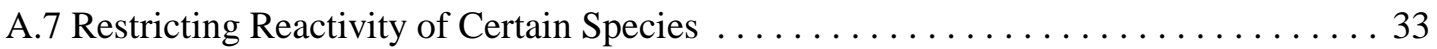

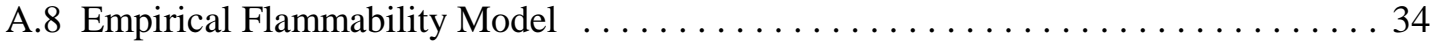

A.9. Problems, Failure Modes, and Additional Remarks ..................... 34

A.10. A Sample Case. . . . . . . . . . . . . . . . . . . . . 35 


\section{APPENDIX B. COMPARISON OF DETONATION MODEL PREDICTIONS}

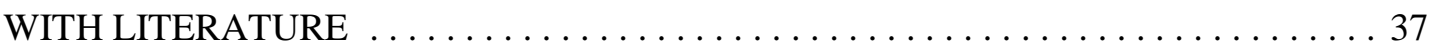

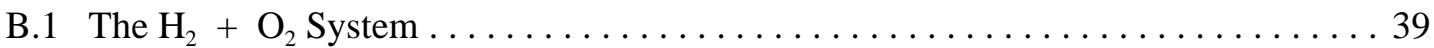

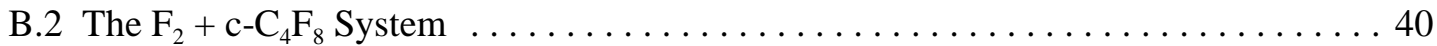

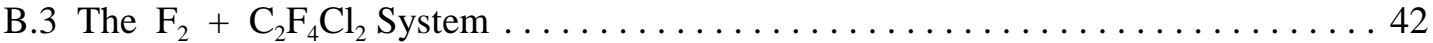

APPENDIX C. THERMODYNAMICS DATA USED IN THE MODEL $\ldots \ldots \ldots \ldots \ldots \ldots 4$

C.1 Enthalpy of Formation for Perfluorotetrahydrofuran $\left(\mathrm{c}^{-} \mathrm{C}_{4} \mathrm{~F}_{8} \mathrm{O}\right) \ldots \ldots \ldots \ldots \ldots$

C.2 Entropy Estimate for $\mathrm{c}^{-\mathrm{C}_{4} \mathrm{~F}_{8} \mathrm{O} \ldots \ldots \ldots \ldots \ldots \ldots \ldots \ldots \ldots \ldots \ldots \ldots \ldots \ldots \ldots \ldots \ldots \ldots \ldots \ldots \ldots}$

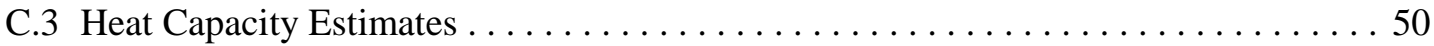

C.4 Thermodynamic property values incorporated into model. . . . . . . . . . . 50

APPENDIX D. EMPIRICAL FLAMMABILITY LIMIT MODEL $\ldots \ldots \ldots \ldots \ldots \ldots 53$

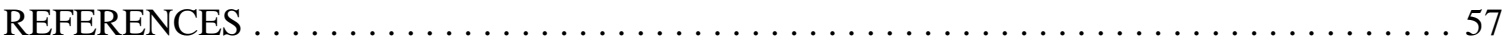

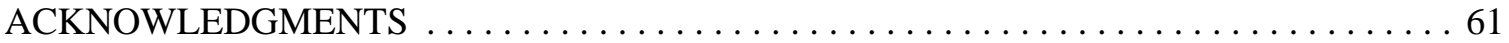




\section{LIST OF FIGURES}

Figure

Page

1 Comparison of detonation pressures $\left(\mathrm{F}_{2}+\mathrm{C}_{2} \mathrm{~F}_{4} \mathrm{Cl}_{2}+50 \% \mathrm{~N}_{2}\right) \ldots \ldots \ldots \ldots \ldots \ldots$

2 Comparison of detonation pressures $\left(\mathrm{ClF}_{3}+\mathrm{C}_{2} \mathrm{~F}_{4} \mathrm{Cl}_{2}+50 \% \mathrm{~N}_{2}\right) \ldots \ldots \ldots \ldots \ldots$

3 Comparison of detonation pressures $\left(\mathrm{F}_{2}+\mathrm{c}-\mathrm{C}_{4} \mathrm{~F}_{8}+50 \% \mathrm{~N}_{2}\right) \ldots \ldots \ldots \ldots \ldots \ldots$

4 Comparison of detonation pressures $\left(\mathrm{ClF}_{3}+\mathrm{c}-\mathrm{C}_{4} \mathrm{~F}_{8}+50 \% \mathrm{~N}_{2}\right) \ldots \ldots \ldots \ldots \ldots \ldots$

5 Comparison of detonation pressures $\left(\mathrm{F}_{2}+\mathrm{C}_{4} \mathrm{~F}_{10}+50 \% \mathrm{~N}_{2}\right) \ldots \ldots \ldots \ldots \ldots \ldots \ldots$

6 Comparison of detonation pressures $\left(\mathrm{ClF}_{3}+\mathrm{C}_{4} \mathrm{~F}_{10}+50 \% \mathrm{~N}_{2}\right) \ldots \ldots \ldots \ldots \ldots \ldots$

7 Comparison of detonation pressures $\left(\mathrm{F}_{2}+\mathrm{c}-\mathrm{C}_{4} \mathrm{~F}_{8} \mathrm{O}+50 \% \mathrm{~N}_{2}\right) \ldots \ldots \ldots \ldots \ldots \ldots$

8 Comparison of detonation pressures $\left(\mathrm{ClF}_{3}+\mathrm{c}-\mathrm{C}_{4} \mathrm{~F}_{8} \mathrm{O}+50 \% \mathrm{~N}_{2}\right) \ldots \ldots \ldots \ldots \ldots$

A.1 Flowchart for equilibrium-based detonation model $\ldots \ldots \ldots \ldots \ldots \ldots \ldots \ldots$

A.2 Screen image of summary and composition tables of detonation model $\ldots \ldots \ldots \ldots 36$

D.1 Flame limit prediction for $\mathrm{F}_{2}+\mathrm{c}-\mathrm{C}_{4} \mathrm{~F}_{8}+\mathrm{UF}_{6}$ system $\ldots \ldots \ldots \ldots \ldots \ldots \ldots \ldots \ldots \ldots \ldots \ldots \ldots \ldots \ldots \ldots \ldots$ 



\section{LIST OF TABLES}

Table

Page

1 Maximum detonation pressures $(\mathrm{atm})$ for fuel + oxidizer $+50 \% \mathrm{~N}_{2}$ mixtures $\ldots \ldots 17$

B.1 Comparison of detonation model results with theoretical results presented by Lewis and von Elbe (1961) for detonations of $\mathrm{H}_{2}+\mathrm{O}_{2} \ldots \ldots \ldots \ldots$

B.2 Comparison of literature $\mathrm{F}_{2}+\mathrm{c}-\mathrm{C}_{4} \mathrm{~F}_{8}$ detonation velocities $(\mathrm{m} / \mathrm{s})$

with theoretical results from the present model. . . . . . . . . . . . . . 41

B.3 Comparison of model results to experimental explosion pressures reported

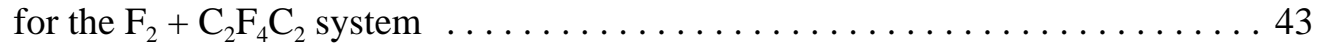

C.1 Group additivity values for heat of formation of perfluorocarbons $\ldots \ldots \ldots \ldots \ldots 48$

C.2 Literature ring strain contributions to standard enthalpy of formation

for selected gaseous ring compounds $\ldots \ldots \ldots \ldots \ldots \ldots \ldots \ldots \ldots \ldots$

C.3 Thermodynamic data incorporated into model $\ldots \ldots \ldots \ldots \ldots \ldots \ldots \ldots \ldots \ldots \ldots \ldots \ldots$

D.1 Fluorine atoms nominally demanded by fuels and supplied by oxidizers $\ldots \ldots \ldots \ldots 56$

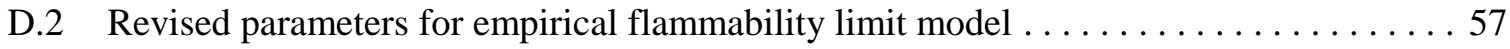





\begin{abstract}
During gaseous diffusion plant operations, conditions leading to the formation of flammable gas mixtures may occasionally arise. Currently, these could consist of the evaporative coolant CFC-114 and fluorinating agents such as $\mathrm{F}_{2}$ and $\mathrm{ClF}_{3}$. Replacement of CFC-114 with a nonozone-depleting substitute is planned. Consequently, in the future, the substitute coolant must also be considered as a potential fuel in flammable gas mixtures. Two questions of practical interest arise: (1) can a particular mixture sustain and propagate a flame if ignited, and (2) what is the maximum pressure that can be generated by the burning (and possibly exploding) gas mixture, should it ignite? Experimental data on these systems, particularly for the newer coolant candidates, are limited. To assist in answering these questions, a mathematical model was developed to serve as a tool for predicting the potential detonation pressures and for estimating the composition limits of flammability for these systems based on empirical correlations between gas mixture thermodynamics and flammability for known systems. The present model uses the thermodynamic equilibrium to determine the reaction endpoint of a reactive gas mixture and uses detonation theory to estimate an upper bound to the pressure that could be generated upon ignition. The model described and documented in this report is an extended version of related models developed in 1992 and 1999.
\end{abstract}




\section{INTRODUCTION}

The purpose of this report is to discuss and document techniques and tools for estimating the behavior of potentially flammable gas mixtures that are occasionally encountered in gaseous diffusion plant (GDP) operations. This work derives from preliminary modeling efforts first carried out in 1990 by Barber (1990), in 1992 by Trowbridge and Barber (1992), and recently enhanced by Trowbridge (1999a). The flammable mixtures of interest consist of oxidizing agents such as $\mathrm{F}_{2}$ and $\mathrm{ClF}_{3}$ reacting with fluorocarbon or chlorofluorocarbon "fuels" such as CFC-114 $\left(\mathrm{C}_{2} \mathrm{~F}_{4} \mathrm{Cl}_{2}\right)$, FC-c318 (cyclo- $\mathrm{C}_{4} \mathrm{~F}_{8}$, or c- $\left.\mathrm{C}_{4} \mathrm{~F}_{8}\right)$, FC-3110 $\left(\mathrm{C}_{4} \mathrm{~F}_{10}\right)$, and c- $\mathrm{C}_{4} \mathrm{~F}_{8} \mathrm{O}$, or mixtures thereof, when mixed with a variety of diluents (e.g., $\mathrm{N}_{2}$ and $\mathrm{UF}_{6}$ ). CFC-114 is presently the primary coolant used in the diffusion plants, and the other three materials are candidate "secondgeneration coolants," replacements for CFC-114 that have no stratospheric ozone depletion potential. ${ }^{1}$

There are two basic questions of practical interest in diffusion plant applications related to flammable gases: (1) Can a particular mixture sustain and propagate a flame if it is ignited, and (2) what is the maximum pressure that can be generated by the burning (and possibly exploding) gas mixture if it should ignite? For specific mixtures, the answers to these questions can be obtained experimentally and indeed have been for many compositions and mixtures of historical interest. Practical cases will inevitably arise that are outside the realm explicitly covered by experimental work due to variations in temperature, pressure, or composition (e.g., a mixture containing different fuels, oxidizers, or diluents or containing multiple fuels, oxidizers, or diluents). In the future, with the implementation of a new coolant in the GDPs, mixtures of the two coolant vapors will be encountered in the cascades. A mathematical model with a reasonably sound theoretical or pragmatic basis can assist not only in interpreting experimental results but also in interpolating when conditions not covered by the experimental work are encountered.

On the specific subject of flammable gas mixtures in diffusion plant applications, a considerable body of experimental work was performed on $\mathrm{C}_{2} \mathrm{~F}_{4} \mathrm{Cl}_{2}$ systems (Bernhardt, et al. 1968a, 1968b) as well as earlier coolants such as C-816 [i.e., $\mathrm{C}_{6} \mathrm{~F}_{10}\left(\mathrm{CF}_{3}\right)_{2}$ ], concentrating mostly on the topic of composition limits of flammability. During the earlier GDP coolant replacement campaign, Bauer and Hamilton of $3 \mathrm{M}$ experimentally determined the composition limits of flammability for the $\mathrm{F}_{2} / \mathrm{C}_{4} \mathrm{~F}_{10} / \mathrm{N}_{2}$ and $\mathrm{F}_{2} / \mathrm{C}_{2} \mathrm{~F}_{4} \mathrm{Cl}_{2} / \mathrm{N}_{2}$ systems (Bauer and Hamilton 1990). Fletcher reported work on flames of undiluted mixtures of $\mathrm{F}_{2}$ or $\mathrm{ClF}_{3}$ with several fluorocarbons, including $\mathrm{c}-\mathrm{C}_{4} \mathrm{~F}_{8}$ (Fletcher and Ambs 1964; Fletcher and Kittelson 1968; Fletcher and Hinderman 1983).

From 1990 to 1992, E. J .Barber (now deceased) developed a series of computer models designed to predict the flame characteristics of burning coolant/fluorinating agent mixtures (Barber 1990; Trowbridge and Barber 1992). In 1999, that series was collapsed into a smaller number of more comprehensive models (Trowbridge 1999a). In both cases, the strategy was similar: for a given pair of reactant gases (one oxidizer and one coolant, plus any of several diluents), a series of reactions was postulated and assumed to go to completion. The reaction products were specified by these postulated reactions, and the heat of reaction was used along with gas explosion theory

1 CFC-114 and FC-3110 both have two isomers; typical commercial mixtures have on the order of 5 to $15 \%$ of the minor isomer. For both coolants difference in the thermodynamic stability of their two isomers is likely to be small relative to other uncertainties inherent in the models presented in this report. For these reasons, isomer differences are ignored 
to predict the explosion or detonation pressure that could be generated by ignition of that gas mixture.

The earlier models by their design suffered from several limitations. By specifying only certain reactions, the reliability of the result in predicting or bounding the effects of an explosion depended on the those selected reactions approximating the reactions that actually occur in the flame or explosion (i.e., predicting approximately the correct energy release and change in the number of moles of gas). The possibility always existed that important high-energy-release reaction pathways might be overlooked. In any given version of the model, only a single fuel and oxidizer could be specified, making examination of mixtures of oxidizers or coolants problematic. High-temperature reaction products (i.e., radicals or other decomposition products) were not included, potentially exaggerating the energy release. It was recognized that many of these limitations could be overcome by integrating a thermodynamic equilibrium calculation into the model. This report describes the results of that integration and documents the resulting model.

\section{MODEL DEVELOPMENT}

\subsection{EXPLOSION THEORY MODELS}

\subsubsection{Explosion Theory Models}

From 1990 to 1992, E. J. Barber developed a computer model designed to estimate the maximum pressure that could be generated on combustion or explosion of a flammable gas mixture (Barber 1990; Trowbridge and Barber 1992). The fuel/oxidizer combinations consisted of pairs taken from the oxidizers $\mathrm{F}_{2}$ and $\mathrm{ClF}_{3}$ and the fuels $\mathrm{C}_{2} \mathrm{~F}_{4} \mathrm{Cl}_{2}, \mathrm{c}-\mathrm{C}_{4} \mathrm{~F}_{8}$, and $\mathrm{C}_{4} \mathrm{~F}_{10}$. This model was also used to empirically predict the composition limits of flammability of gas (Trowbridge and Barber 1992).

Examination of Dr. Barber's archives revealed that this basic model was reproduced in some 22 versions, each devoted to a specific narrow range of conditions: one specific combination of fuel/oxidizer and, within a given fuel oxidizer pair, a limited range of fuel-to-oxidizer ratios. In principle, a complete set of spreadsheets would cover all ratios of all six fuel/oxidizer combinations, but that coverage was incomplete. The general strategy used in all spreadsheets was as follows:

1. Postulate one or more characteristic reactions involved in the combustion, and assume they go to completion.

2. From the starting materials, calculate the quantities of final products.

3. Compute the energy release in the reaction.

4. Apply flame theory to predict the final pressure inside a fixed spherical volume of gas after it burns adiabatically (i.e., without energy gain or loss).

5. Use approximations from flame and detonation theory to estimate the (brief) pressure pulse generated in a fully developed shock.

Though the results of these models were used in the prediction of flammability limits, nothing in the formal model explicitly addresses whether or not a gas mixture would be flammable. The post-combustion temperature was used outside the context of the spreadsheet to generate a

correlation between calculated reaction temperatures and compositions known experimentally to 
be flammable.

The 1992 explosion models were not documented but are an application of a standard model of the burning of a premixed flammable gas in a spherical chamber. This constant-volume spherical flame propagation model is discussed by both Jost (1946) and Lewis and von Elbe (1961). The notation and format used most closely follows that of Jost (1946), Chap. IV. It should be emphasized that this theory is not for detonations (i.e., supersonic shock propagation) but rather for subsonic flame front propagation. The model of an expanding spherical flame front in a fixed- volume spherical chamber should, to the extent that the energetics of the reactions are representative of the actual flame process, give a reasonably accurate depiction of the final pressure attained when all the gas is burned.

During burning, the flame velocity generally increases, possibly eventually running up to sonic, then to supersonic, velocities, at which point this model must be discarded in favor of a direct model of fully developed detonation waves. Since the gas volumes of usual concern in GDP operations are neither spherical nor likely ignited in the center, even subsonic flame velocities and local pressures may well exceed those predicted by the spherical flame propagation model. For this reason, a "detonation pressure" is estimated in the spreadsheet models, in addition to the static, pseudo-adiabatic final pressure. This detonation pressure is estimated simply as twice the final flame pressure, based on an approximation proposed by Langweiler (Jost 1946).

\subsubsection{Explosion Theory Models}

In 1999, a project was commissioned with the intent of updating and documenting the 1992 models. After examining them, however, it became evident that the underlying goal, that of creating documented flame pressure and flammability limit prediction tools usable with current computer technology, was best fulfilled by redesigning the models. To that end, an alternate set of spreadsheets was developed following the general strategy of the Barber models. There were six basic spreadsheets, one version for each combination of fuel and oxidizer, each covering the full range of fuel/oxidizer ratios. The basic strategy of the 1999 versions was similar to that of the 1992 series. A set of characteristic reactions spanning a range of oxidizer/fuel ratios was postulated. Any arbitrary oxidizer/fuel ratio of interest will lie between the ratios of two of these characteristic reactions, or beyond the highest or lowest. Reactants are distributed between two bounding characteristic reactions so as to consume all the fuel and oxidizers. For very high or low ratios, some fuel or oxidizer will be excess and remain unreacted.

The 1999 models did not calculate the flame pressure and temperature by the original subsonic flame propagation method. Instead, two methods were used which were considered to better bound the pressures and temperatures that might be generated in complete gas combustion in an enclosed container. A lower bound was established by calculating the constant-volume adiabatic temperature of the product gas mixture. An upper bound was calculated by using detonation theory to calculate the pressure in a fully developed shock wave. This was the value that the Langweiler approximation sought in the 1992 formulation model. This also allowed computation of a further pressure term, the impulse, which is the force per unit area in the direction of the shock wave propagation. The impulse is a combination of the gas pressure in the shock wave and the momentum of the moving gas in the shock.

The 1999 models also incorporated an empirical flammability limit prediction based on correlations between calculated flame temperature and fluorocarbon/oxidizer mixtures 
experimentally known to be flammable.

The 1999 model series was documented in ORNL/TM-1999/184 (Trowbridge 1999a). It was recognized during the development of the model that the design had several undesirable limitations. The two most important factors in determining flame and shock pressure are the energy release and the change in the number of moles of gas. One factor frequently considered in estimation of flame or explosion temperatures that was necessarily ignored was the formation of transient high-temperature species (i.e., radicals or other high-temperature dissociation products of the more familiar reaction products stable at low temperature). Estimation of the quantity of such species would require a thermodynamic treatment of the product mix at high temperature, or alternatively an elaborate kinetic treatment of the problem, either of which were beyond the design limits of these models. The result of inclusion of such species could be the lowering of final temperatures. Selection of specific reactions also carried with it the danger that the choices made would miss high-energy release reaction pathways. Finally, the basic structure of the models permitted only a single fuel and single oxidizer to be examined. The introduction of a new coolant will result in the mixing of the new with the old coolants, if not in the coolant systems themselves, then via inleakage and mixing in the diffusion plant cascades. These limitations can largely be overcome by abandoning the specified reaction strategy and using a thermodynamic equilibrium calculation to determine the reaction products and heat release. That is the basis for the current model described in this report.

\subsubsection{Equilibrium-Based Detonation Model}

This section will describe the basis of the model. For a description of the actual implementation and a guide to operation, see Appendix A.

The strategy of the present model is similar to those developed earlier in many respects. Overall, the method is as follows:

1. Initial conditions are specified (temperature, volume, pressure, and chemical composition of the starting materials).

2. The adiabatic/constant-volume equilibrium condition is calculated from the initial conditions.

3. In parallel, the initial conditions are used to iteratively compute the equilibrium condition which satisfies the Hugoniot (Chapman-Jouguet) detonation equations (Lewis and von Elbe 1961).

The adiabatic and detonation model calculations, as well as the calculation of thermodynamic equilibrium, are done by iterative numerical techniques. Such calculations are poorly suited to direct implementation within a spreadsheet structure. To preserve the flexibility and familiarity of the spreadsheet interface, however, the overall model was kept in that format, and numeric routines that could not conveniently be performed within the spreadsheet were remanded to external subroutines.

\subsubsection{Thermodynamic Equilibrium Calculations}

Rather than specifying particular reactions, the present model computes the thermodynamic endpoint of a mixture of gases (and to a limited extent, solids) under physical conditions and constraints partly specified by the user and partly dictated by the flame or detonation model which will utilize the results. Thermodynamic equilibrium is calculated using a version of the 
public domain program SOLGASMIX-PV, originally developed by Eriksson (1971). That program has evolved into many divergent forms since its original formulation. The version used here (termed SOLGAS in this report) was developed and adapted in 1995 for use on chemical problems typically encountered in uranium enrichment (Trowbridge and Leitnaker 1995).

The function of the thermodynamics program is to take a list of starting materials (quantities and chemical formulae) and physical conditions (initial temperature and volume, the initial pressure being dictated by the ideal gas law) and, by reference to the thermodynamic properties of these materials and a larger list of potential reaction products, compute the equilibrium state of this system. As used here, SOLGAS is configured to calculate the final quantities of each chemical species and calculate the final pressure and heat absorption or release as the reaction proceeds at constant temperature. Separate initial and final temperatures may be specified, but the temperature is not varied within the calculation. For that reason, SOLGAS must be run several times to find the desired final temperature and pressure. This is done automatically using a simple convergence routine to zero in on the desired end state for each of the two (i.e., adiabatic and detonation) reaction models.

In the earlier explosion model design, reactions were specified. The analog in an equilibriumbased system is the specification of potential reaction products. A specified reaction system might dictate

$$
\mathrm{c}-\mathrm{C}_{4} \mathrm{~F}_{8}+2 \mathrm{~F}_{2} \rightarrow 2 \mathrm{C}_{2} \mathrm{~F}_{6}
$$

as a likely reaction, whereas the real product mix at high temperature will probably contain $\mathrm{CF}_{4}$, $\mathrm{C}_{2} \mathrm{~F}_{6}, \mathrm{C}_{2} \mathrm{~F}_{4}, \mathrm{C}_{3} \mathrm{~F}_{6}, \mathrm{C}_{3} \mathrm{~F}_{8}$, and $\mathrm{C}_{4} \mathrm{~F}_{10}$, as well as radical fragments of these compounds $\left(\mathrm{F}, \mathrm{CF}, \mathrm{CF}_{2}\right.$, $\mathrm{CF}_{3}, \mathrm{C}_{2} \mathrm{~F}_{5}$, etc.) and unreacted reactants. By including these species in the model, the equilibrium calculation will be able to distribute the available $\mathrm{C}$ and $\mathrm{F}$ among these compounds to achieve the most stable state under the prevailing conditions. The thermodynamic equilibrium method is forgiving in the sense that if species are included which are too unstable to meaningfully be part of the product mix, the equilibrium will reflect that instability, allocating little of the available material to such species.

Kinetic limitations can be important in these calculations. The adiabatic reaction calculation approximates the temperature and pressure rise in a subsonic flame before any substantial heat loss occurs to the surroundings. The time scale of concern here is on the order of tens of milliseconds to a few seconds (after which cooling certainly would have begun). Any species that cannot be formed in the available time will be kinetically inaccessible. Similarly, a detonation wave passes through a given quantity of gas in microseconds, after which the gas rarefies and cools. Initial heating is due to compression, which will be boosted further by the heat of reaction of the combusting mixture. Temperatures are higher than in the simple flame case, and thus reaction rates will speed up, but the time scale is much shorter. A detailed determination of which species may be accessible and which may not in a given situation lies in the realm of kinetics and is beyond the scope of this model. Some empirical observations, however, may be useful.

Thermodynamic equilibrium is the stable end state of the chemical system within the constraints established by the physical conditions and chemical species under consideration. The equilibrium state of a diamond sitting in air at room temperature is $\mathrm{CO}_{2}$, but fortunately, kinetics interfere with this state being achieved. Some analogous, though not so extreme, constraints are known to apply to fluorocarbon flames. Many fluorocarbons are thermodynamically unstable 
relative to $\mathrm{CF}_{4}$ and graphite, so a thermodynamic calculation might compute spontaneous exothermic decomposition to form those products. In fact, fluorocarbons are quite stable kinetically and will not decompose to produce solid carbon until rather high temperatures are reached. Another case relevant to uranium enrichment problems is the treatment of $\mathrm{UF}_{6}$. Thermodynamically, $\mathrm{UF}_{6}$ may well be inclined to behave as a fluorinating agent, but in fact, at least at the composition limits of flammability in fluorine/chlorofluorocarbon mixtures, it behaves as a diluent and not as a fluorine source. Thus, it may be wise to prevent reaction of $\mathrm{UF}_{6}$ in the model's calculations by judicious selection of available species. Inclusion or exclusion of product species handles those cases in which species either form at nearly their equilibrium concentration or fail to form due to kinetic limitations. The transition case in which the combination of time, temperature, and reaction rates allows significant formation of a product species but does not allow the reaction to proceed completely to equilibrium cannot be conveniently handled by a thermodynamic approach. Some illustrative cases of this are discussed in Appendix B.

\subsubsection{Theory}

For a given set of conditions [temperature $(\mathrm{T})$, pressure $(\mathrm{P})$, volume $(\mathrm{V})$, and number of moles of initial chemical species $\left(\mathrm{n}_{\mathrm{i}}\right)$ ], thermodynamic equilibrium will predict the final conditions. The consequences of chemical reactions are predicted by two methods. The first calculates the adiabatic (or perhaps more properly, isentropic) pressure and temperature rise upon reaction at constant volume. The second model is a more formal detonation pressure model depicting the behavior of gas immediately behind a fully developed shock wave in a gas explosion. In either model, the chemical reactions, assumed to go to equilibrium, provide the energy to heat the gas, raise its pressure, and in the second model, drive a possible detonation wave. The two models in a sense bound the subsonic flame propagation model used in the original spreadsheets, the first giving the static reaction outcome and the latter giving the worst-case effects of full detonation.

Adiabatic (isentropic) model. The adiabatic model calculates the temperature rise in product and diluent gases in a constant-volume system, assuming no energy gain or loss from the system; that is, the heat of reaction will all go into heating the gases present, with none lost as heat or work to the surroundings. SOLGAS (the program calculating the equilibrium condition) is not set up to directly solve this kind of problem, but it will run a problem at constant temperature and volume to yield (among other output parameters) the heat release. The adiabatic condition is arrived at by guessing a reaction temperature, calling SOLGAS, reading the heat release results, altering the temperature, and rerunning SOLGAS until the result is sufficiently close to the adiabatic (no-heat-gain-or-loss) condition. To accomplish this, a second program, ADIAB95F.EXE, is used. This program is called by a spreadsheet macros. ADIAB95F.EXE is functionally identical to the SOLGAS utility ADIABAT.EXE, documented by Trowbridge and Leitnaker (1995). The primary difference from the original is that the current model produces a full output file for the adiabatic condition (including equilibrium compositions of each species) rather than simply the adiabatic temperature given by the original version of the utility.

This adiabatic result will be slightly lower than the pressure one would calculate using a contained (subsonic) flame model as described by Lewis and von Elbe (1961). It will provide a lower bound on the pressure generated upon combustion of a flammable gas mixture in a confined space, at least a lower bound under the stipulations that all gas reacts to equilibrium and that no heat is lost to the surroundings. In an actual combustion event, some heat might be lost before the reaction is completed, and combustion would likely be incomplete, especially in a 
boundary layer near the walls of the container.

As in the original spreadsheet series, a "detonation pressure" is estimated as simply twice the calculated adiabatic pressure per the Langweiler approximation (Jost 1946, p. 172). Langweiler also approximated the detonation temperature as

$$
\mathrm{T}_{2}=2 \gamma /(\gamma+1) \mathrm{T}_{\mathrm{f}}
$$

where $\mathrm{T}_{\mathrm{f}}$ is the adiabatic temperature attained by combustion and $\gamma$ is the heat capacity ratio $\mathrm{C}_{\mathrm{P}} / \mathrm{C}_{\mathrm{V}}$. The temperature immediately behind the shock front, $\mathrm{T}_{2}$, is also listed in the adiabatic model results under the heading "Detonation."

Detonation model. Throughout this and the previous section, several distinct physical environments should be defined. The initial condition is user specified and is generally near room temperature and atmospheric pressure. It is designated by the subscript " $\mathrm{i}$ " in the adiabatic calculations and "1" in the detonation model, following notation used by both Lewis and von Elbe (1961) and Jost (1946). The adiabatic endpoint, designated here by the subscript " $\mathrm{f}$ ", is the endpoint reached if the gas simply reacts to the specified final products and is heated by its heat of reaction. The "detonation" or "shock" condition is that which applies immediately behind a fully developed shock wave. It may take some time and distance for an initiated flame to accelerate to a shock, especially when the reactant mix is barely within the region of compositions permitting explosions. The shock conditions will persist locally only briefly, being dissipated behind the shock at what must be about the local speed of sound. The shock condition represents both a moving compression wave and physical movement of the gas at the shock front, pushed by the flame and explosion immediately behind the front. This leads to a final pressure-like term called the impulse, which is the momentary force per unit area exerted by the combination of the post-shock pressure plus the momentum of the moving gas. This impulse will persist for the duration of the passage (or arrival) of the shock front, which will be moving at supersonic speed (relative to sound speed in the unburned gas). The momentum portion of the impulse is directional, exerting force in the direction of the bulk motion of gas in the shock but not perpendicular to that motion.

Texts by Jost (1946) and by Lewis and von Elbe (1961) discuss detonation waves in burning gas mixtures in similar terms. The notation used here follows that of Lewis and von Elbe (1961), and the equation numbers are those found in that reference (Chap. VIII, p. 524ff). The theory of gas detonations is based on the Chapman-Jouguet points Hugoniot curves, which relate preburn and postburn pressures and specific volumes under shock and nonshock conditions. Key points of this detonation model are repeated here. Two equations,

$$
\frac{\mathrm{v}_{1}^{2}}{\mathrm{v}_{2}^{2}}-\left(1+\frac{1}{\gamma_{2}}\right) \frac{\mathrm{v}_{1}}{\mathrm{v}_{2}}+\frac{\mathrm{n}_{1} \mathrm{~T}_{1}}{\mathrm{n}_{2} \mathrm{~T}_{2} \gamma_{2}}=0
$$

and

$$
\left\langle\mathrm{C}_{\mathrm{v}}\right\rangle\left(\mathrm{T}_{2}-\mathrm{T}_{1}\right)-\Delta \mathrm{E}-\frac{\mathrm{R}}{2}\left(\frac{\mathrm{v}_{1}}{\mathrm{v}_{2}}-1\right)\left(\mathrm{n}_{2} T_{2}+n_{1} T_{1} \frac{\mathrm{v}_{2}}{\mathrm{v}_{1}}\right)=0
$$

must be solved for the two unknowns $\mathrm{v}_{2}$ and $\mathrm{T}_{2}$. The definitions of some of these variables are 
not what one might first assume. The variable $\mathrm{v}$ is the volume of a unit mass of gas at condition 1 or 2, the pre-shock and shock condition, respectively, while $\mathrm{n}$ is the number of moles per unit mass of the gas at condition 1 or 2 . Therefore $\Delta \mathrm{E}$ and $\left\langle\mathrm{C}_{\mathrm{V}}\right\rangle\left(\mathrm{T}_{2}-\mathrm{T}_{1}\right)$ are in units of energy per unit mass of product gas. The factor $\left\langle\mathrm{C}_{\mathrm{V}}\right\rangle$, intended to mean the average $\mathrm{C}_{\mathrm{V}}$ between $\mathrm{T}_{1}$ and $\mathrm{T}_{2}$ of the product gas mix, is variously taken as the linear average of $\mathrm{C}_{\mathrm{V}}\left(\mathrm{T}_{1}\right)$ and $\mathrm{C}_{\mathrm{V}}\left(\mathrm{T}_{2}\right)$, as the integral of $\mathrm{C}_{\mathrm{V}}$ dT from $\mathrm{T}_{1}$ to $\mathrm{T}_{2}$ divided by $\left(\mathrm{T}_{2}-\mathrm{T}_{1}\right)$, or sometimes (for ease of calculation) simply as $\mathrm{C}_{\mathrm{V}}\left(\mathrm{T}_{2}\right)$. The integral form, the most accurate and defensible, is used in this model.

When the reactions are specified, the product composition and thus $\mathrm{n}_{2}$ are well defined, and Eqns. (21) and (22) can be solved by a convergence technique. When the endpoint is determined by thermodynamic equilibrium, the final composition, and hence also $n_{2}$, vary with $T_{2}$ and $v_{2}$. A final composition which satisfies thermodynamic equilibrium and Eqns. (21) and (22) must be found. In this model, a two-stage iterative method is used to accomplish this task. The algorithm briefly is as follows:

1. An initial guess is made of the shock temperature $T_{2}$; the initial guess of the shock composition is taken from the adiabatic result.

2. Equation (21) is solved analytically for $\mathrm{v}_{1} / \mathrm{v}_{2}$.

3. SOLGAS is run to determine the equilibrium composition at $\mathrm{T}_{2}$ and $\mathrm{v}_{2}$. This calculation determines a new estimate for the equilibrium composition.

4. From this composition, composition-dependent parameters in Eqns. (21) and (22) are reevaluated $\left(\mathrm{n}_{2}, \Delta \mathrm{E},\left\langle\mathrm{C}_{\mathrm{v}}\right\rangle\right.$, and $\left.\gamma_{2}\right)$.

5. Equations (21) and (22) are iteratively solved for $\mathrm{T}_{2}$ and $\mathrm{v}_{1} / \mathrm{v}_{2}$.

6. The current value of $T_{2}$ is recorded; the process returns to step 3 unless the temperature $T_{2}$ has effectively ceased to change from iteration to iteration.

In the model, this algorithm is carried out by the program DET01.EXE. This program, whose source code is written in Borland's Turbo Pascal version 6, is an adaptation of ADIAB95F. The only difference is the details of the convergence criteria: ADIAB95F seeks an equilibrium temperature at which the net heat is zero, while DET01 seeks an equilibrium whose temperature and pressure solve the detonation equations as outlined in the above algorithm.

Once the composition, $\mathrm{v}_{2}$, and $\mathrm{T}_{2}$ have been determined, other parameters are derived. The parameter $\mathrm{P}_{2}$ is obtained from the ideal gas law, which, for the variable definitions used here, is

$$
\mathrm{P}_{2} \mathrm{v}_{2} / \mathrm{n}_{2} \mathrm{~T}_{2}=\mathrm{P}_{1} \mathrm{v}_{1} / \mathrm{n}_{1} \mathrm{~T}_{1}
$$

The detonation velocity, $\mathrm{D}$, is obtained from

$$
\mathrm{D}=\frac{\mathrm{v}_{1}}{\mathrm{v}_{2}} \sqrt{\gamma_{2} \mathrm{n}_{2} \mathrm{RT}_{2}}
$$

The shock impulse is given by

$$
\mathrm{i}=\left(\mathrm{P}_{2}-\mathrm{P}_{1}\right) \mathrm{v}_{1} / \mathrm{v}_{2},
$$

which has units of pressure and includes both the local shock pressure and the momentum term due to local movement of gas.

The pressures and temperatures calculated from this model are presented in the summary section 
of the spreadsheet under the heading "Detonation Model." The "Shock" entries give the T and P values (in several units) within the shock wave. The "Impulse" pressure includes both the shock pressure and the (directed) equivalent pressure due to gas movement.

Though the problems this model was designed to address mainly involve gaseous species, there are cases in which solids may need to be considered. The detonation formulation described above is structured for systems in which all the species present are gases. Ideal gas behavior is embedded in most of these equations. Technically, the formula can be applied to systems involving condensed phases (e.g., solid explosives), but to do so correctly would require modifying the ideal gas behavior to include the compressibility and thermal expansion of the solid species. To treat the cases in which solids participate, we do not attempt to implement a full rigorous approach to the problem but rather treat condensed-phase species in a more approximate way.

The type of solids of interest on the time scale of flame and detonation reactions are not massive isolated items such as the walls of the pipe or container. Rather, they are tiny suspended particulate species that could, on the time scale of the passage of a flame or detonation front, participate in the reaction system either as products or reactants. Examples of such species might be suspended $\mathrm{UF}_{6}$ "snow" in the reactant mix or "smoke" in the reaction product mix (e.g., soot made of solid carbon and particulates of $\mathrm{UF}_{4}$ or $\mathrm{UO}_{2} \mathrm{~F}_{2}$ ). Solid species contribute to the mass, heat of reaction, and heat capacity of the reaction mix, but contribute relatively little to the volume. A typical solid is on the order of 1,000 to 10,000 times as dense as the same material in the gas phase. For purposes of this model, the volume of solid species is neglected. Any terms or variables involving volume will not use a contribution from the solid species. Terms involving heat or mass, however, will use contributions from the solid components. For example, to evaluate the term " $v_{2}$," defined in the detonation formulae as the volume per unit mass in the product mix, we compute the volume of the gaseous species and divide by the mass of all product species, solid or gas.

\subsubsection{Flame limits}

One of the 1992 predictions of flammability was based on a correlation between composition and ( adiabatic, constant- pressure) equilibrium temperature (Trowbridge and Barber 1992). The 1999 detonation theory spreadsheets contained a modification of the original technique, using the constant-volume adiabatic temperature computed from the specific reactions used in each model (Trowbridge 1999a). The present model contains a calculation of the equilibrium (constantvolume) adiabatic temperature rather than the equilibrium constant-pressure adiabatic temperature used in the 1992 model. A flame limit correlation is included in the present model using the same approach (correlation of reaction temperature with compositions experimentally known to sustain combustion). Since the available temperature is obtained under different assumptions, a recalibration of the model was necessary. The details of this are covered in Appendix D. In Appendix D, two set of calibration parameters were developed for each flame limit model, one termed the "best fit" and the other a "conservative fit." The former represents the correlations that most tightly bound the available experimental flammability limit data, while the latter relaxes the correlation function somewhat to anticipate system-to-system variations in the correlation function. 


\subsubsection{Model implementation}

The current version of this explosion theory model is implemented in a hybrid spreadsheetexecutable program form. The user interface is the spreadsheet, but much of the computation is carried out by compiled programs called by spreadsheet macros. The model was developed in Quattro Pro 8 format (part of Corel's WordPerfect Office Suite 8) and was converted to Microsoft Excel 97. Unlike previous models, different versions are not needed for different combinations of fuels and oxidizers; any or all the fuels or oxidizers can simultaneously be active in a run.

Normal user inputs are initial temperature, pressure, volume, and starting composition. Results are not calculated until the user activates the appropriate macros. Key output values are collected in a summary table, consisting of temperatures and pressures of the final adiabatic condition and the shock condition. Details of operation of the models are contained in Appendix A.

Thermodynamic data. The model requires specific thermodynamic data for each reactant, product, or diluent that may be involved in the reaction. Data for the species used are embedded in the spreadsheet. The working part of the spreadsheet (as originally constituted) contains a number of potential reactants, reaction products, and diluents which might appear in GDP experience (e.g., in the operating cascade, in a $\mathrm{UF}_{6}$ cylinder's void space, or in hardware being cleaned up with $\mathrm{F}_{2}$ or $\mathrm{ClF}_{3}$ ). These are nearly all gaseous fluorine-containing species and include both stable molecules and some plausible high-temperature radicals (e.g., $\mathrm{CF}_{2}$ and $\mathrm{CF}_{3}$ ). A few solids are included as well.

The data needed includes species name, chemical formula, heat of formation $\left(\Delta \mathrm{H}_{\mathrm{f}}{ }^{\circ}\right)$, entropy $\left(\mathrm{S}^{\circ}\right)$ at reference conditions ( $298.15 \mathrm{~K}$ and $1 \mathrm{bar}$ ), and parameters for a polynomial fit of the constantvolume heat capacity. The form used is

$$
\mathrm{C}_{\mathrm{P}}(\mathrm{T})=\mathrm{a}+\mathrm{b} \mathrm{T}+\mathrm{c} \mathrm{T}^{2}+\mathrm{d} / \mathrm{T}^{2}+\mathrm{e} / \mathrm{T}^{3}
$$

where $C_{P}$ is in units of $\mathrm{J} / \mathrm{mol} \cdot \mathrm{K}$ and $\mathrm{T}$ is in $\mathrm{K}$. Data embedded in the model are largely curve fit from tabular data in the JANAF Thermochemical Tables (Chase et al. 1985). Specific values and sources are itemized in Appendix C. For all species, $\mathrm{C}_{\mathrm{P}}$ formulae were checked for reasonable behavior from 300 to $4000 \mathrm{~K}$, and several were refit to improve agreement with published tabular data from the JANAF Tables.

User Interface. The model as initially constituted consists of four main files: the spreadsheet (DET7E.XLS or DET7E.WB3 for Excel or Quattro versions, respectively), SOLGAS.EXE, ADIAB95F.EXE, and DET01.EXE. Only the spreadsheet is used directly by the user of the model. The spreadsheet combines the functions of user interface, data base, and central controller for the model, passing data to and from the three executable subroutines. The basic operation of the model requires the user to enter the initial physical conditions of the problem to be solved: the temperature, volume, pressure, and the composition of the gas mixture. The user then executes macros (by activating buttons on the spreadsheet). These macros export the requisite data, run the external models, and import the results to the spreadsheet. A detailed description of the overall system and its setup and operation is given in Appendix A. In addition, abbreviated directions are contained in the spreadsheet on the sheet named Doc. 


\section{RESULTS AND DISCUSSION}

There are many potential uses for this model within the gaseous diffusion complex. The first subsection will discuss tests and demonstrations of the model, comparing the results with theoretical or experimental results in other studies. The second subsection will present comparative results of the present model with corresponding results from the earlier, fixed reaction, models. A third subsection discusses some species selection issues. Finally, limitations of the model will be covered.

\subsection{TESTS OF THE MODEL}

A number of tests of the detonation model were run in order to compare its results with literature results derived from both similar models and from experimental work. Detailed comparisons are listed in Appendix B, and the tests results will only be summarized here.

The theory of detonations in combustible gas mixtures is well developed and well established. However, only a very few references report experimental shock data for fluorocarbon/fluorine systems. One such reference is Fletcher and Kittelson (1968), in which detonation velocities derived both from experiment and detonation theory for $\mathrm{F}_{2}+\mathrm{c}_{-} \mathrm{C}_{4} \mathrm{~F}_{8}$ were reported. The present model was adapted to duplicate several of the experiments reported in that reference. The results of the model were in good agreement with the experimental detonation velocities throughout the range of compositions which produce a detonation. In terms of predicted detonation velocity, the present model was within a few tens of meters per second of the corresponding experimental and theoretical detonations velocities, values which were on the order of 1000 to $1600 \mathrm{~m} / \mathrm{s}$. To produce this agreement, in the fuel rich-region, $\mathrm{C}(\mathrm{s})$ had to be allowed as a potential product. This system produces quite high flame temperatures, so the kinetics apparently permit its formation in the time of the passage of the detonation front. The present model also duplicated reasonably well similar theoretical calculations presented in that report.

The model was also run outside the range of compositions known to detonate. Detonation velocities, pressures, and temperatures were dutifully computed in such cases. Until compositions far outside the detonation region were reached, there was no obvious indication from the model's results that a detonation could not be sustained. This illustrates the fact that limits of flammability and detonability are not strictly determined by the thermodynamics of the system: kinetics, mass transport, and heat transport play roles also. The model is a good predictor of detonation conditions if a detonation occurs but does not directly predict whether a detonation will occur. These runs are discussed in more detail in Appendix B.

The model was also run for several $\mathrm{H}_{2}+\mathrm{O}_{2}$ detonation cases in an attempt to duplicate results presented in Lewis and von Elbe (1961). Reasonable agreement (i.e., detonation pressures within a few percent of the literature values) was obtained in spite of apparent differences in thermodynamic data and computational approach. Again, details of this test series is discussed in Appendix B.

A third study, this one on the $\mathrm{F}_{2} / \mathrm{C}_{2} \mathrm{~F}_{4} \mathrm{Cl}_{2}$ system, reported explosion pressures for several gas mixtures at reduced pressures (Bernhardt et al. 1968a, 1968b). The present model was used in an attempt to duplicate the experimental results. Fair agreement was achieved for most of the experiments examined, though one experiment reported a significantly higher pressure than could be accounted for by any combination of species or conditions. Again, further details are 
discussed in Appendix B.

\subsection{COMPARISON WITH FIXED REACTION DETONATION MODELS}

The series of models started in 1990 and 1992 (Barber 1990; Trowbridge and Barber 1992) and further developed in 1999 (Trowbridge 1999a) predicted gas detonation characteristics using a chemical reaction approach different from that of the present model. In the earlier models, a series of specific chemical reactions were chosen to represent the combustion process. The present model does not specify reactions; instead, it assumes the system reaches thermodynamic equilibrium.

Since the earlier models have been used as a first approach to estimating detonation pressures, it is of interest to compare results of the present model with corresponding results for the previous models. For comparison purposes, an arbitrary set of initial conditions is defined, namely, a temperature of $25^{\circ} \mathrm{C}$, a pressure of $1 \mathrm{~atm}$ (absolute), and an initial composition consisting of 50 mole $\% \mathrm{~N}_{2}$, the balance being varying compositions of coolants and oxidizers. Eight combinations of coolant and oxidizer were examined: each combination of $\mathrm{F}_{2}$ and $\mathrm{ClF}_{3}$ with the three candidate substitute coolants, plus $\mathrm{C}_{2} \mathrm{~F}_{4} \mathrm{Cl}_{2}$. Figures 1 through 8 depict the calculated detonation pressures for these runs as a function of composition. In all eight figures, results from the present equilibrium-based model are shown. Two variations were run, one in which $\mathrm{C}(\mathrm{s})$ (solid carbon) was an allowed product and one in which it was not. In the first six figures, detonation pressures predicted by the 1999 fixed reaction models are also shown. Since no c- $-\mathrm{C}_{4} \mathrm{~F}_{8} \mathrm{O}$ models were developed during that 1999 study, there are no fixed reaction model results in Figs. 7 and 8.

The inclusion of C(s) (i.e., solid carbon) as a possible product has a significant effect on the results for fuel-rich mixtures. Most fluorocarbons are thermodynamically unstable relative to disproportionation into graphite and $\mathrm{CF}_{4}$ (and possibly other species). Pure $\mathrm{c}_{-} \mathrm{C}_{4} \mathrm{~F}_{8}$, for example, is predicted to generate a constant-volume adiabatic equilibrium temperature of $1977 \mathrm{~K}$ simply by decomposition to $\mathrm{C}(\mathrm{s})$ and $\mathrm{CF}_{4}$. but, in fact, does not form these products at any significant rate even when heated to elevated temperatures (Trowbridge 1999b and references therein). At flame temperatures, however, formation of $\mathrm{C}(\mathrm{s})$ is sometimes observed. Fletcher and $\mathrm{Ambs}$ (1964), in a study of flames of $\mathrm{F}_{2}$ plus $\mathrm{C}_{2} \mathrm{~F}_{6}, \mathrm{C}_{3} \mathrm{~F}_{8}$, or $\mathrm{c}-\mathrm{C}_{4} \mathrm{~F}_{8}$, observed $\mathrm{C}(\mathrm{s})$ as a product at its expected equilibrium composition when the mixture was fuel rich and the computed adiabatic reaction temperature exceeded about 2200 to $2400 \mathrm{~K}$. As the computed adiabatic reaction temperature [allowing $\mathrm{C}(\mathrm{s})$ as a product] fell below this range, progressively less $\mathrm{C}(\mathrm{s})$ was experimentally observed until below about 1600 to $1800 \mathrm{~K}$, none was seen even though it still was thermodynamically favored. These observations give some guidelines as to whether $\mathrm{C}(\mathrm{s})$ ought to be included in the product mixture when one is examining the adiabatic reaction portion of our model. One might, if examining results from the adiabatic model, use results which include $\mathrm{C}(\mathrm{s})$ as a product if the calculated temperature is above $2300 \mathrm{~K}$, and not if it is below that level. It is not at all clear, however, how the presence of $\mathrm{Cl}$ (from $\mathrm{ClF}_{3}$ or $\mathrm{C}_{2} \mathrm{~F}_{4} \mathrm{Cl}_{2}$ ) might affect this threshold argument.

The guidance provided is less clear when it comes to application to detonation pressure results. Subsonic flames move at speeds typically measured in tens to a few hundred centimeters per second and the flame front may be on the order of a millimeter wide. That would suggest that the time available for chemical reactions would be on the order of a millisecond, although if we are interested in the maximum pressure than can occur in an enclosed chamber, the appropriate time 


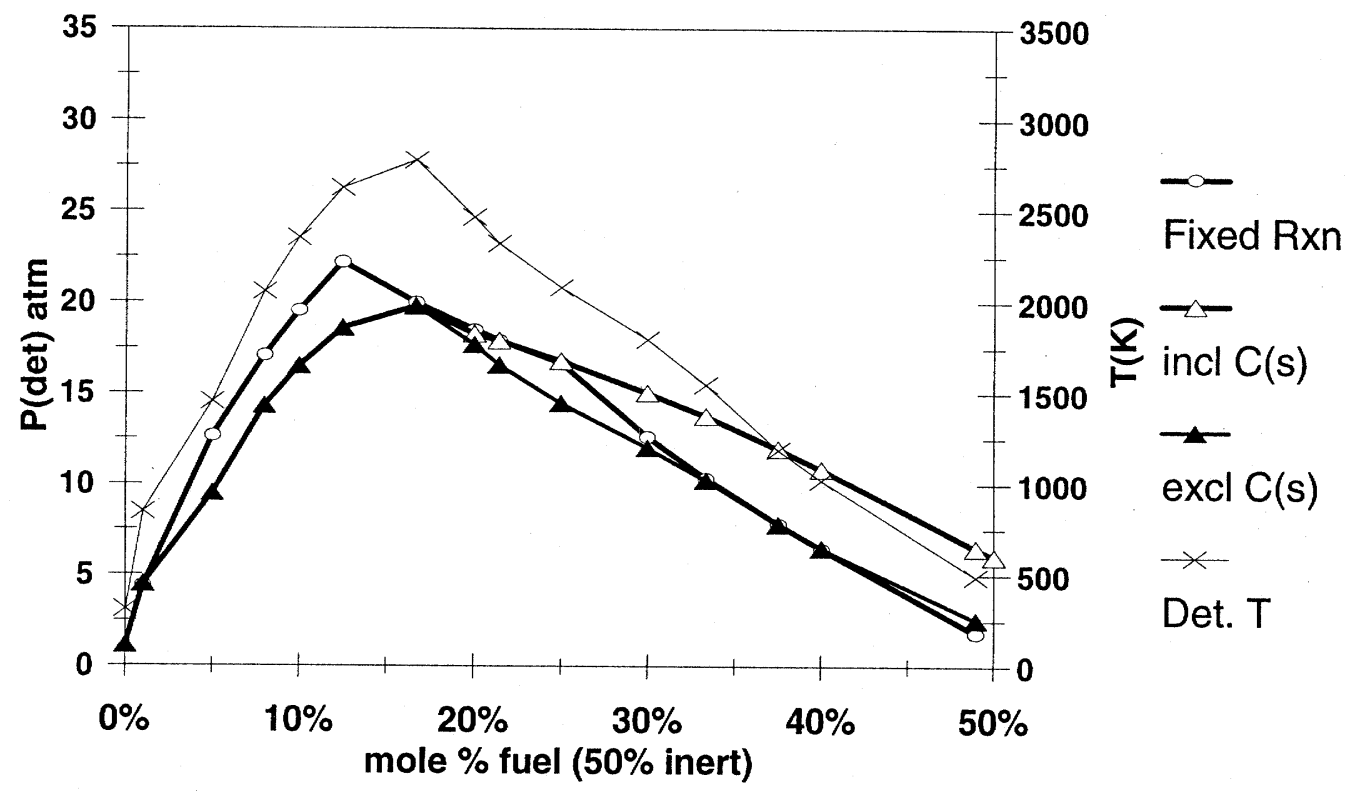

Fig. 1. Comparison of detonation pressures $\left(\mathrm{F}_{2}+\mathbf{C}_{2} \mathbf{F}_{4} \mathbf{C l}_{2}+\mathbf{5 0 \%} \mathbf{N}_{2}\right)$. Predicted detonation pressures for the 1999 fixed reaction model and the present equilibrium-based model, both including and excluding $\mathrm{C}(\mathrm{s})$ as a possible reaction product. Also shown is the predicted detonation temperature [present model, excluding $\mathrm{C}(\mathrm{s})$ ].

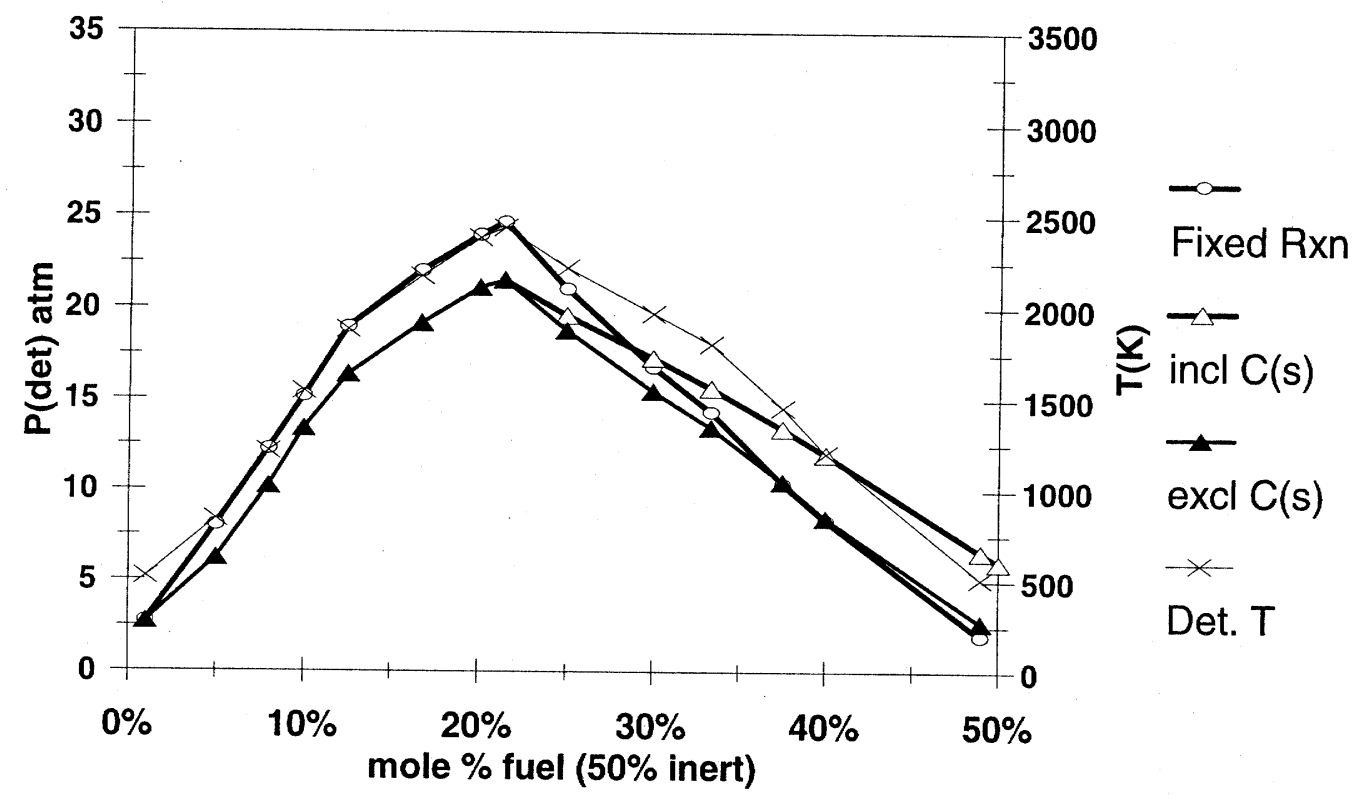

Fig. 2. Comparison of detonation pressures $\left(\mathrm{ClF}_{3}+\mathbf{C}_{2} \mathbf{F}_{4} \mathrm{Cl}_{2}+\mathbf{5 0} \% \mathrm{~N}_{2}\right)$. Predicted detonation pressures for the 1999 fixed reaction model and the present equilibrium-based model, both including and excluding $\mathrm{C}(\mathrm{s})$ as a possible reaction product. Also shown is the predicted detonation temperature 


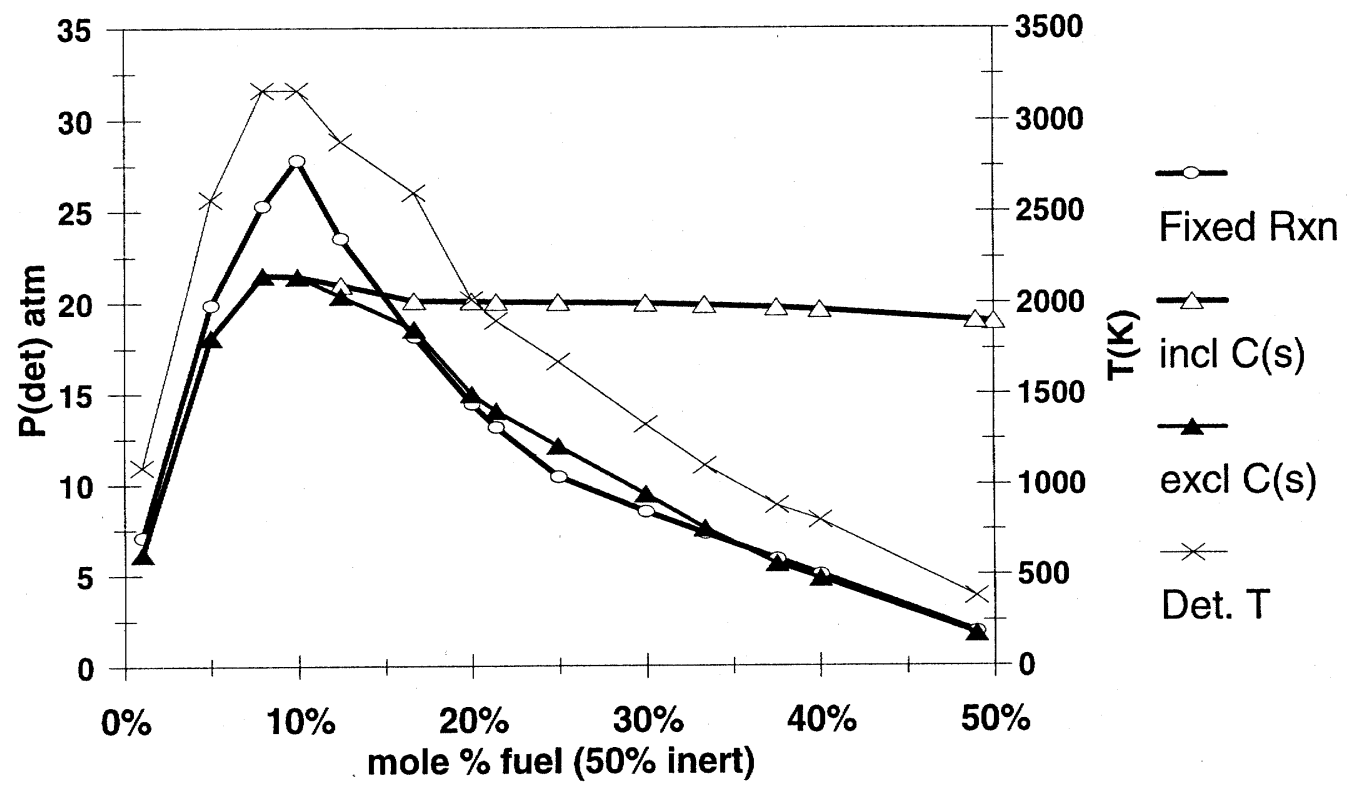

Fig. 3. Comparison of detonation pressures $\left(\mathrm{F}_{2}+\mathbf{c}-\mathrm{C}_{4} \mathrm{~F}_{8}+\mathbf{5 0 \%} \mathrm{N}_{2}\right)$. Predicted detonation pressures for the 1999 fixed reaction model and the present equilibrium-based model, both including and excluding $\mathrm{C}(\mathrm{s})$ as a possible reaction product. Also shown is the predicted detonation temperature [present model, excluding $\mathrm{C}(\mathrm{s})$ ].

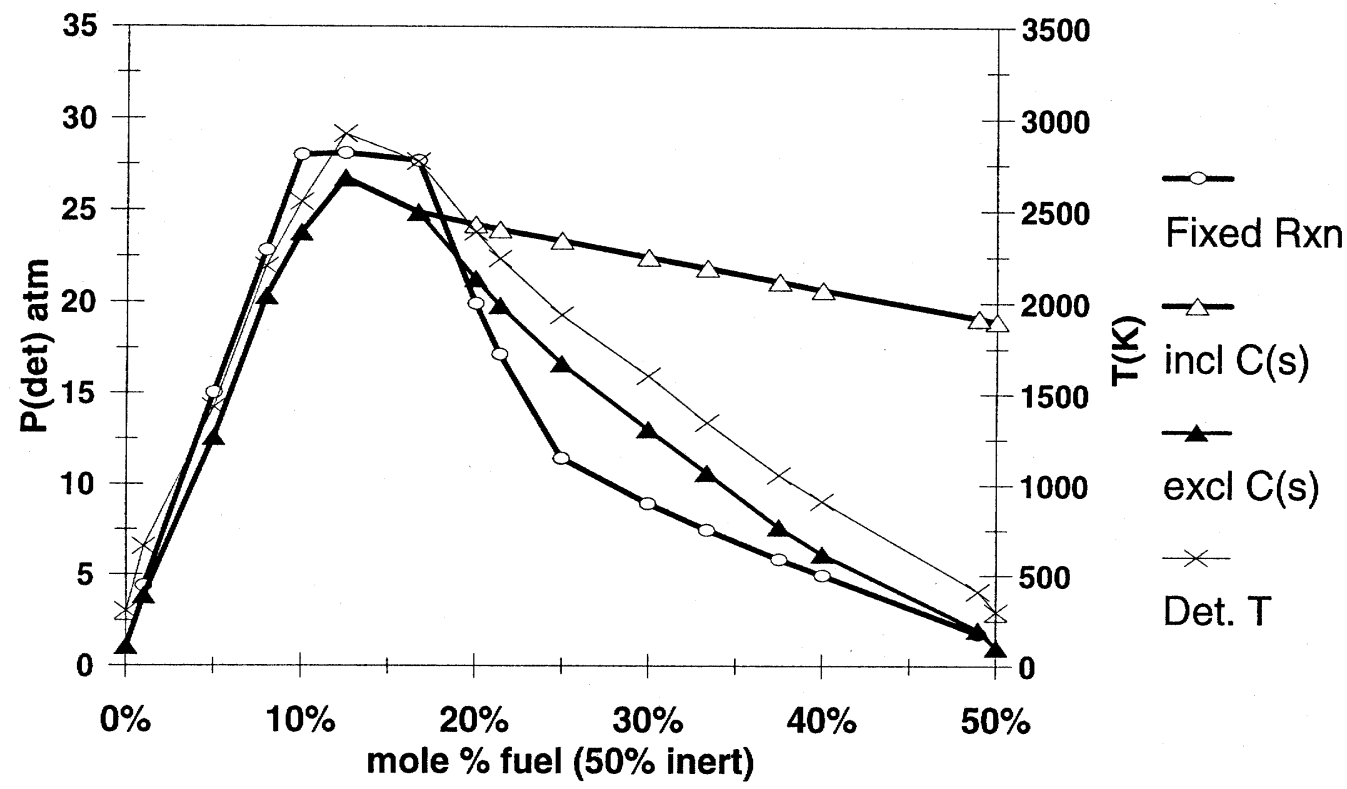

Fig. 4. Comparison of detonation pressures $\left(\mathrm{ClF}_{3}+\mathrm{c}-\mathrm{C}_{4} \mathrm{~F}_{8}+50 \% \mathrm{~N}_{2}\right)$. Predicted detonation pressures for the 1999 fixed reaction model and the present equilibrium-based model, both including and excluding $\mathrm{C}(\mathrm{s})$ as a possible reaction product. Also shown is the predicted detonation temperature [present model, excluding $\mathrm{C}(\mathrm{s})$ ]. 


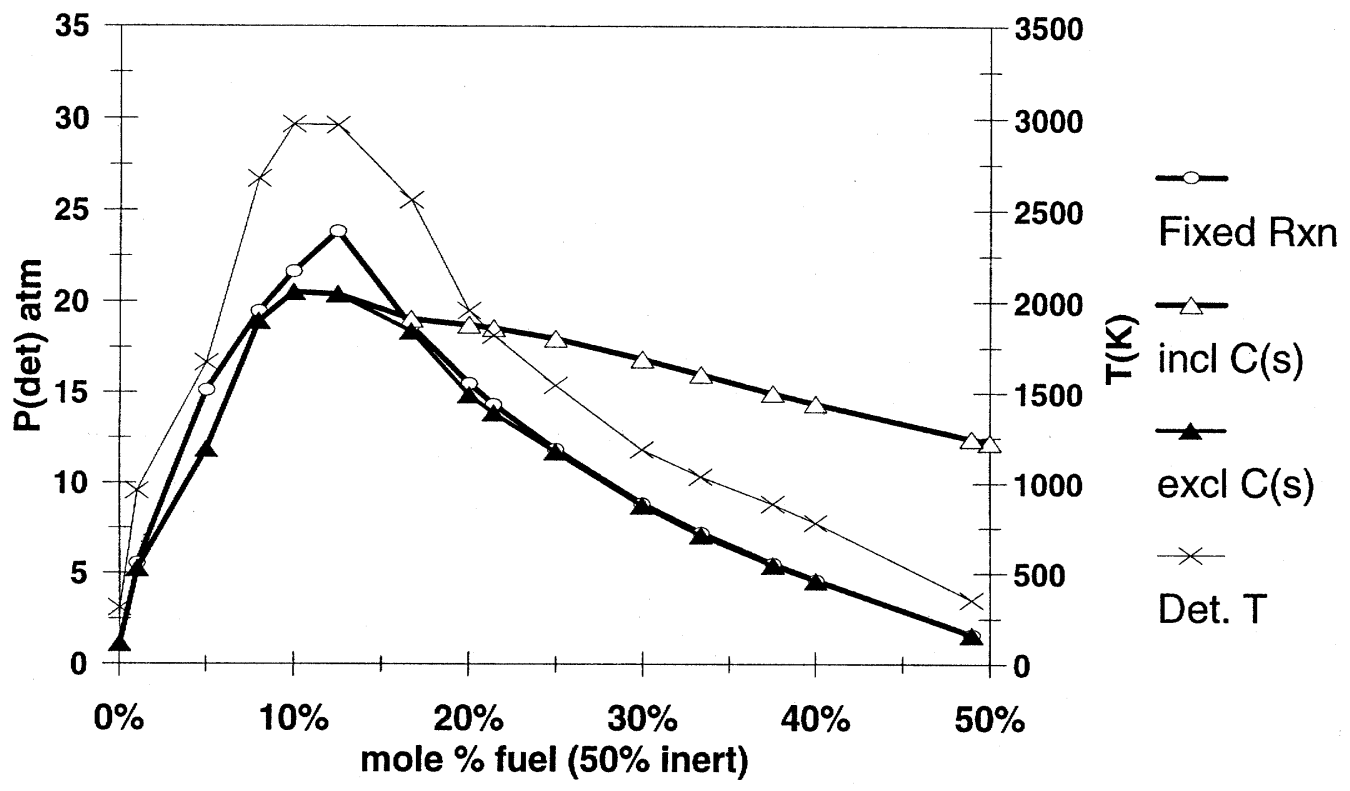

Fig. 5. Comparison of detonation pressures $\left(\mathbf{F}_{2}+\mathbf{C}_{4} \mathbf{F}_{10}+\mathbf{5 0 \%} \mathbf{N}_{2}\right)$. Predicted detonation pressures for the 1999 fixed reaction model and the present equilibrium-based model, both including and excluding $\mathrm{C}(\mathrm{s})$ as a possible reaction product. Also shown is the predicted detonation temperature [present model, excluding C(s)].

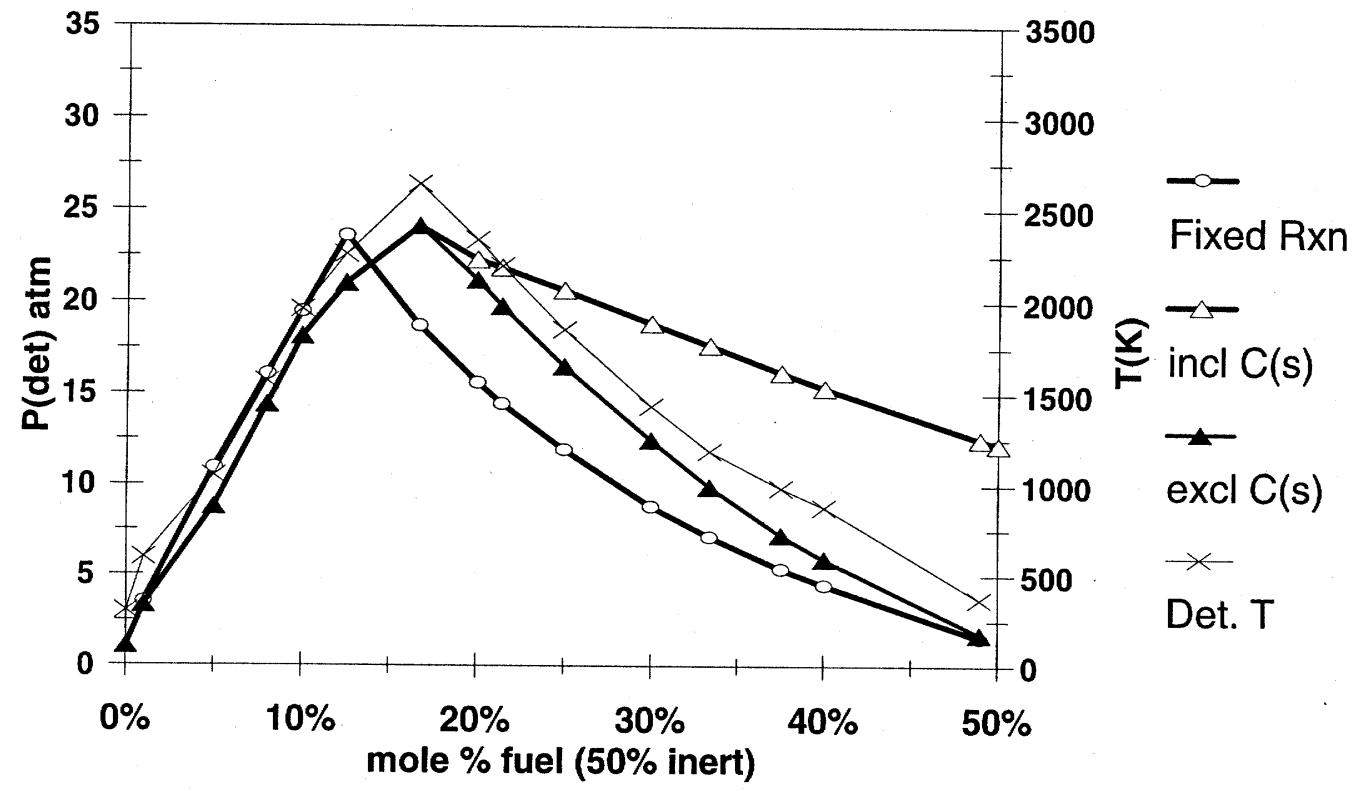

Fig. 6. Comparison of detonation pressures $\left(\mathrm{ClF}_{3}+\mathrm{C}_{4} \mathrm{~F}_{10}+\mathbf{5 0 \%} \mathrm{N}_{2}\right)$. Predicted detonation pressures for the 1999 fixed reaction model and the present equilibrium-based model, both including and excluding $\mathrm{C}(\mathrm{s})$ as a possible reaction product. Also shown is the predicted detonation temperature [present model, excluding $\mathrm{C}(\mathrm{s})$ ]. 


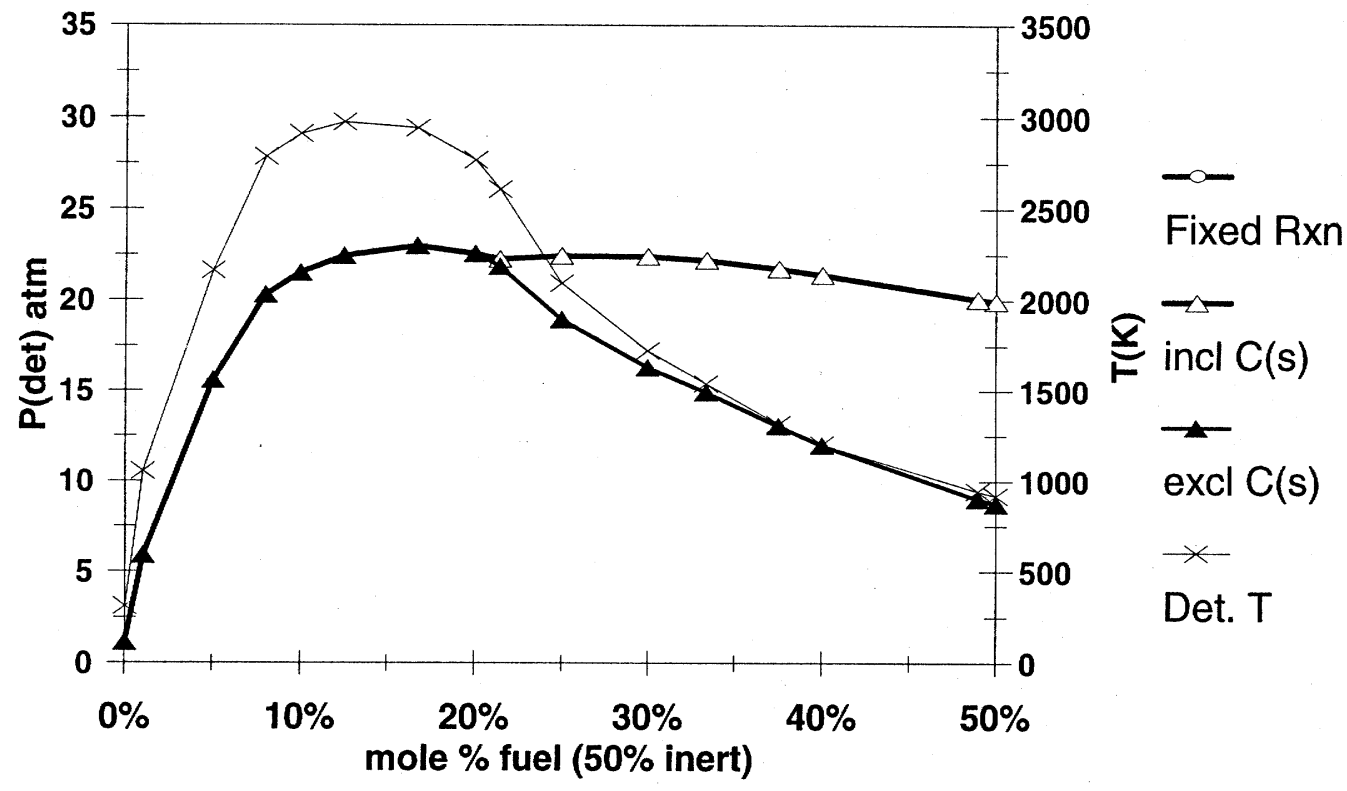

Fig. 7. Comparison of detonation pressures $\left(\mathrm{F}_{2}+\mathbf{c}-\mathrm{C}_{4} \mathrm{~F}_{8} \mathrm{O}+\mathbf{5 0 \%} \mathrm{N}_{2}\right)$. Predicted detonation pressures for the present equilibrium-based model, both including and excluding $\mathrm{C}(\mathrm{s})$ as a possible reaction product. Also shown is the predicted detonation temperature [excluding $\mathrm{C}(\mathrm{s})$ ].

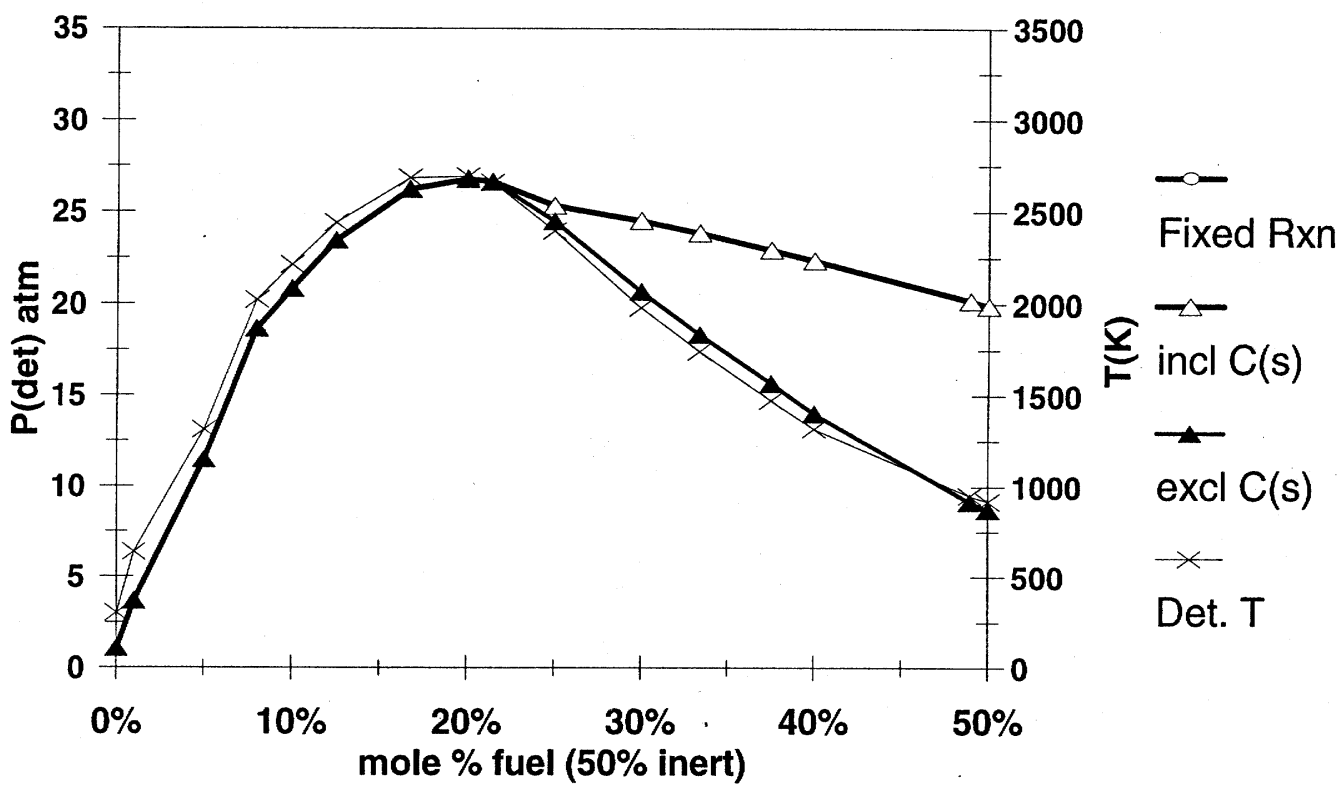

Fig. 8. Comparison of detonation pressures $\left(\mathrm{ClF}_{3}+\mathbf{c}-\mathrm{C}_{4} \mathrm{~F}_{8} \mathrm{O}+50 \% \mathrm{~N}_{2}\right)$. Predicted detonation pressures for the present equilibrium-based model, both including and excluding $\mathrm{C}(\mathrm{s})$ as a possible reaction product. Also shown is the predicted detonation temperature [excluding $C(s)$ ]. 
might be the length of time from the arrival of the flame front at a particular location until significant gas cooling begins, perhaps several seconds. In a detonation, however, the shock wave is driven by chemical reactions that must substantially go to completion in the duration of the passage of the shock wave. Calculated detonation wave velocities in these studies are many hundreds of meters per second, so the passage of the detonation through, say, a 1-mm reaction zone would take about a microsecond. A reaction barely fast enough to participate in a flame would need to proceed at least a thousand times faster to participate in a detonation. That suggests that the appropriate temperature threshold for $\mathrm{C}(\mathrm{s})$ formation in a detonation reaction would be considerably higher than in the flame case.

In the examples presented, some of the computed detonation temperatures, however, do exceed the $2400 \mathrm{~K}$ range at their peak. For three of the coolants, though, such temperatures occur for compositions at which little or no production of $\mathrm{C}(\mathrm{s})$ is predicted. Cyclo- $\mathrm{C}_{4} \mathrm{~F}_{8}$ detonation temperatures exceed $2500 \mathrm{~K}$ over a fairly wide composition range in these $50 \% \mathrm{~N}_{2}$-diluted mixtures. Detonation velocities determined by Fletcher and Kittelson (1968) for fuel-rich regions of the $\mathrm{c}-\mathrm{C}_{4} \mathrm{~F}_{8}+\mathrm{F}_{2}$ system are reasonably-well matched by model predictions only when $\mathrm{C}(\mathrm{s})$ is allowed as a product (Appendix B). For those mixtures, the computed detonation temperature exceeded $2700 \mathrm{~K}$. The other three coolants typically generate lower calculated detonation temperatures.

In summary, for at least three of the coolants, we can make a reasonable if qualitative argument that $\mathrm{C}(\mathrm{s})$ can be neglected as a potential product in detonation reactions, with the exception of the $\mathrm{F}_{2}+\mathrm{c}-\mathrm{C}_{4} \mathrm{~F}_{8}$ system. Note that we are not saying that $\mathrm{C}(\mathrm{s})$ would not be produced or observed as a reaction product following a detonation, but rather that it is unlikely to form rapidly enough to affect the character of the detonation front. Though $\mathrm{C}(\mathrm{s})$ can plausibly be neglected in these systems in detonation calculations, it probably should be considered for adiabatic calculations which have been proven to generate temperatures in excess of 2200 to $2400 \mathrm{~K}$ or detonation calculations that produce temperatures in excess of perhaps $2700 \mathrm{~K}$.

Table 1 lists the maximum detonation pressures calculated in these runs for the old (Trowbridge 1999a) and new models (this work). In no case examined was the maximum detonation pressure affected by consideration of $\mathrm{C}(\mathrm{s})$, as the maxima occur near an ideal stoichoimetry for the mixture under consideration rather than for fuel-rich mixtures. In most cases, the thermodynamic-based model resulted in marginally lower maximum detonation pressures, due essentially to formation of radicals at high temperatures, a highly endothermic process.

Table 1: Maximum detonation pressures (atm) for fuel + oxidizer $+50 \% \mathrm{~N}_{2}$ mixtures (Initial conditions: $1 \mathrm{~atm}, 25^{\circ} \mathrm{C}$ )

\begin{tabular}{cccc}
\hline & & $\begin{array}{c}\text { Old } \\
\text { Model } \\
\text { (fixed reaction) }\end{array}$ & $\begin{array}{c}\text { New } \\
\text { Model } \\
\text { (equilibrium) }\end{array}$ \\
\hline $\mathrm{F}_{2}$ & $\mathrm{C}_{2} \mathrm{~F}_{4} \mathrm{Cl}_{2}$ & 22.2 & 19.8 \\
& ${\mathrm{C}-\mathrm{C}_{4} \mathrm{~F}_{8}}$ & 27.8 & 21.5 \\
& $\mathrm{C}_{4} \mathrm{~F}_{10}$ & 23.9 & 20.5 \\
& $\mathrm{c}-\mathrm{C}_{4} \mathrm{~F}_{8} \mathrm{O}$ & $\mathrm{NA}$ & 23.0 \\
& & & \\
$\mathrm{ClF}_{3}$ & $\mathrm{C}_{2} \mathrm{~F}_{4} \mathrm{Cl}_{2}$ & 24.7 & 21.6 \\
& $\mathrm{C}-\mathrm{C}_{4} \mathrm{~F}_{8}$ & 28.1 & 26.8 \\
& $\mathrm{C}_{4} \mathrm{~F}_{10}$ & 23.6 & 24.1 \\
& $\mathrm{c}-\mathrm{C}_{4} \mathrm{~F}_{8} \mathrm{O}$ & $\mathrm{NA}$ & 26.8 \\
\hline
\end{tabular}


The one case in which this was not true was the $\mathrm{ClF}_{3}+\mathrm{C}_{4} \mathrm{~F}_{10}$ system. In that system, the maximum pressure occurred at a composition rather different from that predicted in the fixed reaction model and the reaction products calculated for that peak composition were considerably different from those assumed in the fixed reaction model. In essence, the reactions chosen in that composition regime in the fixed reaction model did not well represent the thermodynamic equilibrium. In most other cases, the reactions chosen were a fairly good representation of the equilibrium state, at least in terms of energy release if not always in terms of product composition.

Cyclo- $\mathrm{C}_{4} \mathrm{~F}_{8} \mathrm{O}$ produces slightly higher predicted maximum detonation pressures than any of the other coolants. The thermodynamic parameters for this compound, however, are not known and were all estimated (Appendix C). This may lead to considerable uncertainty in the result.

\subsection{SELECTION OF PRODUCT SPECIES}

The detonation pressure model is based on a well-developed and accepted theory of shock propagation and combustion. Its credibility rests primarily on that theory, as there is only sparse experimental data for fluorocarbon-fluorine explosions. For the results to have a degree of validity, however, it is necessary to choose an appropriate set of chemical reaction products. Appropriate, in this case, means a set of potential reaction products which can be formed from the reactants at the temperatures, pressures, and time scale prevailing in the flame or detonation, and excluding species which, for kinetic reasons, cannot form under those conditions. At the temperatures and times appropriate to the presumed detonation, considerable dissociation of fluorocarbons can occur, major radical species being $\mathrm{CF}_{2}$ and $\mathrm{CF}_{3}$. Even at lower temperatures, otherwise unreacted $\mathrm{ClF}_{3}$ will likely dissociate to $\mathrm{ClF}$ and $\mathrm{F}_{2}$. Dissociation of this sort will lower the temperature of the gas mix but increase the number of moles of gas, compensating factors that do not necessarily cancel. The equilibrium-based reaction model is capable of capturing these effects, provided the appropriate fragment species are available to the model. Flames and detonations, however, are ultimately very rapid time- and mass-transport-dependent processes and thus not truly equilibrium phenomena.

The list of chemical species in the model is intended to include both those compounds present initially and any species that may be produced by chemical reaction. The goal in selection of product species is to include any that could plausibly form during the reaction but to exclude those that will not form for whatever reason.

Relatively unstable species, those which will not be present at equilibrium because they are not favored thermodynamically, can be included but may slow down computation. Some species in this category not included in the initial list of compounds are $\mathrm{CF}(\mathrm{g}), \mathrm{U}(\mathrm{g}), \mathrm{C}(\mathrm{g}), \mathrm{O}(\mathrm{g})$, and $\mathrm{ClF}_{5}(\mathrm{~g})$. These (and other compounds) were originally considered but never appeared in significant quantity due to thermodynamic instability relative to species which are included. This judgment was made in the context of the fluorocarbon-fluorine-type combustion reactions at which the model was aimed. The model, however, can readily be used for many other types of gas combustion systems, and the user should select a species list appropriate to the scenario being considered.

A second class of species that might need to be excluded consists of those compounds that, while thermodynamically favorable, do not form in significant quantities for kinetic reasons. As a general rule, one ought to restrict participation of a potential reactant or reaction product only 
when there is empirical evidence that it does not actually participate in the reaction. The inclusion or exclusion of $\mathrm{C}(\mathrm{s})$ as a reaction product was discussed at some length in the examples above. In the chemical systems for which this model was developed, a second prominent example is the participation of $\mathrm{UF}_{6}$. Whether the environment being examined is the void space in a $\mathrm{UF}_{6}$ cylinder or a plant hardware component undergoing a fluorination treatment to revolatilize uranium deposits, $\mathrm{UF}_{6}$ gas will be present in substantial concentration. In the thermodynamic-based model, if $\mathrm{UF}_{6}$ and fluorocarbons are present as reactants and the potential reaction product list includes reduced uranium fluorides such as $\mathrm{UF}_{4}$ or $\mathrm{UF}_{5}$, the equilibrium result will consume $\mathrm{UF}_{6}$ and produce reduced uranium fluorides and lead to additional fluorination of the carbon species. Empirically, the presence of $\mathrm{UF}_{6}$ in a fluorocarbonfluorinating agent mixture inhibits the flammability of the mixture (Trowbridge and Barber 1992; Trowbridge 1999a). That is to say, at least in the vicinity of the composition limits of flammability, $\mathrm{UF}_{6}$ does not significantly participate in the reaction, except to act as a heat sink. To illustrate this, consider a point on the estimated flammability boundary for the $\mathrm{F}_{2}-\mathrm{C}_{2} \mathrm{~F}_{4} \mathrm{Cl}_{2}$ $\mathrm{UF}_{6}$ system in the fuel-rich region, where the effect of $\mathrm{UF}_{6}$ reactivity would be most pronounced. A suitable composition in this region would contain $45 \% \mathrm{C}_{2} \mathrm{~F}_{4} \mathrm{Cl}_{2}, 20 \% \mathrm{~F}_{2}$, and $35 \% \mathrm{UF}_{6}$ (see Fig. 7 in Trowbridge 1999a). This mixture is predicted to be marginally flammable by both flammability models discussed in that report. Starting at initial conditions of $1 \mathrm{~atm}$ and $70^{\circ} \mathrm{C}$, the 1999 fixed reaction model predicts an adiabatic flame temperature for this composition of 1216 $\mathrm{K}$. The present equilibrium-based model, run with full chemical participation of $\mathrm{UF}_{6}$, predicts a flame temperature of $1547 \mathrm{~K}$. All the $\mathrm{UF}_{6}$ in that run is converted to $\mathrm{UF}_{4}$ and $\mathrm{UF}_{5}$, allowing additional fluorination of the coolant above that produced by the consumption of $\mathrm{F}_{2}$. Running the same case, but with chemical participation of $\mathrm{UF}_{6}$ prevented, the adiabatic temperature predicted is $1108 \mathrm{~K}$.

The fact that flammability boundaries shrink rather than expand when $\mathrm{UF}_{6}$ (with its high heat capacity) is substituted for $\mathrm{N}_{2}$ (a lower-heat-capacity diluent gas) suggests that it does not participate in the flame reaction to a significant degree at temperatures that prevail at those boundaries. That does not exclude the possibility of its participation at much higher temperatures (i.e., far inside the boundaries). All we know is that, at the time scale of a flame reaction experiment (perhaps $1 \mathrm{~ms}$ to $1 \mathrm{~s}$ ), the kinetics of reactions allowing $\mathrm{UF}_{6}$ to fully participate are too slow for it to be significantly consumed. Detonation reactions, which must go to completion on a time scale on the order of a microsecond, would have to be a thousand to a million times faster in order to go to completion. A plausible reaction by which $\mathrm{UF}_{6}$ participation would be initiated is

$$
\mathrm{UF}_{6} \rightarrow \mathrm{UF}_{5}+\mathrm{F}
$$

which has known rate constant parameters. The high pressure rate of this reaction is given by

$$
\mathrm{k}_{\infty}=\mathrm{A}_{\mathrm{o}} \mathrm{e}^{\mathrm{Ea} / \mathrm{RT}},
$$

where $\mathrm{E}_{\mathrm{a}}$ is $-68 \mathrm{kcal} / \mathrm{mol}$ (Bostick et al. 1987). This activation energy is much higher than that for the dissociation of $F_{2}$ to produce atomic $F$ (on the order of $19 \mathrm{kcal} / \mathrm{mol}$ ), accounting for the relative inertness of $\mathrm{UF}_{6}$ in these scenarios. This temperature dependence suggests that the $\mathrm{UF}_{6}$ decomposition rate would increase a thousand-fold between $1200 \mathrm{~K}$ and about $1600 \mathrm{~K}$.

Therefore, we would not expect $\mathrm{UF}_{6}$ to significantly participate in detonation reactions for temperatures below $1600 \mathrm{~K}$. These figures are just lower limits. We have no information suggesting its participation even at much higher temperatures in the flame or detonation arena. 
The most plausible treatment to employ in the model would be to never allow it to participate. If one preferred to use conservative assumptions (in the sense of overestimating reactivity when in doubt) then possibly $\mathrm{UF}_{6}$ should be allowed to participate if the adiabatic temperature exceeds $1200 \mathrm{~K}$ or the detonation temperature exceeds $1600 \mathrm{~K}$ (in both cases, these temperatures derived from runs in which it did not participate).

The discussion here has dealt with the general criteria for species selection but not with the mechanics of including or excluding species within the model or restricting the reactivity of species that must be included. Appendix A discusses such operational details.

\subsection{LIMITATIONS}

This equilibrium-based reaction model offers several advantages over its predecessors. It relieves the user from selecting representative reactions (with the possibility of failure to identify the most favorable reactions). By using an equilibrium endpoint, multiple reaction products are accessible, including radicals or other fragment species, a factor known to influence flame reaction temperatures. Further, multiple fuels and oxidizers can simultaneously be considered. There are, however, limitations to this approach.

The detonation pressure model in general predicts what will happen assuming combustion is initiated, propagated, and accelerated to fully developed shock conditions. It does not, except in extreme cases, tell if the system can actually accomplish these events successfully. In extreme conditions, the model may yield results in which the impulse is lower than the detonation pressure. Such cases imply that bulk gas movement is in a direction opposite to the direction of propagation of the shock, hardly a condition conducive to development of a shock. Such conditions are clearly outside the realm in which a shock can be propagated. The true boundaries of explosivity of the gas mixture lie well inside such conditions, however. The model will compute detonation pressures for conditions where, in fact, no detonation would actually occur in a practical case.

In interpreting the effects of potential detonations, it is important to consider the short durations involved. Assuming it forms in the first place, the shock wave may be traveling at many hundreds of meters per second, but the zone of combustion may be on the order of millimeters broad, and the post-shock high-pressure region some multiple of this. The pressures generated may be very high but are present for a very short time, which limits the energy that can be transferred to the walls confining the explosion. Naturally, treating the detonation pressure (or impulse) as though it were a static pressure is conservative but may well be excessively so. If such a treatment suggests that costly countermeasures should be taken, it may be wise to examine the time-dependent effects more closely, and possibly resort to experimentation.

Reaction chamber size effects are not captured by any of the data used in calibration of the flammability limit models or in the functional form of the model. Consequently, phenomena such as quench distance and lower pressure limit of flammability (a related factor) will not be predicted. These phenomena are probably not of great relevance to the intended use of these models.

Flames and detonations are ultimately very rapid time- and mass-transport-dependent processes and, thus, not truly equilibrium phenomena. Discussions of species inclusion and exclusion are essentially aimed at handling cases where the chemical kinetics either permit reactions to 
proceed to completion in the time allowed or where the reactions barely get started. It cannot readily address the case in which the reaction kinetics allow the reaction to proceed substantially but not completely to equilibrium. To more exactly treat these systems would require a much more detailed treatment of the kinetics of combustion than can be contained in a model of this sort. The treatment applied here using thermodynamic equilibrium as the reaction model is, however, a reasonable, flexible, much less-computationally-intensive, if approximate approach, to these systems.

\section{CONCLUSIONS}

A model of flame and detonation reactions of flammable gas mixtures has been developed and documented. The model directly uses a well-established theory of gas detonation to calculate the pressure that would develop if combustion of a flammable gas mixture were to accelerate to a fully developed shock. The model also calculates the constant-volume adiabatic temperature of the mixture upon reaction, which is a reasonable approximation to temperatures and pressures generated in confined flames or explosions in the deflagration regime. Finally, an empirical correlation between adiabatic temperature and gas flammability is used to make a prediction as to the flammability of the mixture under consideration.

While the approach is applicable to any reactive gas mixture, the chemical species included in the model focus on the fluorocarbon / fluorinating agent chemistry commonly encountered in uranium enrichment applications. The current version contains information allowing consideration of gas mixtures containing $\mathrm{F}_{2}, \mathrm{ClF}$, and $\mathrm{ClF}_{3}$ reacting with one or more of the fuels $\mathrm{C}_{2} \mathrm{~F}_{4} \mathrm{Cl}_{2}, \mathrm{C}_{4} \mathrm{~F}_{10}, \mathrm{c}-\mathrm{C}_{4} \mathrm{~F}_{8}$, or $\mathrm{c}-\mathrm{C}_{4} \mathrm{~F}_{8} \mathrm{O}$ (or, in fact, with many other perfluorocarbons and chlorofluorocarbons included as potential reaction products). Modification of the model to incorporate other chemical species is straightforward. Comparison of model results with both experimental and theoretical results from the scientific literature shows reasonable agreement for most cases examined.

The adiabatic reaction and detonation portions of the model are in principle applicable to any reactive gas mixture for which combustion reactions can be adequately represented by thermodynamic equilibrium. This last statement lies at the heart of a key limitation of the model. Thermodynamic calculations in general and this model in particular may not reflect actual events when kinetic (i.e., rate-of-reaction) limitations intervene. Some chemical judgment must be exercised when using the model to capture, or at least approximate, the effect of such kinetic limitations. 
APPENDIX A 



\section{APPENDIX A \\ FUEL-OXIDIZER EXPLOSION MODEL OPERATING INSTRUCTIONS AND DESCRIPTION}

\section{A.1 Introduction}

This appendix contains directions for use of the equilibrium-based detonation model discussed in the main body of this report. The system described here captures the mathematics of the two models described for reactions of flammable gaseous mixtures, calculating the adiabatic pressure and temperature rise were the reaction to proceed reversibly and also the momentary detonation pressure that would occur should the reaction proceed via a fully developed shock wave. It is assumed that the initial gas mixture reacts to completion, with completion being defined here as the equilibrium condition.

This spreadsheet is an adaptation of a series of related spreadsheets developed by E. J. Barber (Barber 1990; Trowbridge and Barber 1992) and later updated by Trowbridge (1999a). Those models defined the reaction products using specific chemical reactions of several fuel / oxidizer combinations. This version, by contrast, treats the reaction as an equilibrium process. No particular fuels, oxidizers, diluents, or reactions are specified. The endpoint is computed solely on the basis of the relative thermodynamic stability of the species available.

Unlike previous models in this series, this reaction formulation is capable of carrying out calculations on mixed fuels or oxidizers. A potential disadvantage (which can to a degree be rectified by user intervention) is that species in the model may react which do not in practice actually do so. This can occur for kinetic reasons; that is, their reaction rates are too slow to be important on the rapid (millisecond to microsecond) time scale of gas explosions.

Most of the calculation is highly iterative - too much so for a spreadsheet to directly handle. Iterative numeric routines are done outside the spreadsheet by calling two programs: (1) ADIAB95f.EXE, which solves the constant-volume adiabatic equilibrium condition, and (2) DET01.EXE, which solves for the fully developed detonation condition using the Hugoniot equations. Both endpoints use the thermodynamic equilibrium as the reaction endpoint, each at their respective temperature and pressure conditions. The thermodynamic endpoints are found by each of these programs by repeatedly calling SOLGAS.EXE until an equilibrium condition is found which satisfies all relevant conditions.

Versions of this model run under Microsoft Excel (version 97) and Corel's Quattro Pro (version 8). They may be upward compatible but have not been tested in later releases of either package. The Quattro is downward compatible, at least to version 7. One or the other spreadsheet package is needed to run the model. The model runs under Windows 95 or 98 . Utilities that are called by the spreadsheet run in DOS windows within the Windows 95 or 98 operating system.

\section{A.2 System Description}

Communication between the various segments of the model is done by means of temporary files. The general communication scheme is shown in the flowchart depicted in Fig A.1. The temporary files generated during operation of the model are written in plain text (i.e., ASCII), and most of these files are not deleted at the end of the run because examination of their contents 


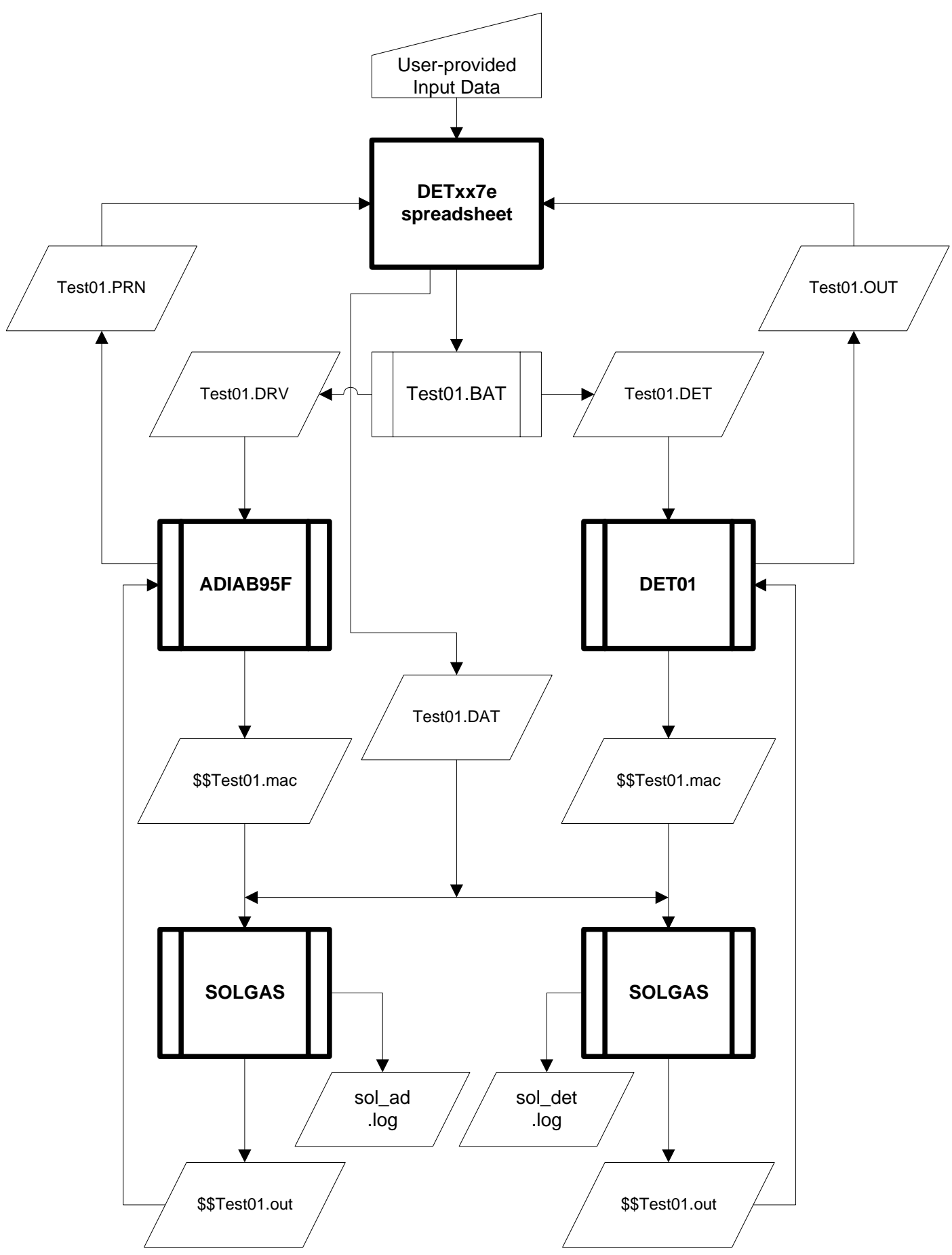

Figure A.1. System flowchart for detonation model.

(For purposes of illustration, this flowchart assumes that the base data file name is "Test01") 
can usually indicate the reason for failure of the external models should that occur. They can be erased using the [Cleanup] macro button. Most of the files have the base file name provided by the user and function-specific filename extensions. Assuming that the base filename chosen was "Test01", the temporary files created are named as indicated in Fig. A.1. The names and functions are as follows:

Test01 .DAT

Test01.DRV

Test01.BAT

Test01.PRN

Test01 .DET

Test01.OUT

Test01.CSV

\$\$temp .MAC

$\$ \$$ temp .OUT

Sol_ad.LOG

Sol_det.LOG
Thermodynamic data file (used by SOLGAS for both models)

Run control file for use by ADIAB95F

Batch file which runs ADIAB95F

Results of ADIAB95F

Run and thermodynamic data for use by DET01.EXE

Results of DET01

Results of DET01 (Excel only)

Keystroke macro used for automatic operation of SOLGAS

SOLGAS temporary results file temporary log of SOLGAS communications with ADIAB95F.EXE

temporary log of SOLGAS communications with DET01.EXE

\section{A.3 Description of the Spreadsheet}

This section describes the regions of this spreadsheet and their general functions. The following spreadsheet regions are all located on Sheet $A$.

Summary Table. The upper left corner of the spreadsheet contains the primary initial and final state (pressure, temperature, volume, and quantities of each species). The left-most data column contains the initial conditions, as specified by the user. The next column contains the results of the adiabatic constant-volume reaction model (or will after the adiabatic model is run). The third column, labeled "Shock(*)," is an approximation (due to Langweiler) which roughly estimates the fully developed shock condition. The next two columns, labeled "Detonation Model," contain the results (again, valid only after the model is run) for the fully developed shock wave and the impulse.

Operational area. To the immediate right of the summary table are the macro buttons for running the model. Very brief instructions are included there as well. One cell in this area is the "initial guess for $\mathrm{T}_{\mathrm{f}}$." Both models (adiabatic and detonation) numerically converge on the solution to their respective problems starting from an initial guess of the final temperature. The adiabatic model is not very sensitive to the value of this guess and will usually find the solution to the problem in one attempt. The detonation model is more sensitive. If it fails to find a solution, the cure generally is to change the $\mathrm{T}_{\mathrm{f}}$ guess to a value closer to the answer. The "shock" temperature estimate produced by the adiabatic model is usually a good value for this guess.

Status. Several status diagnostics are located just below the Summary Table. These are as follows:

Exported Data status indicates whether the currently specified initial data is the same as that last exported to the external models. 
External Models have run (Excel only) Indicates whether the external models have been run since most recent data export.

External Models' Results (Excel only) Indicates whether the results have been imported since the most recent run.

Results Imported (Quattro only, one line for each model) Tells if the most recent data export gave results that were successfully imported.

Initial Mass Balance Tests that the initial gas mole fractions add to 100\% and checks for negative values.

Adiabatic Model and Detonation Model Mass Balance Indicates the degree of mass balance agreement between initial conditions and the currently imported model results. "OK" indicates that there is agreement within the precision allowed by the number of significant digits processed by the external models. A "large error" generally means that SOLGAS or the external models failed to find a satisfactory solution to the equilibrium. If the results are not current, this is indicated.

These status indicators are color coded. If all are green, then the model should be working correctly. If any are pink or red, then either some operation has yet to be completed before the results will display or there is a problem with the particular case.

Composition Table. Below the Summary Table are lists depicting the initial composition, the final adiabatic/constant-volume equilibrium composition, and the final shock condition, again assuming equilibrium. The last two will reflect the current results only after the appropriate external models have been run. In each case, the composition is presented as a mole fraction and as a quantity in gram-moles. The mole fractions are computed considering only the gases. Any solids present will be shown as if they were a mole fraction, but to not contribute to the sum of mole fractions required for normalization of the gaseous species. Several tables are located to the right of the Composition Table. These are as follows:

Thermodynamic Properties Table. Thermodynamic properties for species actively used in the model. These are taken from the more comprehensive table of potential reactants or products on the Thermo sheet.

Mass Balance Table. Table which assists in checking the "before-vs-after" mass balance for several chemical elements.

Starting Quantity Adjustment. In some cases, a trace of otherwise absent species or elements must be added to allow the thermodynamic equilibrium model to run properly; this table makes that adjustment.

Macro for writing SOLGAS data file. This section interprets the starting quantities and species used and generates the thermodynamics data file required by the equilibrium program SOLGAS, which is used by both the adiabatic and detonation model.

Quattro version: this section contains the macro for writing this data file.

Excel version: this section contains the file image of the data file to be exported by a Visual Basic Macro.

Adiabatic Model Results. Once the adiabatic model is run via macro, the results are imported into this table. 
Macro for writing input data (for DET01.EXE).

Quattro version: This section writes a data file used by DET01.EXE defining the preshock state (DET01.EXE will calculate and return the shock state of the system).

Excel version: Blank (this function is contained in the macro module).

Data file image (to be exported to DET01.EXE). This section constructs the file written for the detonation model.

Detonation model results (imported by macro "RUNDET"). Results are imported to this table after DET01.EXE is run.

External Control Files. The external files that run the detonation and adiabatic reaction models require several control files. In the Excel version, file images of some of these are constructed here and then exported. In the Quattro version, these operations are done elsewhere.

Flammability Model Intermediates. A table identifying species treated as fuels or oxidizers.

At the left of the spreadsheet, below the composition table are several sections with more detailed information on the various models, some of which is not listed in the summary table. These are as follows:

Adiabatic Reaction Model. Intermediate calculations related to the adiabatic reaction model.

Detonation Pressure Model. Intermediate calculations related to the detonation model, including some values of possible interest but not displayed elsewhere, such as the speed of the detonation wave and the local speed of sound.

Empirical Flammibility Estimate. This contains an empirical estimate of whether the gas mixture falls within or outside the limits of flammability. This estimate is based strictly on empirical observations of flammability (or lack thereof) in similar gas mixtures (i.e., $\mathrm{F}_{2}$ or $\mathrm{ClF}_{3}$ reacting with relatively low-molecular-weight fluorocarbon or chlorofluorocarbon fuels).

Constants and Conversion Factors. Constants used by the models are collected here.

The above information was all contained on sheet $A$. Other sheets in the model are:

Doc Sheet. Contains brief documentation on the model.

\section{Macro Sheet.}

Quattro Version: This sheet contains macros for running the external adiabatic and detonation models (although a few macros are embedded in sheet $A$ ).

Excel version: This sheet contains an explanation of macros and has directions for updating them as needed. Macros proper are contained in "Module1," which can be accessed using the Visual Basic Editor function of Excel. 
Thermo Sheet. This sheet contains the thermodynamic data base, including thermodynamic and other data for species which can be used in this spreadsheet and in associated SOLGAS runs (SOLGAS being in turn run by DET01 or ADIAB95f). The thermodynamic tables are divided into gases (the upper portion) and solids (the lower portion). Actually, condensed species could include liquid species, although none are included in the present version. Data on this sheet is used as an internal data base from which to look up the thermodynamic and other parameters for the chemical species actually used for the particular case on Sheet $A$.

\section{A.4 Initial Setup}

Initially, the spreadsheet file (DET7e.xls or DET7e.wb3), SOLGAS.EXE, ADIAB95f.EXE, and DET01.EXE should all be put in the same directory. To minimize confusion, it may be helpful if this directory is newly created and fairly near the root directory of its drive. In the auxiliary programs, the total length of file and directory names is limited to 80 characters. If you use a deep or wordy directory structure, this limit could be exceeded, so you may want to put the files in a directory near the root of the drive.

On opening the spreadsheet, one of a series of "sheets" (defined by tabs at the bottom of the window) will be displayed. The main sheet, named $A$, contains the input and output fields for operating the model. Other sheets are named Doc, which has brief documentation, Macro, which has information for running external routines, and Thermo, which contains thermodynamic and other data for the chemical species that can be used by the model.

Prior to use, the spreadsheet needs to be informed of certain machine-specific names, directories, etc. These should be entered in the appropriate cells on the Macro sheet. The information needed is described on that sheet. Mostly it consists of filenames and directories, but the one fairly obscure item is the "COMSPEC," which is the name of the program the computer runs when it opens a DOS window. Directions for identifying the name and location of the COMSPEC are found on the Macro sheet.

Because of differences in functionality of Excel and Quattro, the required information is slightly different and must be entered differently in each version. For Quattro, you simply type the information into the appropriate cells, as indicated on the Macro sheet. In Excel, you must enter the data and then update the macros as described on the macro sheet. In either version, if this has not been done, a diagnostic to the right of the Summary Table on sheet $A$ will indicate that "Macros are not updated."

When the spreadsheet file is first opened, you may (depending on your spreadsheet application configuration) be asked whether you want to enable macros. Respond "yes" to this query.

Once you have arranged the files as described, entered the necessary information as discussed above, and (for Excel) updated the macros, the model should be ready to run.

\section{A.5 Operation}

Items intended to be routinely altered by the user as normal input data are shaded in yellow. These are the initial conditions: the system (gas) volume, the pressure, the temperature, and the starting quantities of chemical species. Temperature, pressure, and volume are listed in the summary sheet in several units. Change only the yellow-highlighted version unless you are 
willing to rearrange the formulae and references to other temperature, pressure, or volume entries in the Summary Table.

Initial quantities of chemical species are entered as mole fractions. The mole fractions for the gases must add to unity; if not, an error message will result. A few solid species are included as well. If any of these are to be present in the starting mix, enter a number in their mole fraction column just as for gases but do not add its value in the total for the gases. For example, if initial reactants consist of 8 moles of $\mathrm{C}_{4} \mathrm{~F}_{10}$ gas, 2 moles of $\mathrm{F}_{2}$ gas, and 5 moles of $\mathrm{UF}_{4}$ solid, the mole fraction numbers entered would be 0.8 for $\mathrm{C}_{4} \mathrm{~F}_{10}, 0.2$ for $\mathrm{F}_{2}$ (the sum of the two gas mole fractions adding to 1.0 ), and 0.5 for the solid $\mathrm{UF}_{4}$.

The species listed on sheet $A$ are the ones that are available as reactants and will be considered as potential products in the reaction. The spreadsheet is not limited to this list. Directions for adding and deleting species from the list will be discussed later.

Operation of the model is most easily accomplished by using the buttons to the right of the Summary Table. The operation differs slightly between versions, however. For the Excel version, aim the cursor at and click the [Export Data], [Run Models], and [Import Results] buttons in that order, waiting for each operation to finish before clicking the next button. For the Quattro version, simply click the [Run Both Models] button.

Clicking these buttons invokes macros for exporting data, running the external routines that solve the current problem, and importing the results back to the spreadsheet. The external routines will run in DOS windows. If the program pauses while displaying a DOS window during the run, push ENTER. There are optional PAUSE statements in batch files used to run the external programs; these are located on the Macro sheet of the Quattro version and at the far right of the Excel version and may be disabled.

The Quattro version also has two buttons for independently operating the two models. The [Adiabatic Model] button exports the data for the case, runs the adiabatic model, and imports its results. The [Detonation Model] button runs the detonation model and imports its results. The detonation model should not be run until the adiabatic model has run once (either via the [Run all models] button or the [Adiabatic Model] button). The adiabatic model usually satisfactorily arrives at an answer in one try, but it is not uncommon for the detonation model to fail to find a solution to a problem if it is given a poor initial guess as to the detonation temperature. The initial guess for the detonation temperature is located in a yellow cell above the buttons.

The model creates several temporary files during its operation. These are not automatically erased at the end of a run, as they may be useful in a postmortem in the event difficulty is encountered running a particular case. They can be removed, however, by clicking the [Cleanup] button.

\section{A.6 Adding and Deleting Species}

Chemical species considered in a calculation are those listed in the Composition Table on Sheet A. Data and formulae for these species are all contained in a contiguous set of rows (rows 27 to 68 as the spreadsheet was originally prepared, though that could change with addition or deletion of species). No formulae other than those that pertain to specific species intrude on this region. Therefore, deleting a species can be done simply by deleting its row (delete the row; don't just 
erase its contents, leaving a blank row). Avoid deleting the first or last row of either the gaseous species section or the solid species section, as those rows define the limits of sums and vector products used throughout the spreadsheet.

Adding a new active species can be done by inserting a row and copying the entire contents of an adjacent row into the new blank row (this will capture all formulae in the row). Then select the cell in the new row with the species name, and enter a reference to the name of a species in the Thermo sheet. For example, to add " $\mathrm{H}(\mathrm{g})$ " (atomic hydrogen) to the list of gases considered on Sheet $A$, insert a row, say at row 50. Then select an entire nearby row (say, row 49), copy $(\{\mathrm{Ctrl}\} \mathrm{C})$, select column A of the blank row, and paste $(\{\mathrm{Ctrl}\} \mathrm{V})$. Then select the new row, column B (the species name column), and reference the name entry for the desired species $H(g)$ on the Thermo sheet. You can simply enter the text " $\mathrm{H}(\mathrm{g})$ ", but it is better to reference the table entry (it avoids misspellings or inadvertent spaces which may foul up table look-ups). To reference the name on the Thermo sheet, select cell B50 of sheet $A$, type the "=" or "+" key, select the Thermo sheet with the mouse, scroll down until you find the " $\mathrm{H}(\mathrm{g})$ " row, select the cell that has the species name " $\mathrm{H}(\mathrm{g})$ " in it, then ENTER. All the other parameters for $\mathrm{H}(\mathrm{g})$ on sheet $A$ will be determined by table look-ups.

The above directions presuppose that the species you want to add is already present in the Thermo sheet. If not, you will need to add data to the Thermo sheet's data base. To add a species to the thermodynamic data base, you will need certain information about that species.

To add a new species to the thermodynamic data base, go to the Thermo sheet, select a row in the middle of the appropriate section of the table (the lighter-shaded section for gases, the darkershaded section for solids or liquids), and then insert a new row. The menu commands in either spreadsheet package for this insertion are [Insert] [Row]. Copy the entire contents of an adjacent row to the new blank row to capture computational and string formulae. Then enter the speciesspecific data in the new row:

1. The name

example: $\quad$ Ethane(g)

2. The chemical formula

example:

C2H6

(Use element symbols and coefficients; do not repeat an element.

For example, ethane is written $\mathrm{C} 2 \mathrm{H} 6$ or $\mathrm{H} 6 \mathrm{C} 2$, but not $\mathrm{CH} 3 \mathrm{CH} 3$ )

3. Standard enthalpy of formation $(\mathrm{J} / \mathrm{mol})$

example: $\quad \mathbf{- 8 3 6 8 0}$

4. Entropy at $298.15 \mathrm{~K}(\mathrm{~J} / \mathrm{mol} \cdot \mathrm{K})$

example:

229.225

5. Heat capacity, coefficient A

example: $\quad \mathbf{2 8 . 2 9 9}$

... coefficient $\mathrm{B}$

0.1409751

... coefficient $\mathrm{C}$

$-3.33 \mathrm{E}-05$

... coefficient $\mathrm{D}$

$-4414835$

... coefficient E

924705192

The Heat Capacity formula used here has the functional form:

$$
C_{P}=A+B T+C T^{2}+D / T^{2}+E / T^{3}
$$


where $C_{P}$ is given in $\mathrm{J} / \mathrm{mol} \cdot \mathrm{K}$ and $T$ is in $K$.

Following the heat capacity coefficients are two columns, one indicating the number of atoms in the molecule and the other containing a "1" if the molecule is linear. These were used for high-temperature heat capacity estimates, and can be ignored.
6. Molecular weight $(\mathrm{g} / \mathrm{mol})$
example:
30
7. Chemical formula coefficients.
example:
"2" under "C" and
"6" under "H".
"6" under "H".

In each column, enter the number of atoms of that column's element that are in the species. These are used to check mass balance for the more common elements. All elements are not included in this table.

8. Flammability model parameters:

If the new compound is to be considered either a fuel or a fluorinating agent/oxidizer, enter its parameters: If it is a fuel or an oxidizer, enter "I" in the appropriate column, and $a$ " $O$ " otherwise. Enter the number of $F$ atoms it can supply, if an oxidizer, and the number of $F$ atoms it demands if a fuel. F-demand is defined as fluorine atoms needed to convert the fuel to $\mathrm{CF}_{4}, \mathrm{CO}$, and $\mathrm{Cl}_{2}$. The example species, ethane, is certainly a fuel, but is not at all similar to the fluorocarbons considered as fuels in the flammability model. The flammability prediction will not be meaningful for this material, so these entries are not relevant for this species.

Once the necessary data has been entered, that species may be referenced from sheet $A$ and used in the model.

\section{A.7 Restricting Reactivity of Certain Species}

If it is empirically known (or if you want to postulate) that certain species do not participate in the reaction, you may want to restrict their reactivity. The rationale for imposing such restrictions is discussed in Sect. 3.3.

To cite an example, it is observed that flammability limits of $\mathrm{C}_{2} \mathrm{~F}_{4} \mathrm{Cl}_{2}$ and $\mathrm{F}_{2}$ are not affected by $\mathrm{UF}_{6}$, other than to the extent that the $\mathrm{UF}_{6}$ absorbs heat. Thus you may want to restrict $\mathrm{UF}_{6}$ from reacting with the coolant, even though thermodynamically it would, if not restricted, form $\mathrm{UF}_{4}$ at equilibrium and add to the fluorination of the fuel.

Two methods can be used to restrict reactivity. First, you can eliminate all possible reaction products from the list of species on sheet $A$. $\mathrm{UF}_{6}$ will not be able to form $\mathrm{UF}_{4}$ if $\mathrm{UF}_{4}$ is not among the potential products. This is not always a convenient solution, however. The second method is to alter the chemical formula of the species to make it appear to have a unique element. By altering the formula from $\mathrm{UF}_{6}$ (which is recognized by SOLGAS as containing one $\mathrm{U}$ and six F's) to Hx (which SOLGAS would interpret as a new element, one not present in any other compound and hence not subject to reaction), the species will be rendered non-reactive. If there are two phases (as in the case of $\mathrm{UF}_{6}$, gas and solid), changing the formula of each $\mathrm{UF}_{6}$ entry to $\mathrm{Hx}$ will allow $\mathrm{UF}_{6}$ to vaporize and condense but will not allow it to contribute fluorine to the 
reaction mix. Formula changes for this purpose are made in the Thermo sheet, column B.

\section{A.8 Empirical Flammability Model}

The flammability model, located at the left and near the bottom of sheet $A$, uses an empirical correlation between the adiabatic temperature the mixture reaches upon reaction and compositions known to be flammable in similar fuel-fluorocarbon systems. The prediction is listed in the Summary Table.

This model relies on fuel and oxidizer concentrations. At present, five species are counted as possible oxidizers (actually, as fluorinating agents): $\mathrm{ClF}_{3}, \mathrm{~F}_{2}, \mathrm{ClF}, \mathrm{ClO}_{2} \mathrm{~F}$, and $\mathrm{COF}_{2}$. Twelve species are counted as fuels, including $\mathrm{C}_{2} \mathrm{~F}_{4} \mathrm{Cl}_{2}, \mathrm{c}-\mathrm{C}_{4} \mathrm{~F}_{8}, \mathrm{c}-\mathrm{C}_{4} \mathrm{~F}_{8} \mathrm{O}, \mathrm{C}_{4} \mathrm{~F}_{10}$, and a number of other fluorocarbons. If your starting mixture contains reactive species other than the ones designated as fuels or oxidizers (e.g., $\mathrm{O}_{2}$, hydrocarbons, or water vapor), the flammability prediction should be ignored. Calibration data was available only for very limited combinations of $\mathrm{F}_{2}$ or $\mathrm{ClF}_{3}$ reacting with $\mathrm{c}-\mathrm{C}_{4} \mathrm{~F}_{8}, \mathrm{C}_{4} \mathrm{~F}_{10}$, and $\mathrm{C}_{2} \mathrm{~F}_{4} \mathrm{Cl}_{2}$ diluted with $\mathrm{N}_{2}$, plus some binary mixtures of $\mathrm{C}_{2} \mathrm{~F}_{6}$, $\mathrm{C}_{3} \mathrm{~F}_{8}$, and $\mathrm{c}-\mathrm{C}_{4} \mathrm{~F}_{8}$ reacting with $\mathrm{F}_{2}$ or $\mathrm{ClF}_{3}$. The applicability of this empirical relationship for other combinations or mixtures of these fuels and oxidizers is conjectural. For further details of the flammability prediction, see Appendix D.

\section{A.9 Problems, Failure Modes, and Additional Remarks}

Occasionally, SOLGAS simply won't run correctly (perhaps displaying repeated error messages stating "translation error: $* * * * * * * * * * * *$ "). If the list of available chemical species was recently changed, it is possible that one or more elements is present in the potential mix but that there is no source in the input mixture for that element. This can cause mass balance difficulties in SOLGAS. On sheet A, tab right to the table entitled Starting Quantity Adjustment and copy the formula in the "adjusted" column under " $\mathrm{N}_{2}$ " to one or more cells containing species with the new element. Alternatively, in the Summary Table (column D, sheet A), put a trace of the new species in the mix (say, 0.0001 mole fraction).

Mass balance error diagnostics can be oversensitive in some cases. If you run a case in which the actual reactants include very few of the elements present in the species list, a trace of each missing element (at the $10 \mathrm{ppm}$ level) is added to the starting mix to avoid computational problems with SOLGAS. A few such elements will not trigger the "large mass balance" error message, but if most of the elements in the species list are in fact not used, the sum of all their slight errors may trigger the message. If you get such a message, check the bottom of the Mass Balance Table and see if the elements "in error" are all in fact ones that are present only in trace quantities. If that is the case, ignore the message.

Color Codes: Items shaded yellow are intended to be routinely user alterable during the course of a run. These are the normal input variables for a problem. Items in green need to change if the chemical species are altered. Green is also used in the diagnostic section to indicate satisfactory conditions. Items in red in the diagnostic section (just below the Summary Table) indicate an unsatisfactory condition (model not yet run; errors). Items in blue or purple are colored solely for emphasis. 


\section{A.10 A Sample Case}

A sample case will be used to illustrate operation of the model. It is assumed that the model has been set up previously, as described in Sec. A.2.

The problem posed is to estimate the pressure generated in a one liter container system at -3 psig and $35^{\circ} \mathrm{C}$ by combustion of a gas mixture consisting of $10 \% \mathrm{C}_{2} \mathrm{~F}_{4} \mathrm{Cl}_{2}, 4 \% \mathrm{c}-\mathrm{C}_{4} \mathrm{~F}_{8} \mathrm{O}, 8 \% \mathrm{~F}_{2}, 2 \%$ $\mathrm{ClF}_{3}, 10 \% \mathrm{UF}_{6}$, and the balance $(66 \%) \mathrm{N}_{2}$, all percentages being volume (i.e., mole) percent. The available species are those listed in Fig. A.2, which is a screen image of the Summary Table area of the Excel version of the spreadsheet after the models have been run.

Following the reasoning described in the text, $\mathrm{C}(\mathrm{s})$ is not included in the list of available species. To ensure that $\mathrm{UF}_{6}$ acts merely as a diluent and not a reactant, on the Thermo sheet we change its chemical formula to "Hx" for both the solid and gaseous form.

Next, we enter the input values for pressure, temperature and volume in the appropriate cells. As soon as any altered input data is changed, the diagnostic indicating "Exported Data is NOT current" appears, as it should. Next, the listed mole fractions are entered in the Summary Table (Sheet $A$, column $\mathrm{D}$ ). If they were entered correctly (and all other initial mole fractions are set to zero), the gas mole fractions should add up to $1.0(100 \%)$, and the diagnostic "Initial Mass Balance OK" should display. The initial guess for the final reaction temperature that resides in cell $\mathrm{K} 3$ at this point happens to be $1500 \mathrm{~K}$.

Inputs being complete, we continue by clicking the [Export Data] button. The diagnostics below the summary table now indicate that the exported data is current but that neither model has run since the last data export operation. Next, click the [Run Models] button. This version pauses in the DOS window after the external routines finish, so we push ENTER. For this case, the models should have run successfully. Next, click the [Import Results] button. The results should be imported and the remaining red diagnostics should turn green, indicating that the latest results have been imported and that the mass balance error for both models is insignificant.

The results of this run are listed in the Summary Table. The computed adiabatic pressure is predicted to be $3.4 \mathrm{~atm}$ (35.7 psig), and the detonation pressure is predicted to be $7.1 \mathrm{~atm}(90.1$ psig). The adiabatic temperature is predicted to be $950^{\circ} \mathrm{C}$ and the shock temperature, $1155^{\circ} \mathrm{C}$.

Looking at the product mixtures in more detail, we see that the predicted product mixtures for the two cases (adiabatic and detonation) differ only slightly, with the detonation case having marginally more radical species, such as $\mathrm{CF}_{2} . \mathrm{UF}_{6}$ and $\mathrm{N}_{2}$, as intended, are unreacted. Both the fuel and oxidizers are essentially completely reacted, forming (in order of concentration) $\mathrm{CF}_{4}$, $\mathrm{CF}_{3} \mathrm{Cl}, \mathrm{CO}, \mathrm{CF}_{2} \mathrm{Cl}_{2}, \mathrm{CFCl}_{3}, \mathrm{C}_{2} \mathrm{~F}_{4}, \mathrm{C}_{2} \mathrm{~F}_{6}, \mathrm{CF}_{2}$ and minor traces of other species. All the available $\mathrm{Cl}$ (from either $\mathrm{C}_{2} \mathrm{~F}_{4} \mathrm{Cl}_{2}$ and $\mathrm{ClF}_{3}$ ) has reacted to form various $\mathrm{CFCs}$, which is possibly unrealistic kinetically, but is the predicted equilibrium outcome. A screen image of the Summary Table and Composition Table area is shown in Fig. A.2. 


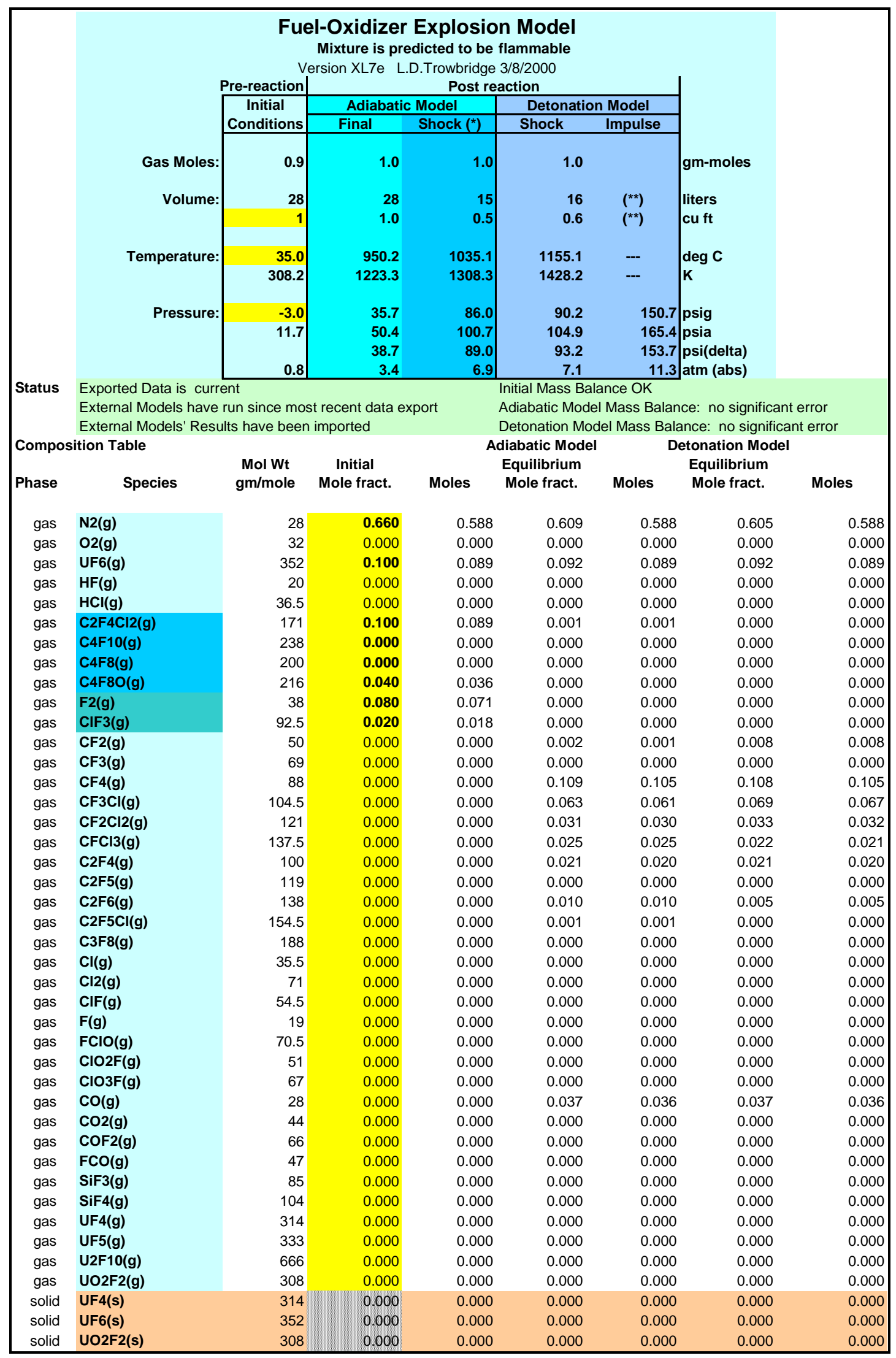

Fig. A.2 Screen image of summary and composition tables of detonation model. 
APPENDIX B 



\section{APPENDIX B \\ COMPARISON OF DETONATION MODEL PREDICTIONS WITH LITERATURE}

\section{B.1. The $\mathrm{H}_{2}+\mathrm{O}_{2}$ System}

The detonation model discussed here is a direct application of a classical technique described in Jost (1946) and Lewis and von Elbe (1961), so a reasonable test of the model is to compare its results with model and experimental results presented in those texts. A series of cases are presented by Lewis and von Elbe (1961) in which various mixtures of $\mathrm{H}_{2}$ and $\mathrm{O}_{2}$ are detonated. These cases were presented to illustrate the necessity of including unstable species, in this case the radicals $\mathrm{H}$ and $\mathrm{OH}$, in the product mix (in addition to the room-temperature stable species $\mathrm{H}_{2}$, $\mathrm{O}_{2}$, and $\mathrm{H}_{2} \mathrm{O}$ ). Thermodynamic calculations were performed for the purpose of determining the equilibrium concentration of the radical species at the detonation temperature and pressure. Detonation parameters [temperature $\left(\mathrm{T}_{2}\right)$, pressure $\left(\mathrm{P}_{2}\right)$, and detonation velocity $(\mathrm{D})$ ] were presented for these cases, along with the mole percent of $\mathrm{OH}$ and $\mathrm{H}$ computed for the product mix. An experimental value for detonation velocity was also given which generally fell within 1 to $5 \%$ of the calculated value. Several cases were run using the present model to attempt to duplicate those calculations. The results listed in Table B.1 are in fairly good agreement, though the present model consistently gives results slightly higher in pressure, temperature, and detonation velocity. There can be several explanations for the difference.

Table B.1 Comparison of detonation model results with theoretical results presented by Lewis and von Elbe (1961) for detonations of $\mathrm{H}_{2}+\mathrm{O}_{2}$. The initial pressure was $1 \mathrm{~atm}$; initial temperature was $291 \mathrm{~K}$; all quantities are mole fraction.

\begin{tabular}{|c|c|c|c|c|c|c|c|c|}
\hline & \multicolumn{3}{|c|}{ Initial } & \multicolumn{5}{|c|}{ Final } \\
\hline & $\mathrm{H}_{2}$ & $\mathrm{O}_{2}$ & $\mathrm{~N}_{2}$ & $\mathrm{OH}$ & $\mathrm{H}$ & $\begin{array}{r}\mathrm{P}_{2} \\
\text { atm } \\
\end{array}$ & $\begin{array}{l}\mathrm{T}_{2} \\
\mathrm{~K} \\
\end{array}$ & $\begin{array}{r}\mathrm{D} \\
\mathrm{m} / \mathrm{s}\end{array}$ \\
\hline Lewis 1961 & 0.67 & 0.33 & 0 & 0.253 & 0.069 & 18.1 & 3583 & 2810 \\
\hline This work & 0.67 & 0.33 & 0 & 0.160 & 0.093 & 18.9 & 3748 & 2870 \\
\hline Variation & & & & & & $4.7 \%$ & $4.6 \%$ & $2.1 \%$ \\
\hline Lewis 1961 & 0.33 & 0.67 & 0 & 0.135 & 0.002 & 15.3 & 2970 & 1925 \\
\hline This work & 0.33 & 0.67 & 0 & 0.080 & 0.005 & 16.2 & 3113 & 1962 \\
\hline Variation & & & & & & $5.7 \%$ & $4.8 \%$ & $1.9 \%$ \\
\hline Lewis 1961 & 0.50 & 0.25 & 0.25 & 0.147 & 0.033 & 17.4 & 3367 & 2378 \\
\hline This work & 0.50 & 0.25 & 0.25 & 0.092 & 0.046 & 18.0 & 3514 & 2429 \\
\hline Variation & & & & & & $3.5 \%$ & $4.4 \%$ & $2.1 \%$ \\
\hline Lewis 1961 & 0.80 & 0.20 & 0 & 0.059 & 0.065 & 17.3 & 3314 & 3354 \\
\hline This work & 0.80 & 0.20 & 0 & 0.037 & 0.083 & 17.9 & 3451 & 3428 \\
\hline Variation & & & & & & $3.6 \%$ & $4.1 \%$ & $2.2 \%$ \\
\hline Lewis 1961 & 0.89 & 0.11 & 0 & 0.003 & 0.011 & 14.2 & 2650 & 3749 \\
\hline This work & 0.89 & 0.11 & 0 & 0.001 & 0.013 & 14.5 & 2711 & 3798 \\
\hline Variation & & & & & & $2.3 \%$ & $2.3 \%$ & $1.3 \%$ \\
\hline
\end{tabular}


Favored values for thermodynamic data change over the decades, though values for the species under consideration here should be in fairly close agreement. There is, however, a consistent discrepancy in the mole fractions given for $\mathrm{H}$ and $\mathrm{OH}$ between the values calculated in the present model and those of Lewis and von Elbe (1961). The values in the current model are obtained from a global equilibrium calculation involving the species $\mathrm{H}_{2}, \mathrm{O}_{2}, \mathrm{~N}_{2}, \mathrm{H}_{2} \mathrm{O}, \mathrm{OH}$, and $\mathrm{H}$. The values in Lewis and von Elbe (1961) were reportedly calculated from three dissociation equilibria:

$\begin{array}{ll}\text { B.1 } & \mathrm{H}_{2} \mathrm{O} \leftrightarrows \mathrm{H}_{2}+1 / 2 \mathrm{O}_{2} \\ \text { B.2 } & \mathrm{H}_{2} \mathrm{O} \leftrightarrows 1 / 2 \mathrm{H}_{2}+\mathrm{OH} \\ \text { B.3 } & \mathrm{H}_{2} \leftrightarrows 2 \mathrm{H}\end{array}$

Mathematically, the results should not differ if the underlying thermodynamic values used were the same.

Elsewhere in that text (Lewis and von Elbe 1961, page 680), recommended values for the equilibrium constant, $\mathrm{K}_{\mathrm{P}}$, for each of these reactions are given, although it is not explicitly stated that the results presented in Table B.1derive from those values for $\mathrm{K}_{\mathrm{P}}$. although only the mole fractions for $\mathrm{H}$ and $\mathrm{OH}$ are presented, partial pressures for the remaining species can mathematically be derived from those two values and known values for $K_{P}$ for the three reactions. For example, for reaction B.3,

$$
\mathrm{K}_{\mathrm{P}}=\mathrm{P}(\mathrm{H})^{2} / \mathrm{P}\left(\mathrm{H}_{2}\right)
$$

Therefore, from the tabulated atomic hydrogen pressure $\mathrm{P}(\mathrm{H})$ and the tabulated value of $\mathrm{K}_{\mathrm{P}}$ at the detonation temperature, one can derive the pressure of molecular hydrogen, $\mathrm{P}\left(\mathrm{H}_{2}\right)$. The partial pressures of $\mathrm{H}_{2} \mathrm{O}$ and $\mathrm{O}_{2}$ can be similarly derived from the equilibria for reactions B.2 and B.1. Unfortunately, when this is done using the values of $K_{P}$ listed in Lewis and von Elbe (1961), the results are internally inconsistent. Mass balance is not correct, and the sum of the partial pressures exceed the reported total detonation pressure. We are left with the conclusion that the $\mathrm{H}$ and $\mathrm{OH}$ compositions listed for these cases are inconsistent with the tabulated values of $\mathrm{K}_{\mathrm{P}}$ for the relevant reaction and were thus probably calculated using different thermodynamic data. In spite of the apparent differences in data, the results quoted by Lewis and von Elbe (1961) and those derived in the present model (using thermodynamics data from the 1980s) agree fairly closely.

\section{B.2 The $\mathrm{F}_{2}+\mathrm{c}-\mathrm{C}_{4} \mathrm{~F}_{8}$ System}

Fluorocarbon literature is fairly sparse but not totally lacking in information on the subject of fluorocarbon flames and detonations. Fletcher and Ambs (1964) studied flame speeds and quench distances for mixtures of $\mathrm{ClF}_{3}$ with three fluorocarbons $-\mathrm{C}_{2} \mathrm{~F}_{6}, \mathrm{C}_{3} \mathrm{~F}_{8}$, and $\mathrm{c}-\mathrm{C}_{4} \mathrm{~F}_{8}$. These studies of the premixed (subsonic) flames proceeded satisfactorily for the first two fluorocarbons, but c- $\mathrm{C}_{4} \mathrm{~F}_{8}$ detonated rather than burning with a controlled flame. A $29 \%$ fuel mixture generated a detonation velocity of approximately $1000 \mathrm{~m} / \mathrm{s}$. From limited information obtained in this experiment, the authors concluded that the detonation was not fully developed within their apparatus (which, incidentally, was destroyed by the detonation) but was still accelerating. The initial pressure and temperature of the mixture were not given, but assuming $25^{\circ} \mathrm{C}$ and $1 \mathrm{~atm}$ as plausible values, the present model predicts a fully developed detonation 
velocity of $1295 \mathrm{~m} / \mathrm{s}$, consistent with their conclusion.

In a later study, Fletcher and Kittelson (1968) reported detonation velocities for binary mixtures of $\mathrm{F}_{2}$ and $\mathrm{c}-\mathrm{C}_{4} \mathrm{~F}_{8}$ and compared the results with theoretical Chapman-Jouguet detonation velocities, with the heats of reaction and product compositions based on thermodynamic equilibrium compositions. Theoretical and experimental results were plotted over the range of compositions which could be made to detonate. The full set of potential reaction products used in their equilibrium calculation was not listed, but major species were $\mathrm{F}_{2}, \mathrm{~F}, \mathrm{CF}_{2}, \mathrm{CF}_{3}, \mathrm{CF}_{4}$, and solid C. Unfortunately, the initial pressure and temperature of the gas mixtures were not given. Presuming, however, that these were likely near room temperature and atmospheric pressure, we can attempt to duplicate the results from this study.

The literature results were presented only in graphical form and could be read from that plot only to the nearest $25 \mathrm{~m} / \mathrm{s}$. Several compositions were extracted from the literature results, including cases from the fuel-lean to fuel-rich limits of detonation. In addition, a composition outside each of these boundaries was chosen. No experimental detonation velocity was, of course, available, but the theory computes velocities even outside the actual boundaries of detonation. These values are listed in Table B.2, along with results generated using the present model.

Table B.2. Comparison of literature $\mathrm{F}_{2}+\mathrm{c}-\mathrm{C}_{4} \mathrm{~F}_{8}$ detonation velocities $(\mathrm{m} / \mathrm{s})$ with theoretical results from the present model.

\begin{tabular}{|c|c|c|c|c|c|c|c|}
\hline \multicolumn{2}{|c|}{$\begin{array}{c}\text { Initial Composition } \\
\text { (mole fraction) }\end{array}$} & \multicolumn{4}{|c|}{ Model Results ${ }^{\mathrm{b}}$} & \multicolumn{2}{|c|}{$\begin{array}{c}\text { Literature } \\
\text { (Fletcher and Kittelson 1968) }\end{array}$} \\
\hline $\mathrm{F}_{2}$ & $\mathrm{c}-\mathrm{C}_{4} \mathrm{~F}_{8}$ & (A) & (B) & (C) & (D) & Expt & Theory \\
\hline 0.95 & 0.05 & 1257 & 1257 & 1257 & 1257 & No Det & 1225 \\
\hline 0.88 & 0.12 & 1635 & 1635 & 1635 & 1635 & 1625 & 1625 \\
\hline 0.8 & 0.2 & 1450 & 1450 & 1450 & 1450 & 1450 & 1450 \\
\hline 0.7 & 0.3 & 1253 & 1253 & 1252 & 1252 & 1225 & 1250 \\
\hline 0.6 & 0.4 & 1014 & 1139 & 1022 & 1137 & 1050 & 1100 \\
\hline 0.5 & 0.5 & 819 & 1061 & 837 & 1060 & 1050 & 1025 \\
\hline 0.4 & 0.6 & 665 & 1000 & 671 & 1000 & 1075 & 950 \\
\hline 0.2 & 0.8 & 383 & 907 & 374 & 907 & No Det ${ }^{a}$ & 850 \\
\hline 0.0 & 1.0 & 119 & 834 & & & & \\
\hline Notes $^{a}$ & $\begin{array}{l}\text { and } 0.2 \\
\text { oses. } \\
\text { otential }\end{array}$ & $\begin{array}{l}\text { ixture } \\
\text { ducts: }\end{array}$ & lot det & ; pure & ${ }_{8}$ case & $\begin{array}{l}\text { ncluded } \mathrm{fc} \\
\mathrm{C}_{4} \mathrm{~F}_{10}, \mathrm{c}-\mathrm{C}_{4}\end{array}$ & $\begin{array}{l}\text { lustration } \\
\mathrm{F}, \mathrm{F}_{2}\end{array}$ \\
\hline
\end{tabular}

Four variations were run for each composition, exploring the effect of the addition of potential product species to the thermodynamic equilibrium calculation. Case (A) included a number of room-temperature-stable species $\left(\mathrm{CF}_{4}, \mathrm{C}_{2} \mathrm{~F}_{4}, \mathrm{C}_{2} \mathrm{~F}_{6}, \mathrm{C}_{3} \mathrm{~F}_{8}, \mathrm{C}_{4} \mathrm{~F}_{10}, \mathrm{c}-\mathrm{C}_{4} \mathrm{~F}_{8}\right.$, and $\left.\mathrm{F}_{2}\right)$, plus some relatively stable radicals $\left(\mathrm{F}, \mathrm{CF}_{2}, \mathrm{CF}_{3}\right.$, and $\left.\mathrm{C}_{2} \mathrm{~F}_{5}\right)$. This duplicates the literature values quite well for compositions containing up to 30 mole $\% \mathrm{c}_{-} \mathrm{C}_{4} \mathrm{~F}_{8}$ but beyond that point predicts lower velocities than those observed. Case (B) adds solid carbon (as graphite) to the list of potential products. This addition results in good agreement throughout the composition range. Case $(\mathrm{C})$ added the less stable radical $\mathrm{CF}$ and its dimer $\mathrm{C}_{2} \mathrm{~F}_{2}$ to the Case (A) mix of potential products; that addition, however, had only a minimal effect on the outcome for fuel-rich mixtures. Case (D) added all three extra species, with results essentially identical to the results for Case (B). 
The question as to whether to include $\mathrm{C}(\mathrm{s})$ as a potential product in thermodynamic calculations involving fluorocarbons is a difficult one. The above results clearly indicate that the inclusion of $\mathrm{C}(\mathrm{s})$ aids in matching experimental and theoretical results. On the other hand, there are also cases where $\mathrm{C}(\mathrm{s})$,al though thermodynamically favored, does not appear as a product, and its inclusion would lead to an overestimate of reaction pressures, temperatures, and shock velocities. An extreme case is illustrated by the last entry in Table B.2. In that entry, a case was run in which the initial gas mixture was chosen to be pure $\mathrm{c}_{-} \mathrm{C}_{4} \mathrm{~F}_{8}$. Case (B), which includes $\mathrm{C}(\mathrm{s})$ as a product, yields a detonation velocity of $834 \mathrm{~m} / \mathrm{s}$ and a shock temperature of $2157 \mathrm{~K}$. The corresponding adiabatic temperature is $1977 \mathrm{~K}$. The equilibrium composition consists largely of $\mathrm{CF}_{4}$ and $\mathrm{C}(\mathrm{s})$. While $\mathrm{c}_{-} \mathrm{C}_{4} \mathrm{~F}_{8}$ is thermodynamically unstable relative to these two compounds, its vapor (thankfully) will not detonate when sparked.

In other studies, elemental carbon has been observed as a product in flames derived from fuelrich mixtures of $\mathrm{F}_{2}$ and various fluorocarbons. It appeared at approximately its equilibrium composition for mixtures whose adiabatic flame temperature exceeded about 2200 to $2400 \mathrm{~K}$, but fell from the level predicted for mixtures whose adiabatic flame temperature could not reach that range (Fletcher and Hinderman 1983). The question as to whether C(s) should be included in the list of potential products obviously requires some case-by-case judgment.

This is an example in which the kinetic limitations of an equilibrium-based model become apparent. A full kinetic model can allow reactions to proceed partially to completion as time and rates allow. An equilibrium model is all or nothing: species are available to the calculation or they are not. From a practical standpoint, however, kinetic models are frequently limited by the fact that all needed rates (and sometimes even the reaction steps themselves) are not available. Furthermore, they are generally very computation intensive.

\section{B.3 The $\mathrm{F}_{2}+\mathrm{C}_{2} \mathbf{F}_{4} \mathrm{Cl}_{2}$ System}

Extensive work exists in the uranium enrichment literature on the flammability limits of coolants (e.g. $\mathrm{C}_{2} \mathrm{~F}_{4} \mathrm{Cl}_{2}$ ) with oxidizers (e.g., $\mathrm{F}_{2}$ ). Two such references reported explosion pressures for compositions well within the region of flammability (Bernhardt et al. 1968a, 1968b, both reporting the same data). Elevated explosion pressures were reported for a number of compositions and initial pressures, three cases of which were extracted and are listed in Table B.3. Initial compositions, pressures, and temperatures are listed along with the reported explosion pressure. As the flame or shock speed was not reported, it is not immediately clear whether these pressures correspond to subsonic flame pressure rise, runup to detonation, detonation, or impulse pressures. The experimental description was sparse but suggests the reported value was taken by a fairly rapid response "maximum pressure" recording device.

The current model was run to simulate each of these experiments, one using a species set that excludes $\mathrm{C}(\mathrm{s})$ and the other one that includes $\mathrm{C}(\mathrm{s})$. Potential products in both cases included all those species previously mentioned in Case $\mathrm{A}$ in the $\mathrm{F}_{2}+\mathrm{c}_{-} \mathrm{C}_{4} \mathrm{~F}_{8}$ system, above, plus $\mathrm{ClF}_{3}, \mathrm{ClF}$, $\mathrm{Cl}, \mathrm{Cl}_{2}, \mathrm{C}_{2} \mathrm{~F}_{4} \mathrm{Cl}_{2}, \mathrm{C}_{2} \mathrm{~F}_{5} \mathrm{Cl}, \mathrm{CF}_{3} \mathrm{Cl}, \mathrm{CF}_{2} \mathrm{Cl}_{2}$, and $\mathrm{CFCl}_{3}$. Results presented in Table B.3 include the adiabatic pressure, the detonation pressure, and the impulse pressure, as well as the detonation temperature. For the 50-50 mixtures, the "with C(s)" case yields higher pressures than the case run without it. The experimental results for the second and third experiments fairly closely match the model results for the detonation pressure. It is difficult to decide which computation ["with $\mathrm{C}(\mathrm{s})$ " vs. "without $\mathrm{C}(\mathrm{s})$ "] better matches the experimental results, as they are not much different from one another. The computed temperatures are in the borderline region for expecting $\mathrm{C}(\mathrm{s})$ to 
be at its thermodynamic equilibrium level. That observation was derived from a flame environment in fluorine-fluorocarbon systems (Fletcher and Hniderman 1983). It is plausible, but certainly not obvious, that the same temperature range would apply to chlorofluorocarbons. Furthermore, in a detonation, much less time is available for equilibrium to be achieved, so it would stand to reason that a higher temperature threshold might apply.

The first experimental entry is an anomaly. While the other two showed slightly lower pressure than the theoretical fully developed shock pressure, this one exceeded even the impulse pressure (although not by a great deal). A third case was devised that included all the species previously mentioned, plus the radicals $\mathrm{CCl}, \mathrm{CCl}_{2}, \mathrm{CCl}_{3}$, and $\mathrm{CF}_{2} \mathrm{Cl}$. The results were substantially the same as the "with $\mathrm{C}(\mathrm{s})$ " results. No combination of products was found which duplicated this experimental point.

Table B.3. Comparison of model results to experimental explosion pressures for the $\mathrm{F}_{2}+\mathrm{C}_{2} \mathrm{~F}_{4} \mathrm{Cl}_{2}$ system $^{\mathrm{a}}$

Initial conditions

$\begin{array}{llrrr}\mathrm{C}_{2} \mathrm{~F}_{4} \mathrm{Cl}_{2} & \text { mole fr } & 0.50 & 0.50 & 0.15 \\ \mathrm{~F}_{2} & \text { mole fr } & 0.50 & 0.50 & 0.85 \\ \mathrm{P} & \text { atm } & 0.53 & 0.33 & 0.32 \\ \mathrm{~T} & { }^{\circ} \mathrm{C} & 107 & 107 & 107\end{array}$

Final Conditions

\begin{tabular}{cllrrr} 
Exptl & dP & atm & 19.0 & 4.4 & 3.7 \\
without & dP(adiab) & atm & 3.3 & 2.0 & 2.0 \\
C(s) & dP(det) & atm & 7.3 & 4.5 & 4.5 \\
& dP(impls) & atm & 12.9 & 7.9 & 7.6 \\
& T(det) & K & 2184 & 2131 & 2227 \\
with C(s) & dP(adiab) & atm & 4.1 & 2.6 & 2.0 \\
& dP(det) & atm & 9.0 & 5.6 & 4.5 \\
& dP(impls) & atm & 16.0 & 9.9 & 7.6 \\
& T(det) & $\mathrm{K}$ & 2447 & 2399 & 2227 \\
\hline
\end{tabular}

axperimental data from Bernhardt et al. (1968a, 1968b)

b $\mathrm{dP}=$ maximum pressure rise from initial pressure

adiab $=$ calculated adiabatic constant volume pressure

det $=$ calculated for fully developed detonation

impls $=$ calculated impulse, as difference from initial pressure 

APPENDIX C 



\section{APPENDIX C}

\section{THERMODYNAMIC DATA USED IN THE MODEL}

Thermodynamic data used in the model is embedded in the spreadsheet. Values are included for the four coolants of immediate concern, plus a fairly extensive variety of light fluorocarbons and chlorofluorocarbons. The lighter species include both stable species and radicals. All are species that plausibly could be reaction products of the coolants when reacted with $\mathrm{F}_{2}, \mathrm{ClF}_{3}$, or $\mathrm{UF}_{6}$, or which may appear as common impurities in systems subjected to these gases.

Thermodynamic data was taken from standard reference sources where available, but the needed information was not always to be found. In such cases, estimates were required.

\section{C.1 Enthalpy of Formation for Perfluorotetrahydrofuran $\left(c-\mathrm{C}_{4} \mathrm{~F}_{8} \mathrm{O}\right)$}

No direct information on the enthalpy of formation of $\mathrm{c}-\mathrm{C}_{4} \mathrm{~F}_{8} \mathrm{O}$ was unearthed in the literature search. Cyclo- $\mathrm{C}_{4} \mathrm{~F}_{8} \mathrm{O}$ consists of a five-membered ring containing four $\mathrm{CF}_{2}$ groups and one ether -O- to complete the ring:

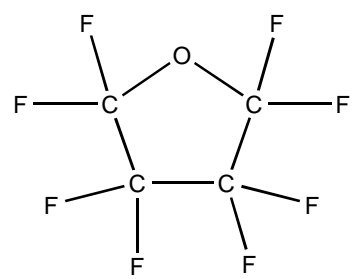

The general thermal and chemical stability of perfluoroethers (as opposed to hydrocarbon ethers) suggests that the $\mathrm{C}-\mathrm{O}$ bond is at least as stable as the $\mathrm{C}-\mathrm{C}$ bonds in these molecules. There is, however, little information in the literature on this point: none for $\mathrm{c}_{-} \mathrm{C}_{4} \mathrm{~F}_{8} \mathrm{O}$ and only very limited indirect information for any perfluoroether (PFE). Two PFEs have reported values for the enthalpy of formation. These are

$$
\left(\mathrm{C}_{4} \mathrm{~F}_{9}\right)_{2} \mathrm{O} \quad \Delta \mathrm{H}_{\mathrm{f}}^{\mathrm{o}}(298.15 \mathrm{~K})=-3,920.8 \mathrm{~kJ} / \mathrm{mol}
$$

and

$$
\left(\mathrm{C}_{5} \mathrm{~F}_{11}\right)_{2} \mathrm{O} \quad \Delta \mathrm{H}_{\mathrm{f}}^{\mathrm{o}}(298.15 \mathrm{~K})=-4,735.9 \mathrm{~kJ} / \mathrm{mol},
$$

both due to Kolesov et al. $(1972 ; 1976)$. Both these values are experimentally derived from combustion calorimetry and are stated by the author to be uncertain to $\pm 15.1 \mathrm{~kJ} / \mathrm{mol}$. In deriving the heats of formation above, the author used values for thermodynamic properties of some reaction products that are slightly different from those we have commonly used in this report. Substituting alternate values where available (Chase et al. 1985) into the calculation of heat of formation, we obtain the following modified values:

$$
\begin{array}{ll}
\left(\mathrm{C}_{4} \mathrm{~F}_{9}\right)_{2} \mathrm{O} & \Delta \mathrm{H}_{\mathrm{f}}^{\mathrm{o}}(298.15 \mathrm{~K})=-3,929.6 \mathrm{~kJ} / \mathrm{mol} \\
\left(\mathrm{C}_{5} \mathrm{~F}_{11}\right)_{2} \mathrm{O} & \Delta \mathrm{H}_{\mathrm{f}}^{\mathrm{o}}(298.15 \mathrm{~K})=-4,746.6 \mathrm{~kJ} / \mathrm{mol},
\end{array}
$$

which we will use for consistency with the other thermodynamic data used in the present model. 
The group additivity method is a scheme for estimating an unknown physical property (such as enthalpies of formation) by attributing a portion of the value of the property to discrete molecular components and estimating the values for each such component by analysis of similar compounds which contain those components and for which the property is known. For example, the heat of formation for $\mathrm{C}_{3} \mathrm{~F}_{8}$, which structurally is $\mathrm{CF}_{3}-\mathrm{CF}_{2}-\mathrm{CF}_{3}$, would be estimated by determining (from other compounds) the contribution due to a $\mathrm{CF}_{3}$ group adjacent to a carbon, and a $\mathrm{CF}_{2}$ group adjacent to two carbon atoms, then adding two times the $\mathrm{CF}_{3}$ contribution and one times the $\mathrm{CF}_{2}$ contribution. A considerable body literature has evolved on these techniques for hydrocarbons and their organic derivatives, and this has been extended in a more limited way to fluorocarbons.

The notation currently used in group additivity analysis would define a group consisting of a carbon bonded to an adjacent carbon, two fluorines, and an oxygen as $\mathrm{C}(\mathrm{C})(\mathrm{F}) 2(\mathrm{O})$. The two PFEs studied by Kolesov can be assembled from two C(F)3(C) groups, four or six C(F)2(C)2 groups, two $\mathrm{C}(\mathrm{F}) 2(\mathrm{C})(\mathrm{O})$ groups, and one $\mathrm{O}(\mathrm{C}) 2$ group. A value for the third of these groups, $\mathrm{C}(\mathrm{F}) 2(\mathrm{C})(\mathrm{O})$, was not found in any group additivity literature. A value for the $\mathrm{O}(\mathrm{C}) 2$ (i.e., the ether oxygen) is available for hydrocarbon ethers. It is plausible that a reasonable value for an ether oxygen in fluoroethers would be significantly different, but since we will need to estimate the value for the adjacent carbon groups, we will adopt the hydrocarbon ether group value from the literature and subsume all the difference between hydrocarbon and fluorocarbon ethers into the adjacent carbon groups (that is, $\mathrm{C}(\mathrm{F}) 2(\mathrm{C})(\mathrm{O})$. The three literature group additivity contributions for fluorocarbons needed to derive the heat of formation of Kolesov's two PFE heats of formation are listed in Table C.1, as is a derived value for $\mathrm{C}(\mathrm{F}) 2(\mathrm{C})(\mathrm{O})$, obtained by averaging the values calculated for that group from each of the two PFEs.

Table C.1. Group additivity values for heat of formation of perfluorocarbons

\begin{tabular}{lcc}
\hline Group & $\begin{array}{c}\Delta \mathrm{H}_{\mathrm{f}}^{\circ} \text { contribution } \\
(\mathrm{kJ} / \mathrm{mol})\end{array}$ & Reference \\
\hline $\mathrm{C}(\mathrm{F}) 3(\mathrm{C})$ & -673.81 & Domalski and Hearing 1993 \\
$\mathrm{C}(\mathrm{F}) 2(\mathrm{C}) 2$ & -411.39 & Domalski and Hearing 1993 \\
$\mathrm{O}(\mathrm{C}) 2$ & -101.42 & Domalski and Hearing 1993 \\
$\mathrm{C}(\mathrm{F}) 2(\mathrm{C})(\mathrm{O})$ & -416.05 & Derived \\
fTHF ring strain & 63.6 & Estimated \\
\hline
\end{tabular}

The $\Delta \mathrm{H}_{\mathrm{f}}{ }^{\circ}$ calculated from these group additivity contributions for the two PFEs are -3929.6 and $-4746.6 \mathrm{~kJ} / \mathrm{mol}$, which is within $3 \mathrm{~kJ} / \mathrm{mol}$ of the experimental values. This is considerably less variation than either the experimental uncertainty quoted by Kolesov or the $4-$ to $8-\mathrm{kJ} / \mathrm{mol}$ uncertainty typically quoted for group additivity results and so should suffice for our purposes.

One additional group contribution needed to estimate the heat of formation for $\mathrm{c}_{-} \mathrm{C}_{4} \mathrm{~F}_{8} \mathrm{O}$ is the ring strain contribution. Related ring strain contributions are given for the hydrocarbon and perfluorocarbon forms of tetrahydrofuran, cyclobutane, and cyclopentane (Domalski and Hearing 1993; Zhang and Pollard 1995) in Table C.2.

A ring strain contribution for $\mathrm{c}-\mathrm{C}_{4} \mathrm{~F}_{8} \mathrm{O}$ is not available but may be estimated by reference to the available values for related compounds. Unfortunately, the available values do not form a 
Table C.2 - Literature ring strain contributions to standard enthalpy of formation for selected gaseous ring compounds

\begin{tabular}{ccccc}
\hline & $\mathrm{c}-\mathrm{C}_{4} \mathrm{X}_{8}$ & $\mathrm{c}-\mathrm{C}_{5} \mathrm{X}_{10}$ & $\mathrm{c}-\mathrm{C}_{4} \mathrm{X}_{8} \mathrm{O}$ & Reference \\
\hline $\mathrm{X}=\mathrm{H}$ & 110.89 & 26.75 & 24.28 & Domalski and Hearing 1993 \\
$\mathrm{X}=\mathrm{H}$ & 109.6 & 26.4 & $\mathrm{n} / \mathrm{a}$ & Zhang and Pollard 1995 \\
$\mathrm{X}=\mathrm{F}$ & 105.9 & 105.0 & $\mathrm{n} / \mathrm{a}$ & Zhang and Pollard1995 \\
\hline
\end{tabular}

coherent picture. In the hydrocarbons, we can see that the ring strain for $\mathrm{c}-\mathrm{C}_{4} \mathrm{H}_{8} \mathrm{O}$ is a little less than that of cyclopentane, so we might estimate the ring strain for $\mathrm{c}^{-} \mathrm{C}_{4} \mathrm{~F}_{8} \mathrm{O}$ as being a bit smaller than that of perfluorocyclopentane, say $\sim 100 \mathrm{~kJ} / \mathrm{mol}$. The ring strain for $\mathrm{c}_{-} \mathrm{C}_{4} \mathrm{~F}_{8}$ is slightly smaller than that of $\mathrm{c}-\mathrm{C}_{4} \mathrm{H}_{8}$, so on that basis we might estimate the ring strain for $\mathrm{c}-\mathrm{C}_{4} \mathrm{~F}_{8} \mathrm{O}$ as being a bit smaller than that of $\mathrm{c}-\mathrm{C}_{4} \mathrm{H}_{8} \mathrm{O}$, or about $23 \mathrm{~kJ} / \mathrm{mol}$.

The range of 23 to $100 \mathrm{~kJ} / \mathrm{mol}$ represents a very large disparity but probably brackets the actual value. An intermediate value can be obtained by resorting to the following line of reasoning: (1) the geometry of the hydrocarbon and fluorocarbon tetrahydrofurans (THFs) and cyclopentane are similar, so the inherent strain due to non-ideal C-C-C bond angles will be assumed to be the same as for THF $(24.28 \mathrm{~kJ} / \mathrm{mole})$. The difference between the cyclopentane and perfluorocyclopentane strain contributions $(105.0-26.4=78.6 \mathrm{~kJ} / \mathrm{mol})$ is assumed to be due to geometric conflict between the fluorine atoms on adjacent $\mathrm{CF}_{2}$ groups. Cyclo- $\mathrm{C}_{5} \mathrm{~F}_{10}$ has five such adjacent- $\mathrm{CF}_{2}$ interactions, but $\mathrm{c}-\mathrm{C}_{4} \mathrm{~F}_{8} \mathrm{O}$ has only three, so the $\mathrm{CF}_{2}$ conflict contribution in c$\mathrm{C}_{4} \mathrm{~F}_{8} \mathrm{O}$ should be no more than $60 \%$ that in $\mathrm{C}_{5} \mathrm{~F}_{10}$. Furthermore, the $\mathrm{CF}_{2}$ groups adjacent to the $\mathrm{O}$ could be expected to distort slightly away from the adjacent $\mathrm{CF}_{2}$ group's $\mathrm{F}$ atoms, lowering the conflict contribution below $60 \%$. We will estimate the $\mathrm{CF}_{2}$-conflict portion of the strain energy in $\mathrm{c}-\mathrm{C}_{4} \mathrm{~F}_{8} \mathrm{O}$ as $50 \%$ of the difference in the strain energies of the two cyclopropanes $(78.6 \times 0.5=$ $39.3 \mathrm{~kJ} / \mathrm{mol}$ ). Adding these two contributions, we obtain an estimate of the $\mathrm{c}-\mathrm{C}_{4} \mathrm{~F}_{8} \mathrm{O}$ ring strain contribution of $24.3+39.3=63.6 \mathrm{~kJ} / \mathrm{mol}$. From these group additivity contributions, we may now estimate the heat of formation of $\mathrm{c}-\mathrm{C}_{4} \mathrm{~F}_{8} \mathrm{O}$ as

$$
\text { c- } \mathrm{C}_{4} \mathrm{~F}_{8} \mathrm{O}(\text { gas }): \quad \Delta \mathrm{H}_{\mathrm{f}}^{\mathrm{o}}=-1692.7 \mathrm{~kJ} / \mathrm{mol}
$$

Had we used the other two estimates, we would have obtained values of -1732 and -1656 $\mathrm{kJ} / \mathrm{mol}$. The uncertainty in this value is difficult to evaluate since much of it is due to inaccuracy of estimates and estimation methods. Considering, however, the experimental uncertainty in the original PFE data and from a general consideration of the accuracy of group additivity methods, the uncertainty is estimated as $\pm 19 \mathrm{~kJ} / \mathrm{mol}$, ignoring the question of reliability of the method by which the strain energy was estimated.

\section{C.2 Entropy Estimate for $\mathrm{c}-\mathrm{C}_{4} \mathrm{~F}_{8} \mathrm{O}$}

For systems in which a reactant such as $\mathrm{c}_{-} \mathrm{C}_{4} \mathrm{~F}_{8} \mathrm{O}$ is fully consumed or decomposed, the enthalpy of formation is important in contributing to the heat of reaction. The main effect of the entropy and heat capacity is to determine the stability of this compound relative to other species in the product mix. By stiplulating that $\mathrm{c}-\mathrm{C}_{4} \mathrm{~F}_{8} \mathrm{O}$ will be fully consumed (which is reasonable in a flame environment of any reasonable duration), we are in effect saying that it will not be a significant component of the product mix. Precise values of $\mathrm{S}^{\circ}$ and $\mathrm{Cp}$ are thus not critical for the present modeling, provided the equilibrium does not favor survival of the compound. Nevertheless, 
values are needed to carry out the calculation, and these must be estimated.

The entropy of $\mathrm{c}-\mathrm{C}_{4} \mathrm{~F}_{8} \mathrm{O}$ gas at $298.15 \mathrm{~K}$ and 1 bar was estimated from group additivity factors given in Domalski and Hearing (1993). As in the enthalpy of formation estimate, values for some specific groups [i.e., $\mathrm{C}(\mathrm{F}) 2(\mathrm{C})(\mathrm{O})$, perfluorocarbon $\mathrm{O}(\mathrm{C}) 2$, and ring strain] were not available in published tables. In the first case, the $\mathrm{C}(\mathrm{F}) 2(\mathrm{C}) 2$ value was used and in the other two, the corresponding hydrocarbon values were employed. The resulting entropy was 440.91

$\mathrm{J} / \mathrm{mol} \cdot \mathrm{K}$. This value for this 13 -atom $\mathrm{c}-\mathrm{C}_{4} \mathrm{~F}_{8} \mathrm{O}$ molecule is very close to the average of the values for the 12-atom $\mathrm{c}-\mathrm{C}_{4} \mathrm{~F}_{8}$ and the 14-atom $\mathrm{C}_{4} \mathrm{~F}_{10}$.

\section{C.3 Heat Capacity Estimates}

Heat capacity values for the $\mathrm{c}-\mathrm{C}_{4} \mathrm{~F}_{8} \mathrm{O}$ vapor between 0 to $110^{\circ} \mathrm{C}$ were provided by United States Enrichment Corporation (Gross 1999). A high-temperature limiting value was estimated from statistical mechanical considerations. The low- and high-temperature data were fit to the polynomial formula demanded by SOLGAS:

$$
\mathrm{C}_{\mathrm{P}}(\mathrm{T})=\mathrm{A}+\mathrm{BT}+\mathrm{C} \mathrm{T}^{2}+\mathrm{D} / \mathrm{T}^{2}+\mathrm{E} / \mathrm{T}^{3},
$$

where $\mathrm{T}$ is measured in $\mathrm{K}$ and $\mathrm{C}_{\mathrm{P}}$ is in $\mathrm{J} / \mathrm{mol} \cdot \mathrm{K}$. The resulting curve was plotted and examined for sensible behavior before incorporation into the model, "sensible" being interpreted as having the same general shape as the heat capacities of polyatomic molecules for which heat capacities are available over the full temperature range of interest. The high-temperature limit is based on the notion that all translational, rotational, and vibrational modes will be saturated at high temperature (i.e., at several thousand Kelvin). In such a case for non-linear molecules, translational modes will contribute $5 / 2 \mathrm{R}$ to the heat capacity, rotational modes will contribute $3 / 2 R$, and vibrational modes will contribute $(3 n-6) R$, where $n$ is the number of atoms in the molecule and $\mathrm{R}$ is the gas constant. The resulting high- temperature heat capacity estimate is

$$
\mathrm{C}_{\mathrm{P}} \approx(3 \mathrm{n}-2) \mathrm{R} .
$$

No account was taken of electronic excitation, which can modify the molecular structure and heat capacity.

For other species, wherever possible, heat capacity parameters were generated by regression fitting of tabular data, primarily from Chase et al. (1985). For several compounds, such data were not available and the above method was used to extend low-temperature data to at least $5000 \mathrm{~K}$. This was done for $\mathrm{C}_{2} \mathrm{~F}_{4} \mathrm{Cl}_{2}, \mathrm{C}_{2} \mathrm{~F}_{5} \mathrm{Cl}, \mathrm{C}_{3} \mathrm{~F}_{8}, \mathrm{C}_{4} \mathrm{~F}_{8}, \mathrm{C}_{4} \mathrm{~F}_{10}$, and $\mathrm{UF}_{5}$. Data for $\mathrm{U}_{2} \mathrm{~F}_{10}$ was estimated from that of $\mathrm{UF}_{5}$ by adjusting for changes in number of translational, rotational, and vibrational modes.

\section{C.4 Thermodynamic property values incorporated into model}

Thermodynamic properties for a number of species relevant to fluorine/fluorocarbon flames are incorporated into the model as an internal data base. Values for these compounds are listed in Table C. 3 for gases and C. 4 for solids. These were largely taken from the JANAF Thermochemical Tables (Chase et al. 1985). Enthalpy of formation and entropy are taken directly, and the parameters for the heat capacity equation were regression fit from tabular data. The few cases in which other sources were utilized are noted. 
Table C.3. Thermodynamic data incorporated into model.

\begin{tabular}{|c|c|c|c|c|c|c|c|c|}
\hline Name & $\begin{array}{c}\Delta \mathrm{H}_{\mathrm{f}}^{\mathrm{o}} \\
\mathrm{J} / \mathrm{mol} \\
\end{array}$ & $\begin{array}{c}\mathrm{S}^{\circ} \\
\mathrm{J} / \mathrm{mol} \mathrm{K} \\
\end{array}$ & $\begin{array}{c}\mathrm{CpA} \\
\mathrm{J} / \mathrm{mol} \mathrm{K} \\
\end{array}$ & $\mathrm{CpB}$ & $\mathrm{CpC}$ & $\mathrm{CpD}$ & $\mathrm{CpE}$ & \\
\hline \multicolumn{9}{|c|}{ Gases } \\
\hline $\mathrm{N}_{2}(\mathrm{~g})$ & 0 & 191.609 & 31.268629 & $2.7567 \mathrm{E}-03$ & $-2.6706 \mathrm{E}-07$ & $-1.3787 \mathrm{E}+06$ & $3.3538 \mathrm{E}+08$ & \\
\hline $\mathrm{O}_{2}(\mathrm{~g})$ & 0 & 205.147 & 34.141113 & $2.1512 \mathrm{E}-03$ & $-7.6318 \mathrm{E}-08$ & $-1.7832 \mathrm{E}+06$ & $3.9036 \mathrm{E}+08$ & \\
\hline $\mathrm{C}_{2} \mathrm{~F}_{4} \mathrm{Cl}_{2}(\mathrm{~g})$ & -890400 & 370.000 & 183.261682 & $-6.8319 \mathrm{E}-05$ & $1.6891 \mathrm{E}-08$ & $-1.4716 \mathrm{E}+07$ & $2.7300 \mathrm{E}+09$ & \\
\hline $\mathrm{C}_{4} \mathrm{~F}_{10}(\mathrm{~g})$ & -2140000 & 481.000 & 353.469197 & $-9.5182 \mathrm{E}-03$ & $1.0796 \mathrm{E}-06$ & $-2.6911 \mathrm{E}+07$ & $3.9804 \mathrm{E}+09$ & \\
\hline $\mathrm{c}-\mathrm{C}_{4} \mathrm{~F}_{8}(\mathrm{~g})$ & -1472768 & 400.000 & 313.511206 & $-1.5076 \mathrm{E}-02$ & $1.9650 \mathrm{E}-06$ & $-3.4984 \mathrm{E}+07$ & $6.3736 \mathrm{E}+09$ & \\
\hline $\mathrm{c}-\mathrm{C}_{4} \mathrm{~F}_{8} \mathrm{O}(\mathrm{g})$ & -1692700 & 440.910 & 300.763300 & $3.6398 \mathrm{E}-03$ & $-3.9664 \mathrm{E}-07$ & $-2.4671 \mathrm{E}+07$ & $3.2939 \mathrm{E}+09$ & \\
\hline $\mathrm{F}_{2}(\mathrm{~g})$ & 0 & 202.789 & 38.954446 & $6.3150 \mathrm{E}-04$ & $-3.9800 \mathrm{E}-07$ & $-2.0670 \mathrm{E}+06$ & $4.1309 \mathrm{E}+08$ & \\
\hline $\mathrm{ClF}_{3}(\mathrm{~g})$ & -158866 & 281.600 & 83.313041 & $-6.5325 \mathrm{E}-05$ & $6.5721 \mathrm{E}-09$ & $-2.9044 \mathrm{E}+06$ & $3.5050 \mathrm{E}+08$ & \\
\hline $\mathrm{CF}(\mathrm{g})$ & 255224 & 213.033 & 36.986595 & $4.0885 \mathrm{E}-04$ & $2.0517 \mathrm{E}-08$ & $-2.1017 \mathrm{E}+06$ & $4.4173 \mathrm{E}+08$ & \\
\hline $\mathrm{CF}_{2}(\mathrm{~g})$ & -182004 & 240.833 & 57.621572 & $-2.6691 \mathrm{E}-04$ & $2.6165 \mathrm{E}-07$ & $-4.3508 \mathrm{E}+06$ & $8.0547 \mathrm{E}+08$ & \\
\hline $\mathrm{CF}_{3}(\mathrm{~g})$ & -470282 & 265.082 & 77.335977 & $2.9448 \mathrm{E}-03$ & $-3.4549 \mathrm{E}-07$ & $-4.6963 \mathrm{E}+06$ & $6.4970 \mathrm{E}+08$ & \\
\hline $\mathrm{CF}_{4}(\mathrm{~g})$ & -933199 & 261.419 & 100.463029 & $3.8598 \mathrm{E}-03$ & $-4.5249 \mathrm{E}-07$ & $-6.5835 \mathrm{E}+06$ & $8.9092 \mathrm{E}+08$ & \\
\hline $\mathrm{CF}_{3} \mathrm{Cl}(\mathrm{g})$ & -707933 & 285.353 & 102.521140 & $2.8391 \mathrm{E}-03$ & $-3.3405 \mathrm{E}-07$ & $-5.7784 \mathrm{E}+06$ & $7.5937 \mathrm{E}+08$ & \\
\hline $\mathrm{CF}_{2} \mathrm{Cl}_{2}(\mathrm{~g})$ & -491620 & 300.897 & 104.339957 & $1.9293 \mathrm{E}-03$ & $-2.2803 \mathrm{E}-07$ & $-5.0121 E+06$ & $6.3618 \mathrm{E}+08$ & \\
\hline $\mathrm{CFCl}_{3}(\mathrm{~g})$ & -288696 & 309.735 & 105.962501 & $1.1108 \mathrm{E}-03$ & $-1.3223 \mathrm{E}$ & $-4.2165 \mathrm{E}+06$ & $5.1096 \mathrm{E}+08$ & \\
\hline${ }_{2} \mathrm{~F}_{2}(\mathrm{~g})$ & 20920 & 244.060 & 83.565173 & $1.6902 \mathrm{E}$ & -1.85 & -6.50 & $1.2272 \mathrm{E}+09$ & \\
\hline $\mathrm{F}_{4}(\mathrm{~g})$ & -658562 & 300.015 & 120.58 & $6.1235 \mathrm{E}$ & -7.07 & -6.796 & $9.1316 \mathrm{E}+08$ & \\
\hline${ }_{2} F_{5}(\mathrm{~g})$ & -896000 & 348 & 524 & $1.1676 \mathrm{E}$ & -1.33 & -1.37 & $2.4338 \mathrm{E}+09$ & \\
\hline${ }_{2} \mathrm{~F}_{6}(\mathrm{~g})$ & 343901 & 33 & 171.9 & $3.6049 \mathrm{E}$ & $-4.3690 \mathrm{I}$ & -1.10 & $1.4869 \mathrm{E}+09$ & \\
\hline${ }_{2} \mathrm{~F}_{5} \mathrm{Cl}(\mathrm{g})$ & -1094116 & 357.800 & 187.338371 & $-1.9428 \mathrm{E}-$ & 2.124 & -1.605 & $2.6709 \mathrm{E}+09$ & \\
\hline${ }_{3} \mathrm{~F}_{8}(\mathrm{~g})$ & -1698704 & 360.000 & 270.880857 & $-5.1478 \mathrm{E}-03$ & $5.1674 \mathrm{E}-07$ & $-3.2707 \mathrm{E}+07$ & $5.7226 \mathrm{E}+09$ & \\
\hline l(g) & 121302 & 16 & 9773 & $-7.9470 \mathrm{E}-04$ & 8 & 3.46 & -1.208 & \\
\hline $\mathrm{l}_{2}(\mathrm{~g})$ & 0 & 3.079 & 8658 & $4.1929 \mathrm{E}-03$ & -5.55 & 8.66 & $-2.6308 \mathrm{E}+08$ & \\
\hline $\mathrm{IF}(\mathrm{g})$ & -50292 & 7.938 & 43.463160 & $.9535 \mathrm{E}-03$ & $2.7083 \mathrm{E}-06$ & $-1.9470 \mathrm{E}+06$ & $3.3456 \mathrm{E}+08$ & \\
\hline (g) & 79390 & 8.750 & 20.914637 & $-5.8256 \mathrm{E}-05$ & $6.4265 \mathrm{E}-09$ & $5.0287 \mathrm{E}+05$ & $-1.0122 \mathrm{E}+08$ & \\
\hline $\mathrm{ClO}(\mathrm{g})$ & -28571 & 5.244 & .016646 & $9.6133 \mathrm{E}-05$ & $-1.1056 \mathrm{E}-08$ & $-2.2948 \mathrm{E}+06$ & $3.6317 \mathrm{E}+08$ & \\
\hline $\mathrm{ClO}_{2} \mathrm{~F}(\mathrm{~g})$ & -25270 & 278.374 & 3751 & $1.7683 \mathrm{E}-04$ & $-1.9619 \mathrm{E}-08$ & -5.593 & $9.7206 \mathrm{E}+08$ & \\
\hline $1 \mathrm{O}_{3} \mathrm{~F}(\mathrm{~g})$ & 0400 & 8.985 & 870 & 3.5483 & -3.90 & $-9.19]^{\prime}$ & $1.6182 \mathrm{E}+09$ & \\
\hline $\mathrm{O}(\mathrm{g})$ & 10527 & 653 & 635 & $2.4280 \mathrm{E}-03$ & -2.32 & -1.59 & $3.7802 \mathrm{E}+08$ & \\
\hline $\mathrm{O}_{2}(\mathrm{~g})$ & & & & 3. & 7 & -5.28 & 1.0595 & \\
\hline $\mathrm{OF}_{2}(\mathrm{~g})$ & -6 & 2 & & 1.236 & -1.17 & -7.8923 & $1.4874 \mathrm{E}+09$ & \\
\hline $\mathrm{CO}(\mathrm{g})$ & -171544 & 8.479 & 4.456812 & $1.6845 \mathrm{E}-03$ & -1.81 & $-4.0546 \mathrm{E}+06$ & $7.8631 \mathrm{E}+08$ & \\
\hline $\mathrm{FF}(\mathrm{g})$ & -272546 & 3.780 & 26.205685 & 4.4854E-03 & -4.01 & $2.3674 \mathrm{E}+05$ & $-2.5765 \mathrm{E}+07$ & \\
\hline $\mathrm{HCl}(\mathrm{g})$ & -92312 & 186.901 & 30.283767 & $3.1782 \mathrm{E}-03$ & $-2.8445 \mathrm{E}-07$ & $-1.3762 \mathrm{E}+06$ & $3.5740 \mathrm{E}+08$ & \\
\hline $\mathrm{H}(\mathrm{g})$ & 217999 & 114.706 & 20.786000 & $0.0000 \mathrm{E}+00$ & $0.0000 \mathrm{E}+00$ & $0.0000 \mathrm{E}+00$ & $0.0000 \mathrm{E}+00$ & \\
\hline $\mathrm{H}_{2}(\mathrm{~g})$ & 0 & 0.680 & 25.817062 & $4.7245 \mathrm{E}-03$ & $-3.4051 \mathrm{E}-07$ & $3.5426 \mathrm{E}+05$ & $-6.1989 \mathrm{E}+07$ & \\
\hline $\mathrm{OH}(\mathrm{g})$ & 38987 & 3.708 & 26.688914 & $4.4718 \mathrm{E}-03$ & $-3.9480 \mathrm{E}-07$ & $1.0631 \mathrm{E}+05$ & $2.2996 \mathrm{E}+07$ & \\
\hline $\mathrm{H}_{2} \mathrm{O}(\mathrm{g})$ & -241826 & 188.834 & 33.879897 & $1.0037 \mathrm{E}-02$ & $-9.3752 \mathrm{E}-07$ & $-1.7337 \mathrm{E}+06$ & $4.3641 \mathrm{E}+08$ & \\
\hline $\mathrm{SiF}_{3}(\mathrm{~g})$ & -1085330 & 282.381 & 82.954698 & $1.0541 \mathrm{E}-04$ & $-1.1747 \mathrm{E}-08$ & $-4.4109 \mathrm{E}+06$ & $6.9627 \mathrm{E}+08$ & \\
\hline $\mathrm{SiF}_{4}(\mathrm{~g})$ & -1614940 & 282.760 & 110.190642 & $-8.8575 \mathrm{E}-04$ & $9.3546 \mathrm{E}-08$ & $-7.3068 \mathrm{E}+06$ & $1.3180 \mathrm{E}+09$ & \\
\hline $\mathrm{U}_{2} \mathrm{~F}_{10}(\mathrm{~g})$ & -3998845 & 577.496 & 286.216196 & $-1.8013 \mathrm{E}-03$ & $2.1044 \mathrm{E}-07$ & $-5.4414 \mathrm{E}+06$ & $3.2874 \mathrm{E}+08$ & \\
\hline $\mathrm{UF}_{4}(\mathrm{~g})$ & -1598700 & 368.000 & 108.290787 & $-8.5519 \mathrm{E}-05$ & $8.9128 \mathrm{E}-09$ & $-2.3286 \mathrm{E}+06$ & $2.4394 \mathrm{E}+08$ & \\
\hline $\mathrm{UF}_{5}(\mathrm{~g})$ & -1917118 & 375.891 & & $-9.0064 \mathrm{E}-04$ & & $-2.7207 \mathrm{E}+06$ & $1.6437 \mathrm{E}+08$ & \\
\hline $\mathrm{UF}_{6}(\mathrm{~g})$ & -2148236 & 377.446 & & $-1.7260 \mathrm{E}-03$ & $2.0249 \mathrm{E}-07$ & $-3.1237 \mathrm{E}+06$ & $8.7610 \mathrm{E}+07$ & \\
\hline $\mathrm{UO}_{2} \mathrm{~F}_{2}(\mathrm{~g})$ & -1351000 & 348.742 & 105.091633 & $1.4747 \mathrm{E}-03$ & $-1.6215 \mathrm{E}-07$ & $-2.5221 \mathrm{E}+06$ & $2.1540 \mathrm{E}+08$ & \\
\hline
\end{tabular}


Table C.3, continued

\begin{tabular}{lrrrrrrrr}
\hline Name & $\begin{array}{c}\Delta \mathrm{H}_{\mathrm{f}}{ }^{\circ} \\
\mathrm{J} / \mathrm{mol}\end{array}$ & \begin{tabular}{c}
$\mathrm{S}^{\mathrm{o}} \mathrm{J} / \mathrm{mol} \mathrm{K}$ \\
\multicolumn{7}{c}{$\mathrm{C} / \mathrm{mol} \mathrm{K}$}
\end{tabular} & \multicolumn{7}{c}{$\mathrm{CpB}$} & $\mathrm{CpC}$ & $\mathrm{CpD}$ & $\mathrm{CpE}$ \\
\hline $\mathrm{C}(\mathrm{s})$ & 0 & 5.740 & 19.833088 & $3.7085 \mathrm{E}-03$ & $-4.2791 \mathrm{E}-07$ & $-2.2070 \mathrm{E}+06$ & $3.1752 \mathrm{E}+08$ & $\mathrm{k}$ \\
$\mathrm{UF}_{4}(\mathrm{~s})$ & -1910218 & 151.640 & 124.625851 & $1.1433 \mathrm{E}-02$ & $-1.2178 \mathrm{E}-06$ & $-1.9585 \mathrm{E}+06$ & $2.7321 \mathrm{E}+08$ & $\mathrm{k}$ \\
$\mathrm{UF}_{6}(\mathrm{~s})$ & -2198118 & 227.793 & 211.066891 & $-2.2812 \mathrm{E}-04$ & $-3.6345 \mathrm{E}-09$ & $-5.2008 \mathrm{E}+06$ & $3.8061 \mathrm{E}+08$ & ${ }^{\mathrm{n}}$ \\
$\mathrm{UO}_{2} \mathrm{~F}_{2}(\mathrm{~s})$ & -1648100 & 135.545 & 121.784532 & $6.4682 \mathrm{E}-03$ & $-3.0094 \mathrm{E}-07$ & $-1.6933 \mathrm{E}+06$ & $-1.0899 \mathrm{E}+08$ & \\
\hline
\end{tabular}

${ }^{\mathrm{a}} \Delta \mathrm{H}_{\mathrm{f}}{ }^{\circ}$, Wagman et al. (1982); $\mathrm{S}$ estimated; low-T Cp (Wilson and Hules 1981) [see note x].

${ }^{\mathrm{b}} \Delta \mathrm{H}_{\mathrm{f}}^{\mathrm{o}}$, (Rhodes 1984); $\mathrm{S}$ and low-T Cp (Harkins 1990a, 1990b, 1990c); [see note x].

${ }^{c} \Delta H_{\mathrm{f}}^{\mathrm{o}}$, (Duus 1955); $\mathrm{S}$ estimated; low-T Cp: (Harkins 1990a, 1990b, 1990c) [see note $\mathrm{x}$ ].

${ }^{\mathrm{d}} \Delta \mathrm{H}_{\mathrm{f}}^{\mathrm{o}}$ and $\mathrm{S}$ estimated; low-T Cp (Gross 1999) [see note $\mathrm{x}$ ].

e (Gurvich et al.1989) [see note $\mathrm{x}$ ].

${ }^{\mathrm{f}} \Delta \mathrm{H}_{\mathrm{f}}^{\mathrm{o}}$ (Foon and Tate 1972); $\mathrm{S}$ (Wagman et al. 1982); Cp estimated [see note $\mathrm{x}$ ].

${ }^{\mathrm{g}} \Delta \mathrm{H}_{\mathrm{f}}^{\mathrm{o}}$ (Fletcher and Ambs 1964); $\mathrm{S}$ and Cp estimated [see note $\mathrm{x}$ ].

${ }^{\mathrm{h}} \Delta \mathrm{H}_{\mathrm{f}}^{\mathrm{o}}$ derived from equilibrium data in Cooper et al. (1972); $\mathrm{S}$ and $\mathrm{Cp}$ : unpublished statistical mechanics treatment by the present author based on structure and frequency data in Andrews et al., (1974).

${ }^{i}$ Derived from analysis of data in Gatti et al. (1960).

${ }^{\mathrm{j}} \Delta \mathrm{H}_{\mathrm{f}}^{\mathrm{o}}$, adapted from data in Cartwright and Woolf (1979) and Wagman et al. (1982); $\mathrm{S}$ and Cp: (Chase et al.1985).

${ }^{k}$ Leitnaker 1983 [ see note $\mathrm{x}$ ].

1 Wagman et al.1982; [see note $\mathrm{x}$ ].

${ }^{m}$ Lau et al.1985.

${ }^{\mathrm{n}} \Delta \mathrm{H}_{\mathrm{f}}^{\mathrm{o}}$ (Wagman et al.1982); $\mathrm{S}$ and Cp: (Leitnaker 1983).

${ }^{x} \mathrm{Cp}$ extended to high temperature by estimation method described in the text. 
APPENDIX D 



\section{APPENDIX D}

\section{EMPIRICAL FLAMMABILITY LIMIT MODEL}

Flammability limit models for fuel oxidizer systems (fuels being PFCs or CFCs and oxidizers being $\mathrm{F}_{2}$ or $\mathrm{ClF}_{3}$ ) were presented by Trowbridge and Barber (1992) and updated by Trowbridge (1999a). These models were based on purely empirical correlations between temperatures calculated to be generated for gas mixtures which were known from experiment to be at the composition boundary of flammability. A version of one of these models was included in the 1999 detonation spreadsheet models (Trowbridge 1999a). That version used the temperatures calculated for adiabatic reactions according to the fixed reactions used in that set of models. The present equilibrium-based model has a different set of reaction products and therefore will generate somewhat different product compositions and temperatures. The model as calibrated and presented in the 1999 spreadsheets cannot therefore directly be used in this model. The other flammability limit model was based on the constant-pressure adiabatic equilibrium product temperature and used a set of chemical reaction species essentially identical to those included in the present model (Trowbridge 1999a). The present model calculates the constant-volume adiabatic temperature for the reaction mix. This will yield a somewhat higher temperature for the same reaction mix. The general approach, which is to say, the same experimental data and parametric equations, is used in the flammability limit estimation in the present model, but the values of the parameters are recalibrated to the higher temperatures generated by the constantvolume temperature available in the current calculation.

The empirical formula used for the flammability threshold temperature is

$$
\mathrm{T}_{\text {threshold }}=\left(\mathrm{T}_{\text {lean }}^{\mathrm{N}}+\mathrm{T}_{\text {rich }}{ }^{\mathrm{N}}\right)^{1 / \mathrm{N}} \text {, }
$$

where

$$
\mathrm{T}_{\text {lean }}=\mathrm{A}_{\text {lean }} / \mathrm{X}_{\text {oxidizer }}+\mathrm{B}_{\text {lean }}
$$

and

$$
\mathrm{T}_{\text {rich }}=\mathrm{A}_{\text {rich }} / \mathrm{S} \mathrm{X}_{\text {fuel }}+\mathrm{B}_{\text {rich }} .
$$

A and B parameter values for fuel-rich mixtures are selected so as to produce a lower bound on all adiabatic temperatures calculated for fuel-rich mixtures experimentally observed to be flammable. Similarly, lean parameter values were obtained from fuel-lean flammable compositions and computed temperatures. The variable $\mathrm{X}$ in the above equations is the mole fraction of the species indicated and $\mathrm{S}$ is a stoichiometry ratio, the number of moles of oxidizer (fluorinating agent, actually) needed to completely react a mole of fuel to $\mathrm{CF}_{4}$ and $\mathrm{Cl}_{2}$. A value of 4 was used for the exponent $\mathrm{N}$, used in the smoothing function which combines the lean and rich temperatures into a single-threshold temperature. The model predicts that any mixture whose calculated adiabatic temperature exceeds the calculated threshold temperature is a flammable mixture.

The earlier models were aimed at gas mixtures containing a single fuel and single oxidizer, as all available experimental data were of that character. Some modification is necessary to handle gas 
mixtures containing more than one fuel or oxidizer. For a mixture of oxidizers, $\mathrm{X}_{\text {oxidizer }}$ can simply be taken as the sum of all species treated as oxidizers $\left(\mathrm{F}_{2}\right.$ and $\mathrm{ClF}_{3}$, certainly, but possibly also others which could supply $\mathrm{F}$ at high temperatures, such as $\mathrm{ClF}, \mathrm{ClO}_{2} \mathrm{~F}$, and $\mathrm{COF}_{2}$ ). The factor $\mathrm{S} \cdot \mathrm{X}_{\text {fuel }}$ is more complicated to treat but, in essence, represents a fluorine demand. In the singlefuel/single-oxidizer model, $\mathrm{S}$ is the number of moles of one particular oxidizer needed to react one particular fuel to completion. For mixtures, $\mathrm{S}$ will be the number of moles of that particular mixture of oxidizers needed to react that particular mixture of fuels to completion. The factor equivalent to $\mathrm{S} \cdot \mathrm{X}_{\text {fuel }}$ can be obtained by suitable weighting of mole fractions of fuels and oxidizers:

$$
Y=\frac{\sum_{\text {oxidizers }} X_{\text {oxidizer }} \sum_{\text {fuels }} F_{\text {fuel }} X_{\text {fuel }}}{\sum_{\text {oxidizers }} F_{\text {oxidizer }} X_{\text {oxidizer }}},
$$

where $\mathrm{F}_{\text {fuel }}$ is the fluorine demand of each fuel and $\mathrm{F}_{\text {oxidizer }}$ is the fluorine supply for each oxidizer. These values are listed in Table D.1 for all species included in the spreadsheet and treated as fuels or oxidizers.

\begin{tabular}{|c|c|c|c|}
\hline \multicolumn{2}{|c|}{$\overline{F_{\text {fuel }} \text { (Fluorine demand, fuels) }}$} & \multicolumn{2}{|c|}{$\mathrm{F}_{\text {oxidizer }}$ (Fluorine Supply, oxidizers) } \\
\hline $\mathrm{C}_{2} \mathrm{~F}_{4} \mathrm{Cl}_{2}(\mathrm{~g})$ & 4 & $\mathrm{~F}_{2}(\mathrm{~g})$ & 2 \\
\hline $\mathrm{C}_{4} \mathrm{~F}_{10}(\mathrm{~g})$ & 6 & $\mathrm{ClF}_{3}(\mathrm{~g})$ & 3 \\
\hline $\mathrm{c}-\mathrm{C}_{4} \mathrm{~F}_{8}(\mathrm{~g})$ & 8 & $\mathrm{ClF}(\mathrm{g})$ & 1 \\
\hline $\mathrm{c}-\mathrm{C}_{4} \mathrm{~F}_{8} \mathrm{O}(\mathrm{g})$ & 4 & $\mathrm{ClO}_{2} \mathrm{~F}(\mathrm{~g})$ & 1 \\
\hline $\mathrm{CF}_{3} \mathrm{Cl}(\mathrm{g})$ & 1 & $\mathrm{COF}_{2}(\mathrm{~g})$ & 2 \\
\hline $\mathrm{CF}_{2} \mathrm{Cl}_{2}(\mathrm{~g})$ & 2 & & \\
\hline $\mathrm{CFCl}_{3}(\mathrm{~g})$ & 3 & & \\
\hline $\mathrm{C}_{2} \mathrm{~F}_{2}(\mathrm{~g})$ & 6 & & \\
\hline $\mathrm{C}_{2} \mathrm{~F}_{4}(\mathrm{~g})$ & 4 & & \\
\hline $\mathrm{C}_{2} \mathrm{~F}_{6}(\mathrm{~g})$ & 2 & & \\
\hline $\mathrm{C}_{2} \mathrm{~F}_{5} \mathrm{Cl}(\mathrm{g})$ & 3 & & \\
\hline $\mathrm{C}_{3} \mathrm{~F}_{8}(\mathrm{~g})$ & 4 & & \\
\hline $\mathrm{C}(\mathrm{s})$ & 4 & & \\
\hline
\end{tabular}

The list of fuels includes not only the four coolants of particular interest but also several other perfluorocarbons and chlorofluorocarbons. Species stable only at high temperature are not listed, as it is unlikely that they would be present in the initial gas mix. Oxidizers listed include the five species previously mentioned, although the inclusion of the last three as viable fluorine sources is conjectural. Flammability predictions for gas mixtures in which $\mathrm{ClF}, \mathrm{ClO}_{2} \mathrm{~F}$, or $\mathrm{COF}_{2}$ are the major oxidizers are likely to significantly overpredict the boundaries of flammability. 
The inclusion of $\mathrm{c}-\mathrm{C}_{4} \mathrm{~F}_{8} \mathrm{O}$ in the list of coolants requires that some consideration be given to the fate of its oxygen. The equilibrium results calculated with the data used in this model indicate that in a high-temperature fluorinating environment, the oxygen appears as $\mathrm{CO}$; hence, that is the form we assume it will take for purposes of calculating fluorine demand for $\mathrm{c}-\mathrm{C}_{4} \mathrm{~F}_{8} \mathrm{O}$.

The empirical flammability model, as described here, was recalibrated to the same experimental data set discussed by Trowbridge (1999a), but with the adiabatic temperatures computed at constant volume rather than pressure. The revised parameter values thus derived are listed in Table D.2. As in the earlier model, both a "best fit" and "conservative fit" are provided, the former giving the best match to experimental boundary points for the limited data available and the latter adjusted to lower temperatures to attempt to allow for system-to-system variability. The second parameter set is conservative in the sense that those parameters are less likely to predict that a mixture is not flammable when in fact it is.

\section{Table D.2. Revised parameters for empirical} flammability limit model

\begin{tabular}{cccc}
\hline Model parameters & & A & B \\
\hline \multirow{2}{*}{ Best fit } & lean & 100 & 1400 \\
& rich & 160 & 850 \\
\multirow{2}{*}{ Conservative fit } & lean & 40 & 1400 \\
& rich & 110 & 830 \\
\hline
\end{tabular}

Some limited testing of the behavior of this revised model was performed. Flammability composition boundaries generated by this variation of the model for the cases tested were within $1 \%$ of boundaries predicted by the earlier equilibrium model (Trowbridge 1999a). Figure D.1 shows a comparison of the composition limits of flammability predicted from the present (constant-volume) equilibrium-based model with similar predictions from the earlier fixedreaction model and the (constant-pressure) equilibrium model. The system chosen for this comparison is the $\mathrm{F}_{2}+\mathrm{c}_{-} \mathrm{C}_{4} \mathrm{~F}_{8}+\mathrm{UF}_{6}$ system. $\mathrm{UF}_{6}$ was not allowed to participate in the chemical reactions, and $\mathrm{C}(\mathrm{s})$ was not considered as a reaction product. No ternary experimental data is known for this system, but Fletcher and Hinderman (1983) reported binary flame and explosion information for $\mathrm{F}_{2}+\mathrm{c}-\mathrm{C}_{4} \mathrm{~F}_{8}$ which is plotted in the figure.

The entire model, as has been stated, is based purely on empirical correlations and should not be considered a hard and fast guide to flammability of gas mixtures, particularly for systems not chemically similar to those from which the calibration data was derived. No real theoretical justification exists for this prediction scheme, though some precedent has been established for use of similar empirical schemes in other chemical systems (Jost 1946; Lewis and von Elbe 1961). 


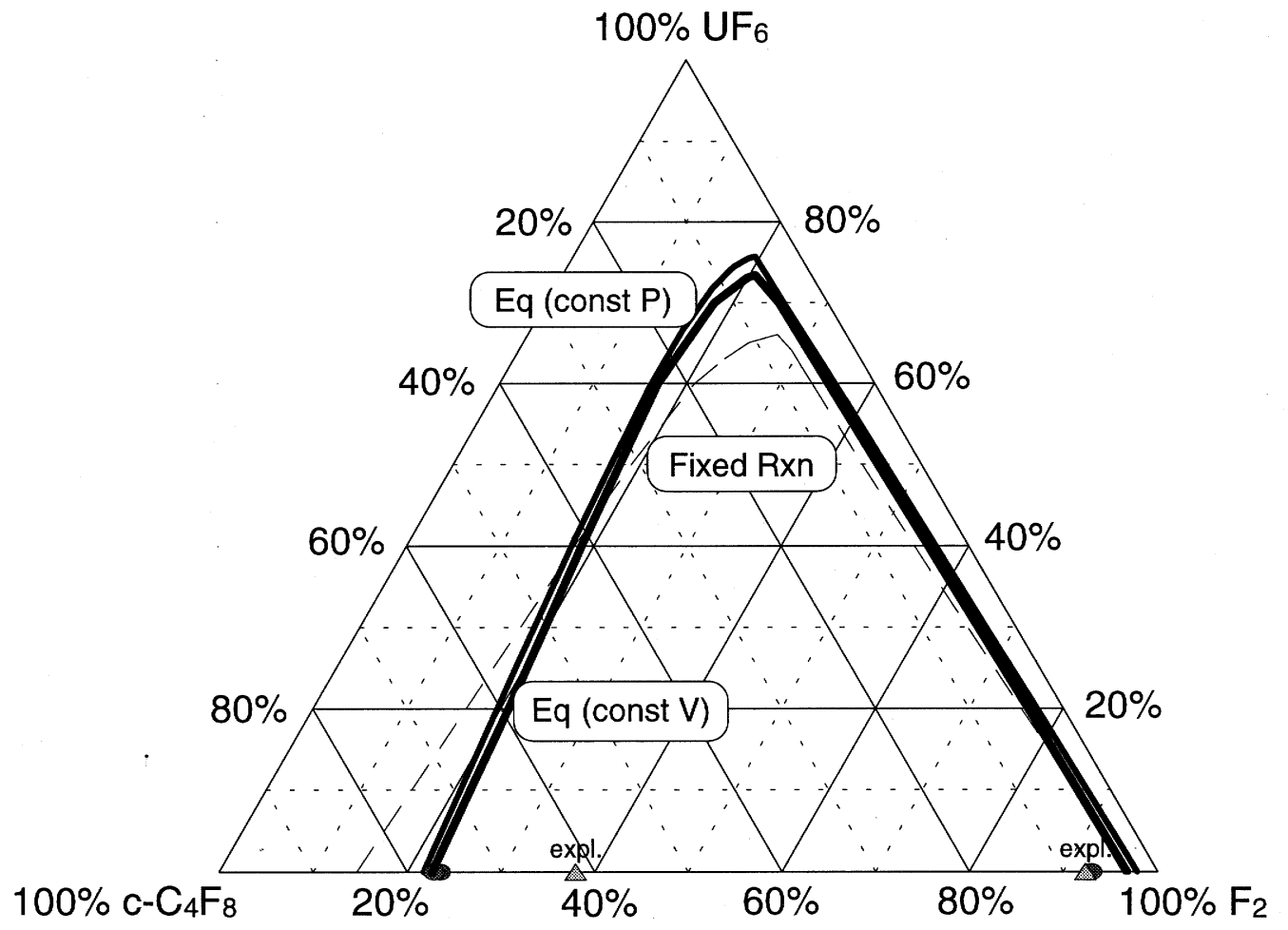

Fig. D.1. Flammability boundaries predicted for $\mathrm{F}_{2} / \mathbf{c}-\mathrm{C}_{4} \mathrm{~F}_{8} / \mathrm{UF}_{6}$ mixtures. Compositions are mole $\%$.

"Eq (const V)" = present model; "Eq (const P)" = constant pressure equilibrium-based correlation (1999); "Fixed Rxn" = correlation from fixed reaction adiabatic temperature (1999); circle = data point on flammability boundary; triangle $=$ data point inside boundary (these two compositions detonated). Experimental data from Fletcher and Hinderman (1983). All model predictions based on conservative parameter sets. 


\section{REFERENCES}

Andrews, L., Chi, F. K., and Arkell, A. 1974. "Matrix Infrared Spectrum and Vibrational Analysis of the FClO Intermediate," J. Am. Chem. Soc. 96(7), 1997.

Barber, E. J. 1990. Maximum Detonation Pressures (U), K/ETO-47, Martin Marietta Energy Systems, Oak Ridge, Tenn.

Bauer, G. L., and Hamilton, D. W. 1990. Flammability of Fluorocarbons and Chlorofluorocarbons in Gas Mixtures Containing Fluorine, 3M Corporation, St. Paul, Minn. (proprietary information).

Bernhardt, H. A., Hale, C. F., and Barber, E. J. 1968a. Explosive Reactions Produced by Spark Ignition of Freon-114 and Freon-114A with Fluorine, K-L-6124-A, Union Carbide Corp.- - Nuclear Division, Oak Ridge Gaseous Diffusion Plant, Oak Ridge, Tenn.

Bernhardt, H. A., Hale, C. F., and Barber, E. J. 1968b. Explosive Reactions Produced by Spark Ignition in Mixtures of Fluorine with Fluorocarbons and Chlorofluorocarbons, K-L-6154-R, Union Carbide Corp.- Nuclear Division, Oak Ridge Gaseous Diffusion Plant, Oak Ridge, Tenn.

Bostick, W. D., McCulla, W. H., and Trowbridge, L. D. 1987. Gas-Phase Thermal Dissociation of Uranium Hexafluoride: Investigation by the Technique of Laser-Powered Homogeneous Pyrolysis, K/PS-1187, Martin Marietta Energy Systems, Oak Ridge Gaseous Diffusion Plant, Oak Ridge, Tenn.

Cartwright, M., and Woolf, A. A. 1979. "A Redetermination of the Heat of Formation of Perchloryl Fluoride," J. Fluorine Chem. 13, 353.

Chase, M. W., et al. 1985. "JANAF Thermochemical Tables, 3rd ed.," J. Phys. Chem. Ref. Data 14(1), suppl. 1.

Cooper, T. D., Dost, F. N., and Wang, C. H. 1972. "Evidence for ClOF as a Primary Product of the Reaction of $\mathrm{ClF}_{3}$ with $\mathrm{H}_{2} \mathrm{O}$," J. Inorg. Nucl. Chem. 34, 3564.

Domalski, E. S., and Hearing, E. D. 1993. "Estimates of the Thermodynamic Properties of C-HN-O-S-Halogen Compounds at 298.15K," J. Phys. Chem. Ref. Data, 22(4), 805.

Duus, H.C. 1955. "Thermochemical Studies on Fluorocarbons: Heat of Formation of $\mathrm{CF}_{4}, \mathrm{C}_{2} \mathrm{~F}_{4}$, $\mathrm{C}_{3} \mathrm{~F}_{6}, \mathrm{C}_{2} \mathrm{~F}_{4}$ Dimer, and $\mathrm{C}_{2} \mathrm{~F}_{4}$ Polymer," Ind. Eng. Chem. 47, 1445.

Eriksson, G. 1971. "Thermodynamic Studies of High Temperature Equilibria III. SOLGAS, a Computer Program for Calculating the Composition and Heat Condition of an Equilibrium Mixture," Acta Chem. Scand. 25(7), 2651. 
Fletcher, E. A., and Ambs, L. L. 1964. "Fluorocarbon Combustion Studies-The Combustion of Perfluoroethane, Perfluoropropane and Perfluorocyclobutane with Chlorine Trifluoride," Combust. Flame 8, 275.

Fletcher, E. A., and Hinderman, J. 1983. "Fluorocarbon Combustion Studies VI-Competitive Combustion Reactions of Fluorocarbons Burning with Fluorine," Combust. Flame 51, 193.

Fletcher, E. A., and Kittelson, D. B. 1968. "Fluorocarbon Combustion Studies II-Detonation Velocities and Limits of Perfluorocyclobutane-Fluorine Mixtures," Combust. Flame 12, 119.

Foon, R., and Tait, K. B. 1972. "Chlorine Abstraction Reactions of Fluorine. Part 3:

Thermochemical Data for Chlorofluoroalkanes," J. Chem. Soc. Faraday Trans. 1 68, 1121.

Gatti, R., Sicre, J. E., and Schumacher, H. J. 1960. "Die Kinetik des thermischem Zerfalls von Perchlorylfluorid $\left(\mathrm{FClO}_{3}\right)$ und der Einfluß von Fremdgasen auf die Reaktion," Z. Phys. Chem. NF 23, 164.

Gross, R. B. Aug. 11, 1999. Private communication to L. D. Trowbridge containing Cp data for c- $\mathrm{C}_{4} \mathrm{~F}_{8} \mathrm{O}$, originally from $3 \mathrm{M}$ Corporation.

Gurvich, L. V., Veyts, I. V., and Alcock, C. B. 1989. Thermodynamic Properties of Individual Substances, 4th ed., vol. 2, part 2, Hemisphere Pub. Corp., New York.

Harkins, D. A. 1990a. Evaluation of Available Perfluorobutane Data for Selected Physical Properties, K/QT-331, Martin Marietta Energy Systems, Oak Ridge, Tenn.

Harkins, D. A. 1990b. Selected Physical Properties of n-Perfluorobutane Vapor, K/ETO-21, Martin Marietta Energy Systems, Oak Ridge, Tenn.

Harkins, D. A. 1990c. Selected Properties of c-Perfluorobutane, K/ETO-29, Martin Marietta Energy Systems, Oak Ridge, Tenn.

Jost, W. 1946. Explosion and Combustion Processes in Gases, Chapters 4 and 5, McGraw-Hill, New York.

Kolesov, V. P., et al. 1972. "Standard Enthalpies of Formation of Perfluorodi-n-butyl Ether and Trifluoroacetic Acid," Russ. J. Phys Chem. 46(3), 474.

Kolesov, V. P., et al. 1976. "Thermodynamic Properties of Oxygen-Containing Organofluorine Compounds. Enthalpies of Formation of Dimethyl Perfluoroglutarate and Perfluoro-di-n-amyl Ether," J. Chem. Thermodyn.. 8, 907.

Lau, K. H., Brittain, R. D., and Hildenbrand, D. L. 1985. "Thermochemical Properties of the Gaseous Lower Valent Fluorides of Uranium," J. Phys. Chem. 89, 4369.

Leitnaker, J. M. 1983. Thermodynamic Data for Uranium Fluorides, K/PS-352, Union Carbide Corp., Oak Ridge Gaseous Diffusion Plant, Oak Ridge, Tenn. 
Lewis, B., and von Elbe, G. 1961. Combustion, Flames and Explosions in Gases, 2nd ed., Academic Press, New York.

Rhodes, C. L., III. 1984. A Computer Algorithm to Perform Chemical Structure Analysis for Group Contribution Calculations, M.S. Thesis, Pennsylvania State University, University Park, Penn.

Trowbridge, L. D., and Barber, E. J. 1992. Flammability Limits of Coolants and Fluorinating Agents $(U), \mathrm{K} /$ ETO-111, Martin Marietta Energy Systems, Oak Ridge, Tenn.

Trowbridge, L. D., and Leitnaker, J. M. 1995. A Spreadsheet-Coupled SOLGAS-A

Computerized Thermodynamic Equilibrium Calculation Tool, K/ETO-140, Rev. 1, Lockheed Martin Energy Systems, Oak Ridge K-25 Site, Oak Ridge, Tenn.

Trowbridge, L. D. 1999a. Estimated Flammability Limits of Selected Fluorocarbons with $F_{2}$ and $\mathrm{ClF}_{3}$, ORNL/TM-1999/184, Oak Ridge National Laboratory, Oak Ridge, Tenn.

Trowbridge, L. D. 1999b. Potential Hazards Relating to Pyrolysis of c- $C_{4} F_{8}$ in Selected Gaseous Diffusion Plant Operations, ORNL/TM-13758, Oak Ridge National Laboratory, Oak Ridge, Tenn.

Wagman, D. D., et al. 1982. "The NBS Tables of Chemical Thermodynamic Properties," J. Phys. Chem. Ref. Data 11, suppl. 2.

Wilson, D. P., and Hules, K. R. 1981. "Experimental Study of Thermodynamic Properties of 1,2, Dichlorotetrafluoroethane," In Proceedings: 8th Symposium on Thermophysical Properties, ed. J.V. Saengers, NBS, Gaithersburg, Md.

Zhang, Z., and Pollard, R. 1995. "Group Additivity Values for Standard Heats of Formation of Gaseous Chlorofluorocarbons and Relates Species," Thermochim. Acta 257, 21. 



\section{ACKNOWLEDGMENTS}

This work was made possible by the contributions of many individuals. The late Dr. E. J. Barber, Jr., in his 1990-1992 work, defined the general approach to theoretically estimating gas explosion characteristics in gaseous diffusion applications, an approach continued and extended in the present work. Technical personnel at USEC, in particular R. B. Gross provided ongoing support, comment, and encouragement during the development stage of the work and Mr. Gross reviewed the report and associated software during the documentation stage. The work was funded by USEC via its CFC replacement program, thanks are due and S.A.Wagner, the program manager who supported this activity. The author also would like to thank Dr. D.F.Williams for peer review and comment of this report. Finally, recognition is also due to D. P. Stevens and M. K. Savage, Chemical Technology Division technical editors, for editing and publication. 



\section{INTERNAL DISTRIBUTION}

1. T. M. Besmann

2. A. G. Croff

3. G. D. Del Cul

4. A. S. Icenhour

5. R. T. Jubin

6. L. E. McNeese
$7 . \quad$ D. W. Simmons

8-16. L. D. Trowbridge

17. D. F. Williams

18. Central Research Library

19. ORNL Laboratory Records - RC

20-21. ORNL Laboratory Records - OSTI

\section{EXTERNAL DISTRIBUTION}

22-26. W. J. Spetnagel, Bldg X-710, Portsmouth Gaseous Diffusion Plant, 3930 US Route 23 South, Piketon, Ohio 45661-0628

$27 . \quad$ D. M. Manuta, Bldg X-710, Portsmouth Gaseous Diffusion Plant, 3930 US Route 23 South, Piketon, Ohio 45661-0628

28-32. R. B. Gross, Bldg C-710, Paducah Gaseous Diffusion Plant, P.O. Box 1410, 5600 Hobbs Road, Paducah, KY 42001

33. S. A. Wagner, Bldg C-100-T, Paducah Gaseous Diffusion Plant, P.O. Box 1410, 5600 Hobbs Road, Paducah, KY 42001 
